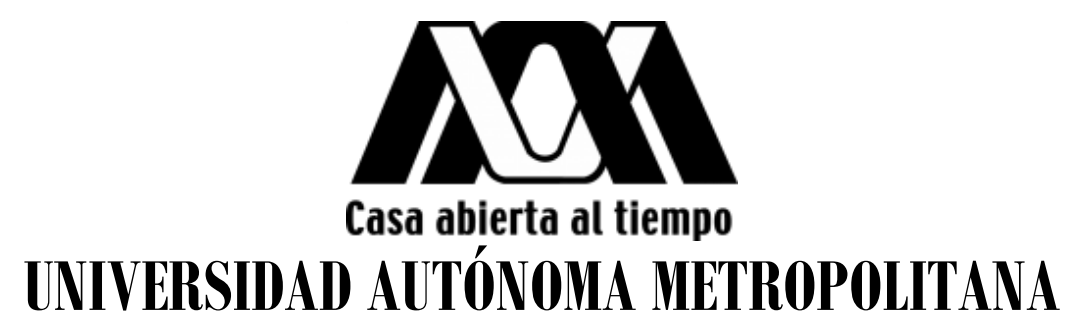

División de Ciencias Básicas e Ingeniería

\title{
Propuesta y evaluación de un protocolo híbrido de control de acceso al medio (MAC) con reservación de recursos
}

Idónea comunicación de resultados presentada por

\author{
Pablo Damián Hernández Durán \\ Para obtener el grado de \\ Maestro en Ciencias y Tecnologías de la \\ Información
}

Asesor: Dr. Miguel López Guerrero

Defendida públicamente en la UAM-Iztapalapa el 31 de Agosto del 2010 a las 10:00 hrs.

\section{Jurado Calificador:}

Presidente: Dr. Javier Gómez Castellanos

Secretario: Dr. Víctor Manuel Ramos Ramos

Vocal: Dr. Miguel López Guerrero

Derechos reservados (C) Pablo Damián Hernández Durán 2010. 



\section{Agradecimientos}

Agradezco profundamente al Dr. Miguel López Guerrero, mi asesor, por aceptarme en este proyecto y orientarme durante la realización de este trabajo. Le agradezco por todos sus consejos y extensas correcciones, con las cuales he crecido de forma académica y profesional. También le doy las gracias por formar parte del jurado para la defensa pública de este proyecto.

Extiendo mi agradecimiento al Dr. Víctor Manuel Ramos Ramos y al Dr. Javier Gómez Castellanos por hacerme el honor de participar en el jurado para la defensa pública de este trabajo. Gracias por todos sus comentarios y sugerencias, los cuales son sumamente valiosos. También agradezco a todos los profesores de la Maestría por sus consejos, sus recomendaciones y sus múltiples enseñanzas.

Vaya mi gratitud a la Universidad Autónoma Metropolitana por darme la oportunidad de desarrollarme académicamente y por el apoyo otorgado para la realización de una estancia en España, ya que, a través de la Coordinación de la Maestría en Ciencias y Tecnologías de la Información, financió parcialmente los gastos. También agradezco al Dr. Luis Orozco Barbosa por los comentarios vertidos en relación a este trabajo y por todo el apoyo otorgado para que la realización de la estancia fuera posible. 


\section{Agradecimientos}

Mi más profunda gratitud a toda mi familia. A mi madre, Evangelina, porque es para mí el mayor ejemplo de lucha y superación en la vida. A mi padre, Francisco, por su apoyo y por entender la importancia que tiene este proyecto en mi desarrollo personal. A mi hermano, Oscar, por motivar mis ganas de crecer profesionalmente y por su apoyo incondicional en todo momento. También, le doy las gracias a mi novia, compañera y amiga, Ana Judith Rodríguez Contreras, quién ha guiado cada uno de mis pasos y a quien agradezco su comprensión durante estos dos años que duró el proyecto. También le doy las gracias a una persona muy especial sin la cual yo no estuviera aquí, mi mami Nieves, al igual que agradezco a mis tías Regina y Rocío por todo su apoyo.

Extiendo mi agradecimiento a todos mis compañeros de la Maestría, a Esther, Sandra, Cesar Cabrera, Cesar García, Gustavo, Orlando, Israel De Olmos e Israel Hernández Merchand, a quienes les doy las gracias por sus comentarios, su apoyo y su compañía, los cuales influyeron en distintos aspectos para que esta empresa llegara a un buen final. Por último, también agradezco a CONACYT por el apoyo financiero que me brindó, el cual fue indispensable para que yo pudiera dedicarme por completo a desarrollar este trabajo. 


\section{Resumen}

En este trabajo se propone y se evalúa, principalmente por medio de simulación, un protocolo híbrido de control de acceso al medio con reservación de recursos, el cual también es un protocolo síncrono de detección limitada, que denominamos protocolo $2 \mathrm{C}-\mathrm{R}^{2}$ ( $2 \mathrm{C}$ con reservación de recursos). El enfoque híbrido que se propone en este trabajo intenta aprovechar las características positivas tanto de los protocolos MAC dinámicos de acceso aleatorio, como lo es el protocolo $2 \mathrm{C}$, así como las características positivas de los protocolos de acceso por reservación.

El protocolo propuesto consiste de dos fases: la fase de reservación de recursos y la fase de transmisión de datos. Durante la fase de reservación de recursos se permite a las estaciones, que tengan paquetes de datos para transmitir, contender por la reservación de hasta $M$ ranuras de tiempo para la fase de transmisión de datos. Una vez que las estaciones han logrado acceder al medio de transmisión y realizar su reservación, pueden transmitir datos sin competir con las demás estaciones. Los posibles conflictos durante la fase de reservación de recursos se resuelven de manera similar a como lo hace el protocolo $2 \mathrm{C}$, el cual también se evalúa principalmente por medio de simulación en este trabajo, para efectos de comparación con nuestra propuesta.

En primera instancia, durante el proceso de evaluación de desempeño, se encontró que el protocolo $2 \mathrm{C}$, en su modalidad de detección limitada, puede alcanzar una máxima utilización efectiva del medio de transmisión, en condiciones estables, de $42.52 \%$. 
Posteriormente, se encontró que el protocolo $2 \mathrm{C}-\mathrm{R}^{2}$ puede alcanzar una máxima utilización efectiva del medio de transmisión, en condiciones estables con $M=1, M=2$ y $M=3$, de $94.30 \%, 97.07 \%$ y $98.03 \%$ respectivamente, y que este valor se va acercando al 100\%, sin llegar a alcanzarlo, conforme aumenta la cantidad de ranuras reservadas por solicitud de reservación, es decir, conforme aumenta el valor de $M$. Después se encontró que, en las mismas condiciones de carga ofrecida, el protocolo $2 \mathrm{C}-\mathrm{R}^{2}$ presenta un menor retardo de acceso promedio, con respecto al protocolo $2 \mathrm{C}$ en su modalidad de detección limitada.

Además, también se encontró que, cuando las estaciones en la red ofrecen cargas de tráfico altas, el protocolo $2 \mathrm{C}-\mathrm{R}^{2}$ desperdicia poca energía en transmisiones que no tienen éxito. Por el contrario, cuando la carga ofrecida es baja, el protocolo $2 \mathrm{C}$ aprovecha muy bien la energía utilizada para transmitir paquetes de datos; pero cuando la carga ofrecida es alta, la energía desperdiciada, en transmisiones sin éxito, llega a superar a la que es bien aprovechada. Al final de este trabajo, se hace una evaluación de desempeño, entre el protocolo $2 \mathrm{C}$ y el protocolo $2 \mathrm{C}-\mathrm{R}^{2}$, considerando la utilización efectiva del medio de trasmisión, el retardo de acceso al medio y el porcentaje efectivo del tiempo total en estado de transmisión. 


\section{Acrónimos}

CDMA

CRI

CRP

CSMA

CSMA/CA

CSMA/CD

CTS

DCF

DTP

EB

FDMA

MAC

RI

RRP

RTS

SC

SNR

TC

TDMA

WC

WLAN

WSN
Code Division Multiple Access

Collision Resolution Interval

Collision Resolution Point

Carrier Sense Multiple Access

Carrier Sense Multiple Access with Collision Avoidance

Carrier Sense Multiple Access with Collision Detection

Clear to Send

Distributed Coordination Function

Data Transmission Phase

Exponential Backoff

Frequency Division Multiple Access

Medium Access Control

Reservation Interval

Resource Reservation Phase

Request to Send

Stack Counter

Signal to Noise Ratio

Transmission Cell

Time Division Multiple Access

Waiting Cell

Wireless Local Area Network

Wireless Sensor Network 


\section{Contenido}

1. Introducción .....................................................................................................................1

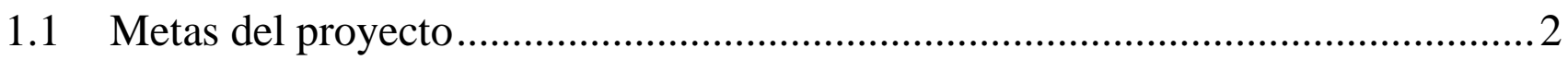

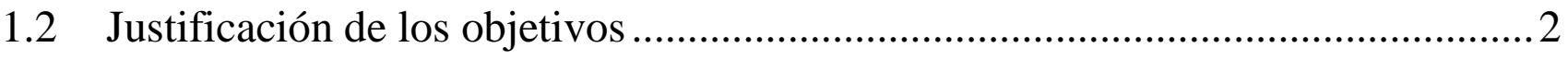

1.3 Método de investigación....................................................................................

1.4 Contribución .............................................................................................

1.5 Estructura del documento ............................................................................

2. Control de acceso al medio .................................................................................................9

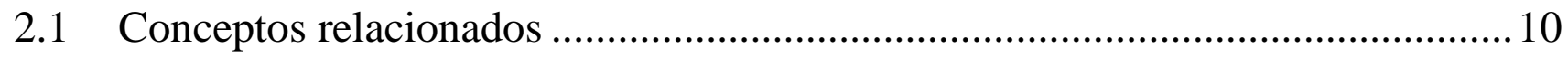

2.2 Estrategias de control de acceso al medio ............................................................12

2.3 Protocolos MAC afines a la propuesta ............................................................15

2.3.1 Protocolo de árbol binario ..................................................................... 15

2.3.2 Protocolo de pila ................................................................................. 17

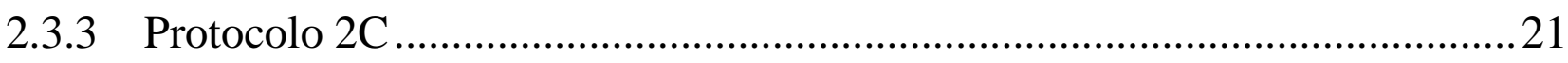


2.3.4 Protocolo básico de reservación ................................................................25

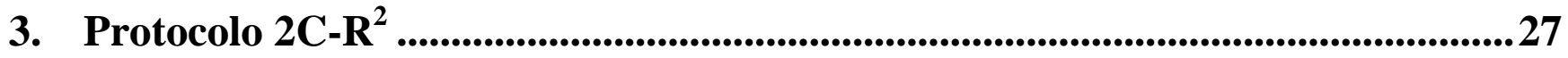

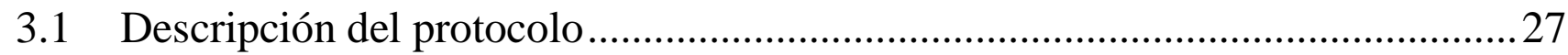

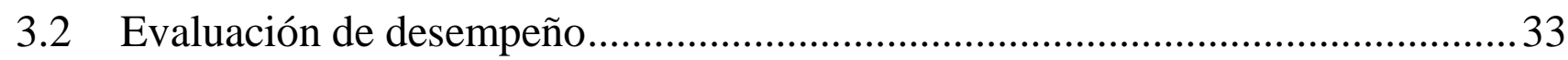

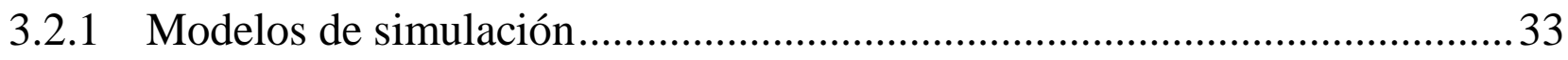

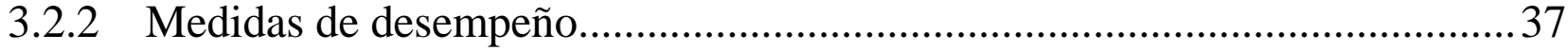

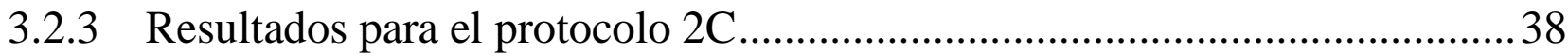

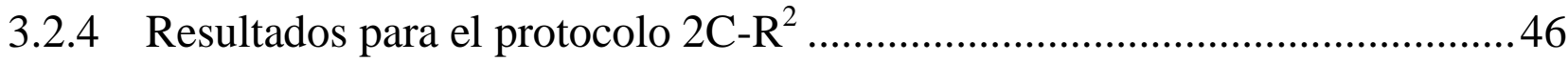

3.2.5 Comparación del 2C- $\mathrm{R}^{2}$ con respecto al 2C............................................57

Conclusiones.........................................................................................................................59

Referencias ................................................................................................................................................661

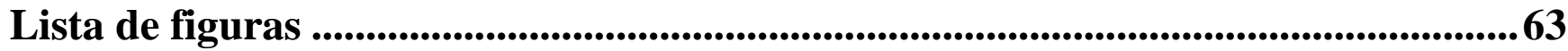

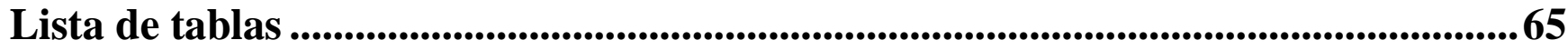

Apéndice A: Simulador de eventos discretos OMNeT++ ..............................................67

Apéndice B: Modelado del 2C como una cadena de Markov ........................................69

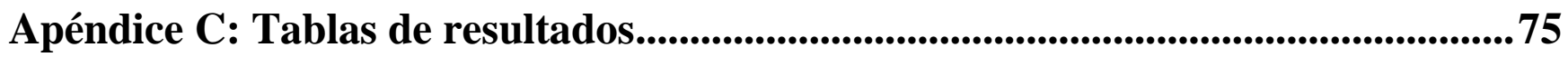




\section{Capítulo 1}

\section{Introducción}

De forma general, se puede definir a una red de comunicaciones como un conjunto de elementos que permiten la comunicación a distancia entre las distintas estaciones que la conforman. Normalmente, estas estaciones intentan transmitir datos, audio y vídeo por ondas electromagnéticas a través de diversos medios de transmisión, como por ejemplo el espacio libre, el cable de cobre y el cable de fibra óptica.

De acuerdo a la manera en que las estaciones de la red comparten el medio de transmisión, las redes de comunicación se pueden clasificar en dos categorías [1]: las que utilizan conexiones punto a punto y las que utilizan canales de difusión. En las redes punto a punto, se emplean enlaces entre cada par de estaciones, lo que simplifica la transmisión ya que no hay interferencia provocada por la existencia de transmisiones simultáneas. Esta clase de red puede resultar muy costosa conforme el número de estaciones aumenta. Por otro lado, las redes de difusión utilizan un medio de transmisión compartido y esto permite generar una red a un menor costo; pero con el peligro de interferencia cuando dos o más estaciones transmiten simultáneamente, ya que lo hacen sobre el mismo medio de transmisión. 
Cuando dos o más estaciones transmiten al mismo tiempo, las señales se traslapan y se dice que se ha presentado una colisión. Si se logra disminuir la cantidad de colisiones, entonces se logra aumentar el desempeño de la red en distintos aspectos.

\subsection{Metas del proyecto}

El objetivo general de este proyecto es proponer y evaluar un protocolo híbrido de control de acceso al medio con reservación de recursos. Para tal efecto, se deben identificar los parámetros relevantes de nuestra propuesta y su efecto en el desempeño de la red. De la misma manera, se debe encontrar la diferencia en desempeño con respecto a una variante sin reservación, la cual es el protocolo $2 \mathrm{C}$ en el cual se basa nuestra propuesta.

\subsection{Justificación de los objetivos}

La principal problemática en las redes de difusión es determinar cuándo y quién puede utilizar el medio de transmisión compartido, cuando dos o más estaciones quieren transmitir. Los protocolos utilizados para evitar o limitar esta situación pertenecen a la subcapa inferior de la capa de enlace de datos llamada subcapa MAC (del inglés medium access control) [1]. En las redes de difusión, el papel de la subcapa MAC es coordinar el acceso al medio de transmisión compartido, para evitar la interferencia entre las estaciones que forman parte de la red [2]. Las redes de difusión también se conocen con el nombre de redes de acceso múltiple, ya que múltiples estaciones comparten el mismo medio de transmisión. En resumen, el control de acceso al medio es la parte de una arquitectura de red que permite compartir un único medio de transmisión entre varias estaciones. 
En general, existen diversos protocolos de control de acceso al medio, conocidos como protocolos MAC. Algunos de ellos intentan dividir, en cierta forma, el medio de transmisión para que pueda ser compartido entre distintas estaciones. Por ejemplo, el medio de transmisión se puede dividir en tiempo, en frecuencia, en espacio o mediante códigos ortogonales, y a todos estos métodos se les conoce como métodos de multicanalización. Existen otros protocolos MAC que intentan asignar el uso del medio de transmisión de forma autoritaria, es decir, el uso del medio se realiza de forma planeada. Finalmente, existen protocolos MAC que asignan el uso del medio de transmisión de forma aleatoria. Todas estas propuestas tienen sus ventajas y desventajas, ello depende en gran medida de las características del medio de transmisión y de las características de las estaciones involucradas en la red.

En la actualidad, los protocolos MAC más populares son los del tipo dinámico de acceso aleatorio, como lo son los del tipo CSMA (del inglés carrier sense multiple access). En este tipo de protocolos MAC, las estaciones monitorean el canal de comunicaciones, es decir, escuchan si se está llevando a cabo una transmisión y actúan de acuerdo con ello. Las versiones básicas de los protocolos con detección de portadora son CSMA 1-persistente, no persistente y p-persistente. A continuación se realiza una breve descripción de estos protocolos (como se efectúa en [1]).

En CSMA 1-persistente, cuando una estación tiene paquetes de datos para transmitir, primero escucha el medio de transmisión para saber si se está realizando otra transmisión en ese momento. Si se está realizando otra transmisión, la estación espera hasta que el medio de transmisión se desocupa. Cuando la estación detecta que la transmisión en curso ha terminado, entonces transmite un paquete. Si ocurre una colisión, la estación espera un intervalo aleatorio de tiempo y comienza de nuevo. El protocolo se llama 1-persistente porque la estación transmite con una probabilidad de 1 cuando encuentra que el medio de transmisión no está siendo ocupado.

Otro protocolo con detección de portadora es CSMA no persistente. En este protocolo, cuando una estación desea transmitir, primero debe escuchar el canal de comunicaciones. Si ninguna estación está transmitiendo, entonces la estación comienza a transmitir. Por el contrario, si alguna estación ya está utilizando el medio de transmisión, la estación no monitorea el canal de comunicaciones de 
manera continua, como sucede en CSMA 1-persistente, lo que hace es dejar de escuchar el medio de transmisión, esperar un periodo aleatorio y repetir el algoritmo. Este protocolo presenta una mayor utilización del medio de transmisión que CSMA 1-persistente, pero produce mayores retardos de acceso.

Por ultimo mencionamos a CSMA p-persistente, el cual puede utilizarse cuando el tiempo está dividido en intervalos, es decir, cuando se asumen ranuras de tiempo. Cuando una estación genera algún paquete para su transmisión, escucha si alguna otra estación está utilizando el canal de comunicaciones. Si ninguna estación lo está ocupando, la estación transmite con una probabilidad $p, y$ con una probabilidad $q=1-p$ se espera hasta la siguiente ranura. Si esa ranura también está desocupada, la estación transmite o espera nuevamente, con probabilidades $p$ y $q$ respectivamente. El proceso anterior se repite hasta que el paquete ha sido transmitido o hasta que otra estación ha comenzado a transmitir. Si otra estación ha comenzado a transmitir, la estación se comporta como si se hubiera presentado una colisión, por lo tanto espera un tiempo aleatorio y comienza de nuevo. Si al principio la estación detecta que el medio de transmisión compartido está ocupado, espera hasta la siguiente ranura y pone en marcha el algoritmo anterior.

En general, los protocolos de acceso aleatorio del tipo CSMA presentan algunas limitaciones asociadas principalmente a las garantías de calidad de servicio que pueden ofrecer, ya que, con este tipo de protocolos, el acceso al medio de transmisión no está garantizado. Por ejemplo, en CSMA/CA (del inglés carrier sense multiple access collision avoidance) se tiene que competir, para usar el medio de transmisión, por cada paquete de información que se requiera transmitir; y cuando la carga ofrecida a la red es alta, entonces el tiempo que tarda un paquete, desde que generó su requerimiento de transmisión hasta es transmitido satisfactoriamente, puede llegar a ser demasiado grande en comparación con el tiempo que tarda un paquete en ser trasmitido cuando la carga es baja. El ejemplo más conocido en donde se utiliza una técnica CSMA/CA es el protocolo 802.11 para redes inalámbricas de área local WLAN (del inglés wireless local area network) [3]. La función de coordinación distribuida DCF (del inglés distributed coordination function) es un esquema que está basado en el protocolo CSMA/CA, y es la técnica primaria de control de acceso al medio del protocolo IEEE 802.11 para WLANs [1]. Cabe mencionar que la función de coordinación distribuida también está basada en el protocolo de retracción binaria exponencial EB (del inglés exponential backoff). La 
DCF puede funcionar en dos diferentes modalidades: la técnica denominada RTS/CTS (del inglés request to send/clear to send) y la técnica denominada mecanismo de acceso básico (para mayor información, sobre la DCF y sus dos modalidades, consultar [1]). En [15] se realiza un análisis del desempeño de la DCF del protocolo IEEE 802.11 para sus dos modalidades. A partir de los resultados encontrados en [15] se puede deducir que la utilización efectiva del medio de transmisión, en la modalidad de acceso básico, depende en gran medida de la cantidad de estaciones en la red; así como de algunos parámetros de inicio del protocolo de retracción binaria. En la modalidad de RTS/CTS, la utilización efectiva del medio de transmisión no depende, en gran medida, de la cantidad de estaciones en la red, pero presenta un mejor desempeño, con respecto a la modalidad de acceso básico, cuando la cantidad de estaciones en la red es grande; es decir, mayor a diez estaciones según [15]. Por ejemplo, de los resultados encontrados en [15] se puede deducir que la DCF del protocolo IEEE 802.11, en su modalidad de RTS/CTS, presenta una máxima utilización efectiva del medio de transmisión, en condiciones estables, no mayor a $84 \%$, cuando la cantidad de estaciones en la red varía desde cinco hasta cincuenta estaciones y la carga ofrecida es alta, y presenta un mejor desempeño que cuando se utiliza la modalidad de acceso básico en las mismas condiciones. De igual forma, cuando se utiliza el mecanismo de acceso básico, independientemente de la cantidad de estaciones en la red y de los parámetros de inicio del protocolo de retracción binaria, presenta una máxima utilización efectiva del medio de transmisión, en condiciones estables, no mayor a $84 \%$, pero es demasiado volátil en función de las características de la red. El protocolo 802.11 puede disminuir el gasto de energía reduciendo el tamaño máximo del EB para que el tiempo que cada dispositivo tiene que esperar para intentar transmitir sea menor, y por lo tanto esté menos tiempo gastando energía, pero al reducir el tamaño máximo del EB se provoca que se presente una mayor cantidad de colisiones cuando existen muchos dispositivos en la red. Entonces, se puede decir que el protocolo 802.11 funciona bien cuando los dispositivos que se comunican no tienen limitantes en el consumo de energía, pero cuando el consumo de energía es un problema critico para los dispositivos que se comunican (por ejemplo, en redes inalámbricas de sensores), entonces dicho protocolo no es la mejor opción [4]. 
Por todo lo anterior, es necesario desarrollar protocolos de acceso aleatorio que permitan un bajo retardo de acceso al medio de transmisión, una alta carga admitida por la red, y que no presenten tanta variabilidad en su desempeño cuando las condiciones en la red estén cambiando, por ejemplo, cuando la cantidad de estaciones en la red está variando constantemente; pues así lo demandan distintas aplicaciones sobre redes inalámbricas, como por ejemplo, aplicaciones para multimedia a la demanda. También es necesario desarrollar protocolos de acceso aleatorio que presentan una alta utilización del medio de transmisión y que intenten usar de una mejor forma la energía de las estaciones que forman parte de la red, pues así se requiere, por ejemplo, en redes inalámbricas de sensores.

En este trabajo se propone un protocolo híbrido de control de acceso al medio con reservación de recursos, el cual permite variaciones en la cantidad de estaciones que forman parte de la red y además presenta mejores garantías en la calidad de servicio con respecto a los protocolos del tipo dinámico de acceso aleatorio.

\subsection{Método de investigación}

El método a seguir es el siguiente:

- Investigación documental acerca de los protocolos de control de acceso al medio

- Propuesta del protocolo híbrido de control de acceso al medio con reservación de recursos

- Implementación de los modelos de simulación

- Validación de los modelos de simulación

- Selección de las medidas de desempeño

- Selección de los escenarios de simulación

- Reporte de resultados 


\subsection{Contribución}

La contribución de este trabajo es la propuesta y la evaluación de un protocolo híbrido de control de acceso al medio con reservación de recursos, que también es un protocolo síncrono de detección limitada, que de aquí en adelante llamamos protocolo $2 \mathrm{C}-\mathrm{R}^{2}$ (2C con reservación de recursos), el cual presenta varias ventajas sobre los protocolos de control de acceso al medio similares, las cuales se exponen en este trabajo.

\subsection{Estructura del documento}

A continuación se describe cómo está organizado el resto de este documento. En el capítulo 2 de este trabajo se hace una revisión general de los protocolos MAC; y más a detalle se revisan los protocolos de control de acceso al medio relacionados con nuestra propuesta. En el capítulo 3 se describe el protocolo $2 \mathrm{C}-\mathrm{R}^{2}$. De igual forma en el capítulo 3 , se muestra la validación de los modelos de simulación, tanto para el modelo de simulación del protocolo $2 \mathrm{C}$ como para el modelo de simulación del protocolo $2 \mathrm{C}-\mathrm{R}^{2}$; así como también se determinan las medidas de desempeño para evaluar nuestra propuesta. Al final del capítulo 3, se realiza la comparación del desempeño de nuestra propuesta con respecto al protocolo 2C. Finalmente, en el capítulo 4 se plasman nuestras conclusiones sobre los resultados obtenidos en este trabajo. 


\section{Capítulo 2}

\section{Control de acceso al medio}

El control de acceso al medio (MAC) es la parte de una arquitectura de red que permite compartir un medio de transmisión entre múltiples estaciones. La componente MAC es indispensable ya que establece cómo se debe acceder al medio y soluciona los conflictos que se originan cuando dos o más transmisiones se realizan simultáneamente. En la figura 1 se puede observar una transmisión exitosa, y en la figura 2 se puede observar que ocurre una colisión.

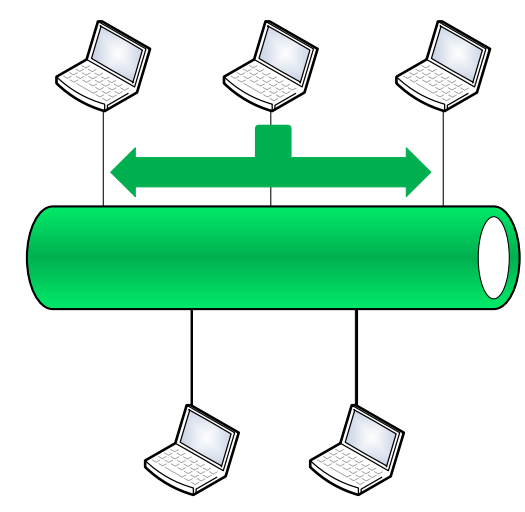

Figura 1. Sólo una estación transmite sobre el medio compartido

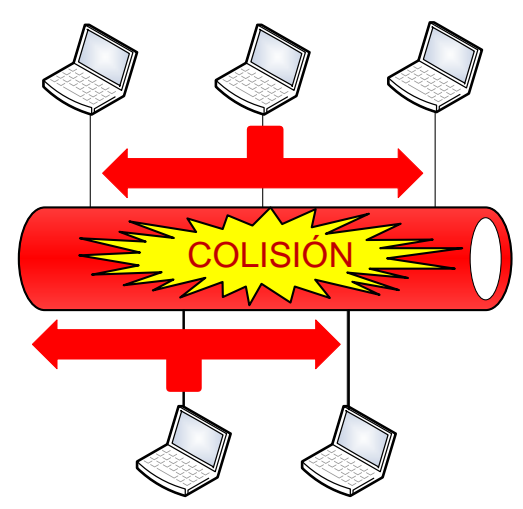

Figura 2. Dos o más estaciones transmiten simultáneamente 


\subsection{Conceptos relacionados}

Existen varios conceptos relacionados con las características de los elementos que forman parte de una red en donde se requiere del control de acceso al medio. A continuación, se describe el significado de algunos de éstos a fin de lograr una mejor comprensión de los temas que se exponen en este trabajo.

Medio de transmisión compartido. Quiere decir que existe un único medio de transmisión disponible para todas las comunicaciones. Todas las estaciones pueden transmitir y recibir a través de él [1].

Estaciones activas. Son las estaciones que se encuentran en proceso de transmisión, es decir, las estaciones que están involucradas en la transmisión de algún paquete o que tienen algún paquete por transmitir [2].

Carga ofrecida. Es la cantidad total de paquetes por unidad de tiempo que las estaciones ofrecen a la red [14].

Carga ofrecida normalizada. Es la cantidad total de paquetes por unidad de tiempo que las estaciones ofrecen a la red entre el tiempo necesario para la transmisión exitosa de un paquete [14].

Colisión. Si dos o más estaciones transmiten paquetes en forma simultánea, los paquetes se traslapan en el tiempo, la señal resultante se altera y el receptor no realiza una correcta recepción; a este evento se le conoce como colisión. Un paquete involucrado en una colisión usualmente debe retransmitirse posteriormente [2]. 
Tiempo ranurado. El tiempo se divide en intervalos conocidos como ranuras de tiempo. Una ranura puede contener cero, una o más transmisiones, correspondientes a una ranura inactiva, una transmisión con éxito o una colisión, respectivamente [1].

Sincronización en redes con tiempo ranurado. Implica la existencia de un reloj global que marca intervalos de tiempo de igual longitud, llamados ranuras de tiempo, en donde cada estación puede comenzar a enviar paquetes sólo al inicio de cada ranura [14].

Multiplicidad de la colisión. Es la cantidad de estaciones que envían paquetes simultáneamente, y que por consecuencia se traslapan en el tiempo y dan lugar a una colisión [14].

Red en condiciones estables. En este trabajo, se dice que una red se encuentra en condiciones estables cuando la tasa promedio de generación de paquetes, que necesitan ser transmitidos por las estaciones que forman parte de la red, es menor a la tasa promedio en la que los paquetes pueden ser transmitidos exitosamente sobre el medio de transmisión compartido.

Máxima carga admitida. Se define, en este trabajo, como la máxima carga ofrecida, por parte de todas las estaciones, que la red puede admitir para continuar operando en condiciones estables. 


\subsection{Estrategias de control de acceso al medio}

Dependiendo de la forma en que un protocolo MAC permite el acceso de las estaciones al medio de transmisión compartido, se puede decir que pertenece a alguna de las dos categorías siguientes [2]:

- Protocolos MAC estáticos. En estos protocolos el medio de transmisión se divide en canales de comunicación separados, y cada uno de los canales se dedica a las transmisiones generadas por una sola estación. Por lo general, estos protocolos se utilizan cuando las estaciones transmiten continuamente paquetes sobre un medio de transmisión compartido. Una desventaja de esta técnica es que se asignan recursos aún cuando éstos no se estén utilizando. Cabe mencionar que la cantidad de estaciones permitidas es limitada, pues la cantidad de canales que se puede asignar es finita y depende de las características del medio de transmisión y de las garantías de calidad de servicio que sean requeridas.

- Protocolos MAC dinámicos. En estos protocolos, todas las estaciones que tengan algún paquete por transmitir, pueden emplear el medio de transmisión compartido, y el mismo protocolo se encarga de decidir cuándo pueden disponer de él. Una característica de estos protocolos es que permiten que las estaciones ocupen el medio de transmisión a toda su capacidad en un tiempo dado. Los protocolos MAC dinámicos se pueden agrupar en dos categorías:

- Acceso aleatorio. También conocidos como protocolos de contienda, en estos protocolos el uso del medio de transmisión compartido se realiza de manera aleatoria. De esta forma, cada estación decide entre utilizar el medio de transmisión o esperar para intentar realizar su transmisión. 
- Acceso por reservación. A diferencia de los protocolos dinámicos de acceso aleatorio, en los protocolos dinámicos de reservación el uso del medio de transmisión compartido se realiza de forma planeada; es decir, no interviene la aleatoriedad para que una estación pueda utilizar el medio de transmisión.

Algunos ejemplos de esta forma de clasificar a los protocolos MAC se muestran en la figura 3. Cabe mencionar que los protocolos MAC dinámicos de acceso aleatorio se pueden clasificar dentro de dos categorías, dependiendo de la forma en que monitorean el medio de transmisión compartido [2]:

- Detección limitada (limited sensing). En esta clase de protocolos, sólo las estaciones activas (aquellas que tienen, están intentando o que están transmitiendo algún paquete) actúan como monitores del medio de transmisión.

- Detección completa (full sensing). En los protocolos de detección completa, todas las estaciones actúan como monitores del medio de transmisión, estén o no transmitiendo o intentando transmitir.

Como ya se mencionó, en este trabajo se propone un enfoque híbrido que intenta aprovechar las características positivas tanto de los protocolos MAC dinámicos de acceso aleatorio como las de los protocolos de acceso por reservación. 


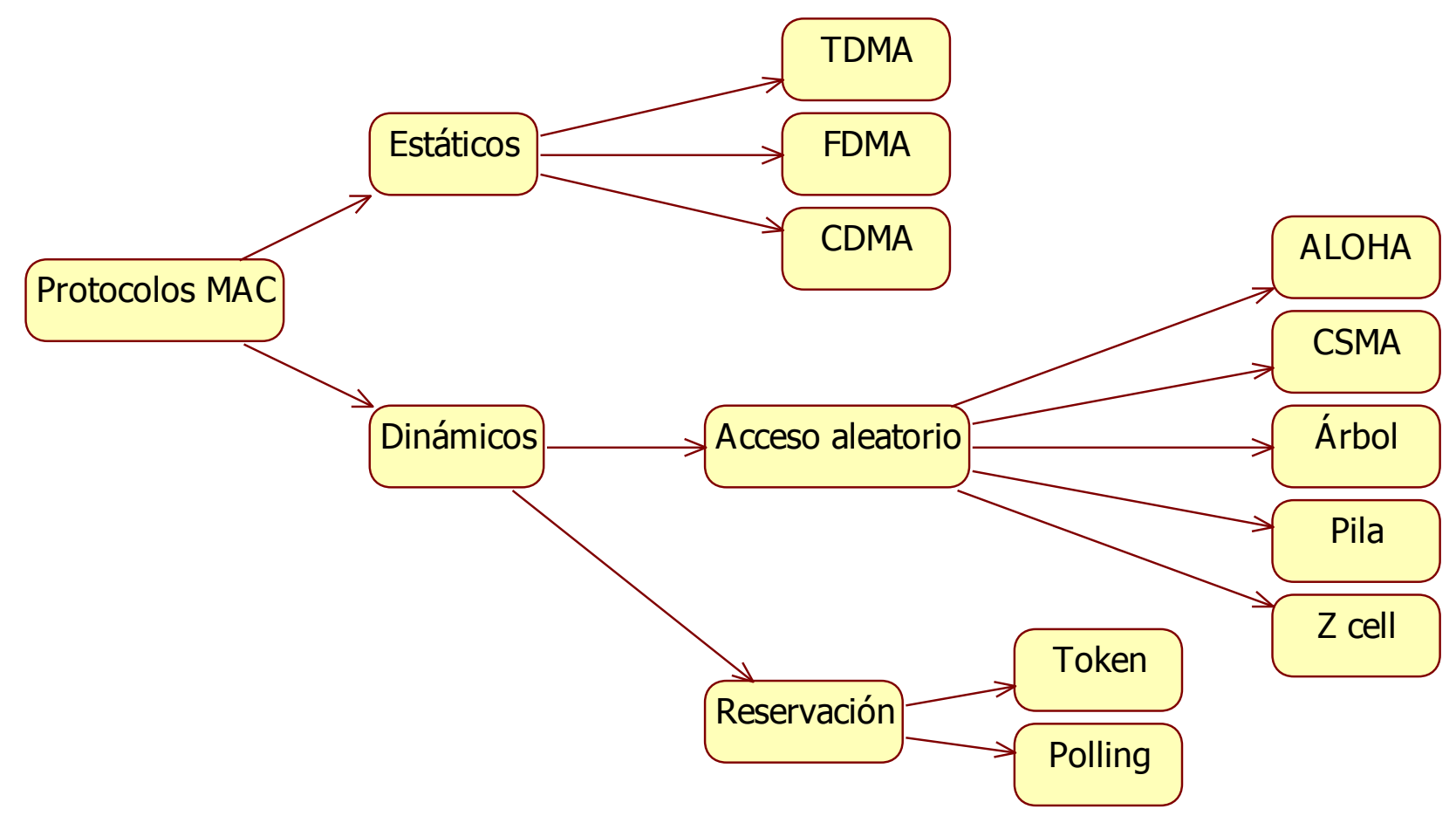

Figura 3. Ejemplos de la clasificación de los protocolos MAC con base en la clasificación proporcionada en [2]. 


\subsection{Protocolos MAC afines a la propuesta}

En este trabajo se propone un protocolo híbrido de control de acceso al medio con reservación de recursos. Los posibles conflictos durante el proceso de reservación se resuelven de forma similar a como lo hace el protocolo $2 \mathrm{C}$, el cual es un protocolo MAC que presenta atractivas propiedades, ya que es un protocolo dinámico de acceso aleatorio que está basado en operaciones muy sencillas, además es relativamente fácil de implementar en cualquier tipo de red ya que no se necesita gran capacidad de procesamiento y se requiere una mínima capacidad de almacenamiento por parte de las estaciones que lo utilizan. Cabe mencionar que el protocolo $2 \mathrm{C}$ no se define para algún medio de transmisión en particular pero puede ser fácilmente adaptado a cualquiera dada la simplicidad del protocolo, lo cual es una característica muy atractiva. El protocolo 2C está basado en los protocolos de árbol y de pila. A continuación, se describen los tres protocolos antes mencionados y un protocolo básico de reservación, el cual también se relaciona con este trabajo.

\subsubsection{Protocolo de árbol binario}

Este protocolo fue propuesto por Capetanakis en [5], en dos versiones, una versión estática y otra dinámica. En ambos casos el tiempo se asume ranurado, por lo tanto las estaciones en la red están sincronizadas, y existe una estación central encargada de recibir la transmisión de todas las demás estaciones.

En este protocolo se propone que a cada estación se le considere como una hoja de un árbol binario. Las estaciones involucradas en una colisión se dividen en dos grupos: hijos izquierdos e hijos derechos. En la versión dinámica, el árbol binario se va formando conforme se van presentando colisiones y cada estación va decidiendo a qué grupo pertenecer mediante un experimento aleatorio de Bernoulli. En la versión estática, el árbol binario ya esta predefinido, la cantidad de estaciones en la 
red es fija y cada estación tiene asociada una dirección binaria que sirve para conocer su posición dentro del árbol.

En la primera ranura de contención, se les permite a todas las estaciones, que tengan paquetes por transmitir, usar el medio de transmisión compartido. Si ocurre una colisión en la primera ranura, se examina todo el árbol para localizar a todas las estaciones activas. Cada ranura de tiempo está asociada a un nodo en particular del árbol. Si ocurre una colisión, continúa la búsqueda recursivamente: primero con los hijos del lado izquierdo y luego con los hijos del lado derecho del nodo. Si una ranura está vacía, o si sólo transmitió una estación en ella, puede detenerse la búsqueda del nodo respectivo, pues significa que ya han transmitido todas las estaciones activas de esa rama del árbol, ya que si hubiera existido más de una estación habría ocurrido una colisión. Si otras estaciones, diferentes a las involucradas en la colisión de la primera ranura, desean transmitir, entonces deben esperar a que finalice la resolución de la colisión en curso.

Como se puede intuir, el protocolo de árbol binario requiere de una buena coordinación por parte de las estaciones que forman parte de la red. Cabe mencionar que el protocolo de árbol ha sido modificado de varias maneras para lograr un mejor desempeño. En [14] se puede ver una descripción de tales propuestas.

En la figura 4, se puede observar un ejemplo de una red que opera con el protocolo de árbol binario. En este ejemplo, las estaciones $A, C, D, G$ y $H$ transmiten paquetes de datos simultáneamente en la primera ranura de contención (ranura cero) y en consecuencia, se produce una colisión. El árbol mostrado en este ejemplo se puede construir de forma dinámica o puede ser un árbol estático predeterminado. En el ejemplo, se puede observar que el protocolo de árbol binario tiene desventajas, ya que la división del árbol provoca que existan ranuras vacías, como ocurre en la ranura siete, lo cual puede significar un desperdicio de tiempo y de ancho de banda. 


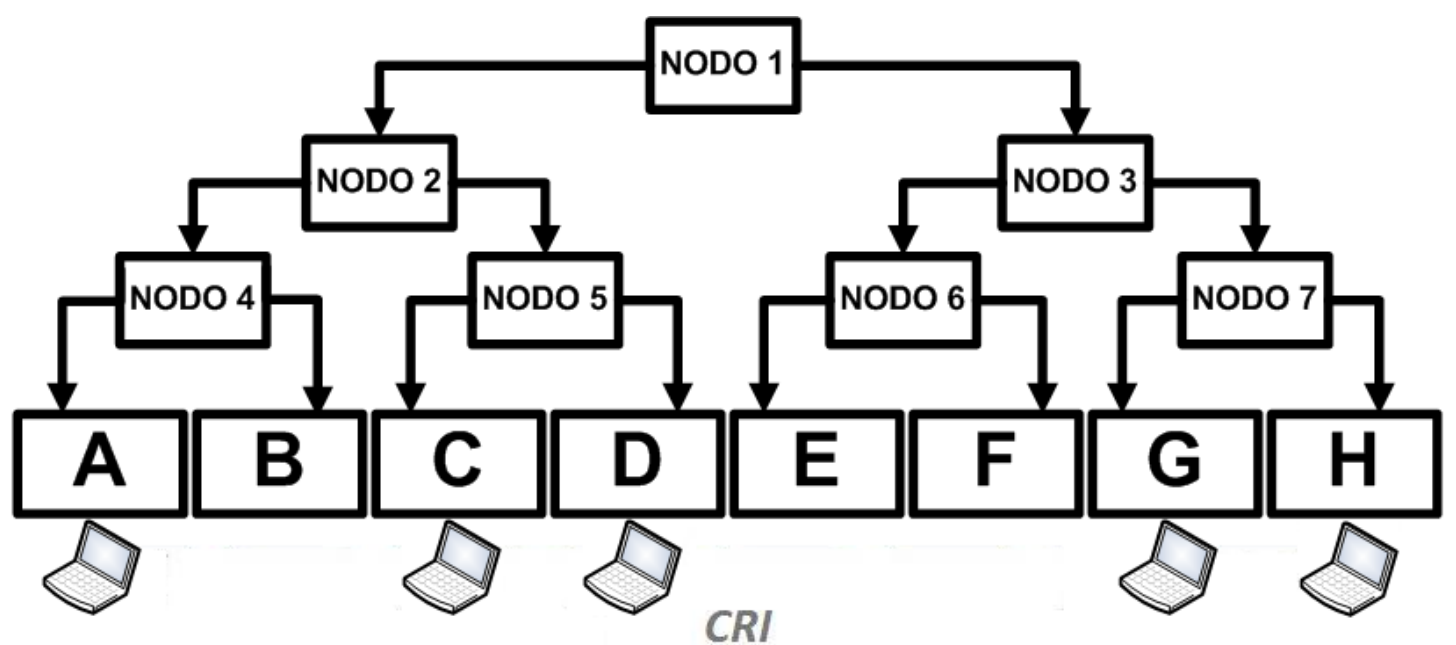

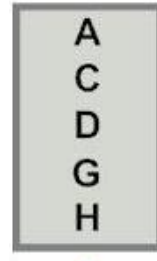

0

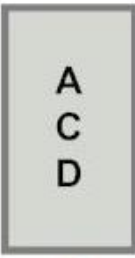

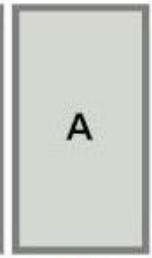

2

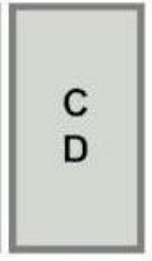

3

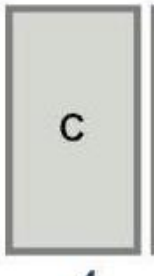

4
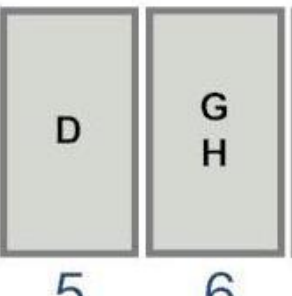

6

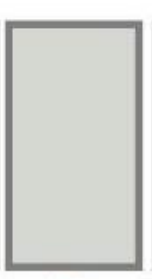

7

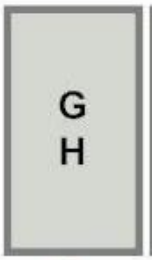

8

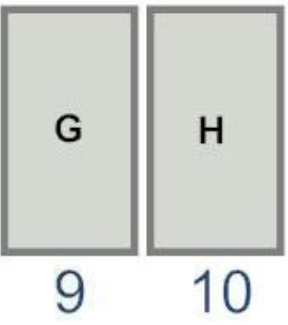

Figura 4. Ejemplo del protocolo de árbol binario para cinco estaciones activas

\subsubsection{Protocolo de pila}

Este protocolo fue propuesto por Tsybakov en [6]. En este protocolo el tiempo se supone ranurado, y sólo es posible comenzar a transmitir al inicio de cada ranura de tiempo. También se asume una estación central que informa a las demás estaciones, al final de cada ranura, si la ranura estuvo vacía, si tuvo un Éxito o si se presentó una colisión. Suponga que en un tiempo $t$ se han resuelto todas las colisiones y que cada estación tiene un variable llamada contador de pila SC (del inglés stack counter). Entonces, el funcionamiento del protocolo es el siguiente: 
1. Cuando las estaciones tienen paquetes de datos para transmitir, éstos siempre se envían al momento en que son generados. En la primera transmisión de un paquete, cada estación involucrada fija su contador $S C=0$. Si dos o más estaciones transmiten, entonces sucederá una colisión. Si sólo una estación transmite, entonces la transmisión se realizará con éxito.

2. Si se produce una colisión, la estación central sabe que esto ha ocurrido, pero desconoce la cantidad de estaciones involucradas. La estación central informa a las demás estaciones que hubo una colisión mediante una realimentación (feedback) de colisión. Cuando una transmisión se realiza exitosamente, la estación central lo informa mediante una realimentación de ÉXITO.

3. Cada estación involucrada en la transmisión sabe que hubo una colisión, por lo que realiza un experimento aleatorio de Bernoulli, el cual es 1 con probabilidad $p$, y 0 con probabilidad 1- $p$. Si después de realizar el experimento se encuentra que el resultado es 1 , entonces incrementan su contador $S C$ en 1 y no intentan transmitir en la siguiente ranura. Por el contrario, si el experimento arrojó un 0 , fijan su contador $S C=0$ y transmiten en la siguiente ranura.

4. Si al intentar de nuevo la retransmisión hay una colisión, se repite el paso tres para las que colisionaron; pero para las que no transmitieron y se encuentran esperando, se incrementa su contador $S C$ en 1.

5. Si por el contrario la transmisión es exitosa, las estaciones en espera no modifican su contador $S C$ a menos que la realimentación sea de ranura vaCía; en este caso, su contador $S C$ debe ser disminuido en 1.

6. Nuevas estaciones son libres de entrar en la competencia por el medio de transmisión, en el momento que tengan algún paquete de datos por transmitir. Sin embargo, puede ocurrir que se genere una colisión; de ser así, el protocolo continúa con la nueva estación en contienda. 
Un posible ejemplo de la evolución de una red con tres estaciones, operando con el protocolo de pila, se ilustra en la figura 5; en donde se puede observar cuáles estaciones se encuentran en espera y cuáles intentan transmitir. En este ejemplo, se puede observar que, en la primera ranura de tiempo, las tres estaciones desean transmitir al mismo tiempo (estaciones $A, B$ y $C$ ) y entonces cada una fija su apuntador a la pila $S C$ en cero y transmiten sus respectivos paquetes de datos (figura 5a). Como se presenta una CoLIsión en la primera ranura, aleatoriamente deciden, de forma independiente, cuales continúan al "tope" de la pila, y entonces pueden transmitir en la siguiente ranura de tiempo, y cuales tienen que esperar para transmitir posteriormente y deben "descender" un lugar desde su posición actual dentro de la pila. En el ejemplo, únicamente una de las estaciones involucradas en la colisión decide esperar (la estación $B$ ) y las demás estaciones deciden transmitir en la segunda ranura de tiempo y por lo tanto se vuelve a presentar una colisión (figura 5b). El procedimiento anterior se repite para decidir qué estaciones transmiten en la tercera ranura de tiempo, en donde por fin se realiza una transmisión exitosa por parte de la estación $C$ (figura 5c). Las estaciones que se encuentran esperando, para poder transmitir, deben de recibir una realimentación de ranura vacía por parte de la estación central (figura 5d) para "subir" un lugar en la pila y continuar en su intento por transmitir (figura 5e). Como se puede observar en el ejemplo, se pueden presentar ranuras vacías y en colisión, lo cual repercute en desperdicio de tiempo y ancho de banda.

El protocolo de pila es muy semejante al protocolo de árbol; sin embargo, el protocolo de pila explota la realimentación, algo que el protocolo de árbol no hace. La intención del protocolo de pila es que todas las estaciones transmitan su paquete de datos tan pronto como sea posible. El protocolo de pila tiene un caudal de datos máximo de $\lambda=0.36017$ paquetes por ranura, es decir, una utilización efectiva del medio de transmisión del 36.02\%, cuando se toma $p=0.5$ (ver [12]). Por último, se puede observar que el tipo de realimentación empleada en el protocolo es ternaria, de tal suerte que sólo tres avisos son válidos: COLISIÓN, VACío y ÉXITO. 


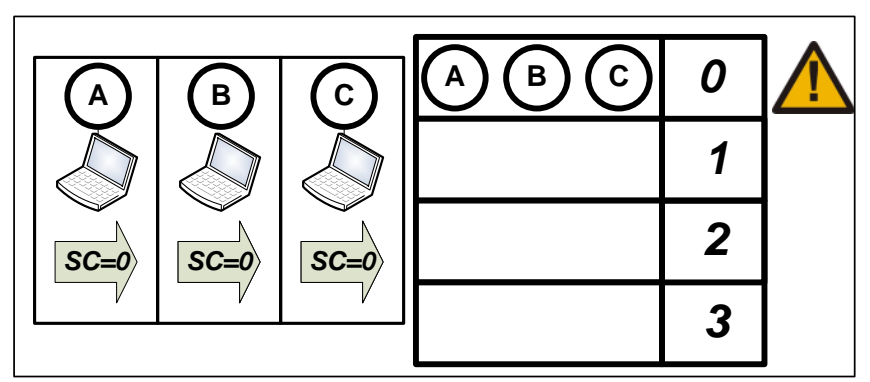

(a)

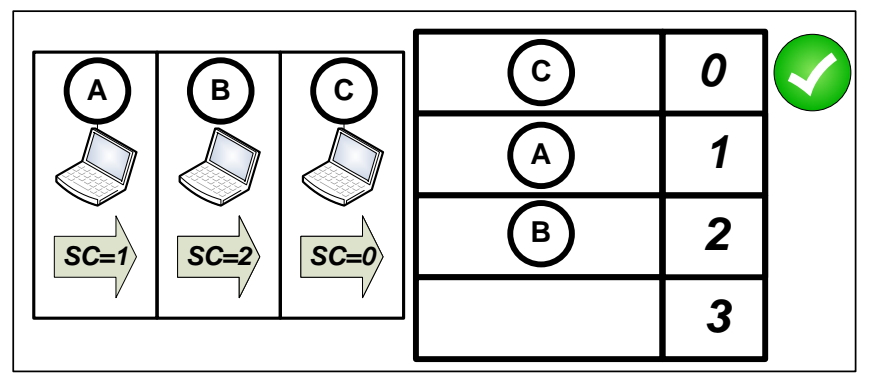

(c)

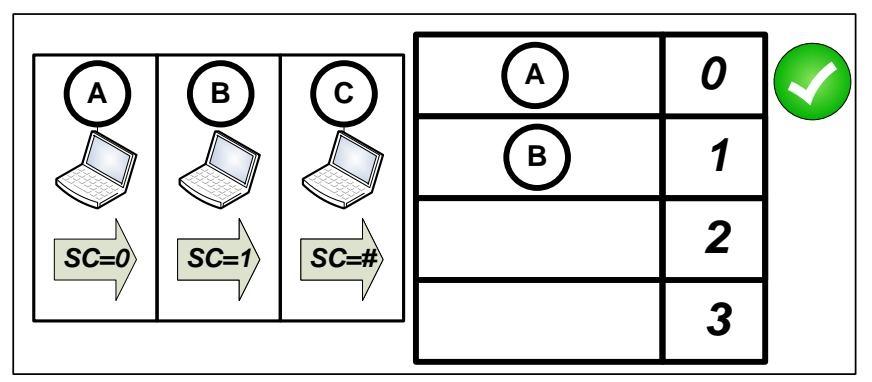

(e)

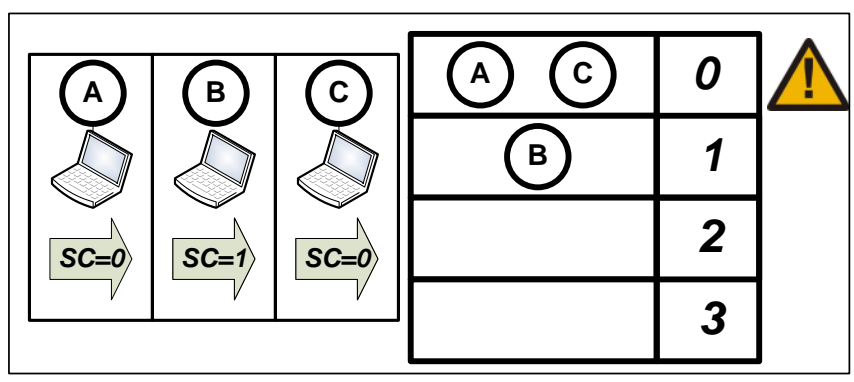

(b)

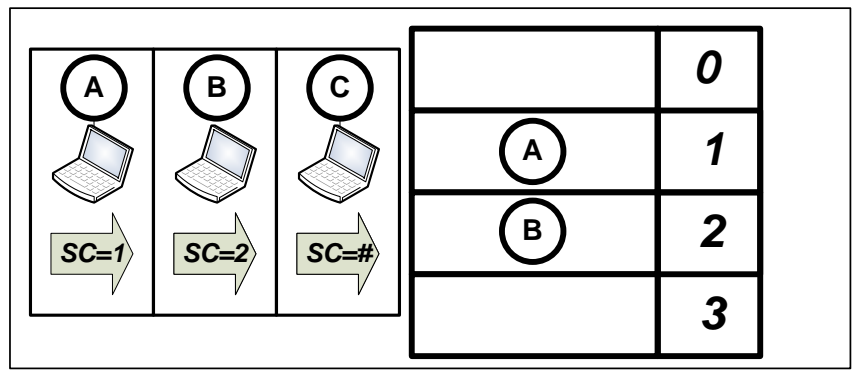

(d)

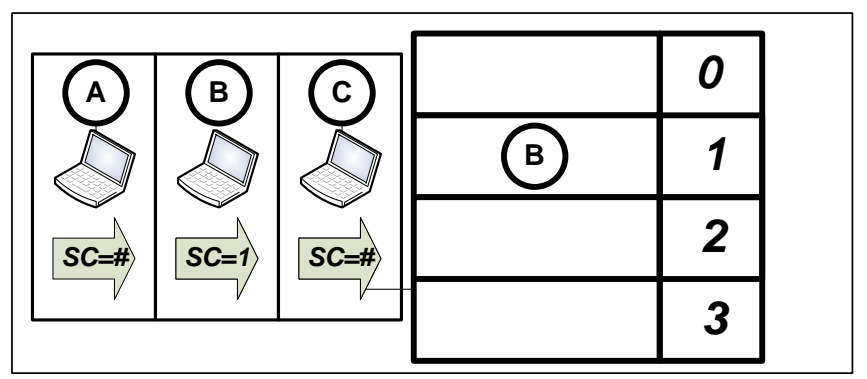

(f)

Figura 5. Ejemplo del protocolo de pila para una red con tres estaciones para la $(a)$ primera ranura tiempo, $(b)$ segunda, $(c)$ tercera, $(d)$ cuarta, $(e)$ quinta y $(f)$ sexta 


\subsubsection{Protocolo 2C}

El protocolo 2C para resolución de colisiones fue propuesto por Paterakis y Papatoni-Kazakos en [7]. En su trabajo se asume: tiempo ranurado, la transmisión de un paquete de datos por ranura de tiempo, realimentación binaria de colisión $(C)$ o No_Colisión $(N C)$ al final de cada ranura de tiempo, retardo de propagación igual a cero y que un paquete colisionado debe ser retransmitido de nuevo en el futuro. También se asume la ausencia de errores en la realimentación, es decir, todas las estaciones reciben correctamente la realimentación de la estación base.

El tiempo es medido en unidades de ranuras de tiempo; la ranura $t$ corresponde al intervalo de tiempo $[t, t+1)$, y $x_{t}$ denota la realimentación que corresponde a la ranura $t ; x_{t}=C$ y $x_{t}=N C$ representan una Colisión y una No_Colisión en la ranura $t$, respetivamente. El protocolo $2 \mathrm{C}$ utiliza una ventana de tamaño $\Delta$ ranuras de tiempo. Digamos que $t$ es el instante de tiempo que corresponde al inicio de una ranura que, para algún $t_{l}<t$, todos los paquetes de datos que llegaron en el intervalo $\left(0, t_{l}\right]$ han sido transmitidos satisfactoriamente. El instante $t$ se conoce como el punto de resolución de colisión CRP (del inglés collision resolution point), y al intervalo $\left(0, t_{l}\right]$ se le conoce como intervalo resuelto. En la ranura $t$ se intentan transmitir los paquetes que llegan en $\left(t_{1}, t_{2}\right]$, donde $t_{2}$ es el valor mínimo entre $t_{1}+\Delta$ y $t$; el intervalo de llegadas $\left(t_{1}, t_{2}\right]$ se conoce como "intervalo examinado". Si el intervalo $\left(t_{1}, t_{2}\right]$ contiene a lo más un paquete, entonces se transmite exitosamente en la ranura $t$. Si $\left(t_{1}, t_{2}\right]$ contiene al menos dos paquetes, entonces $x_{t}=C$, es decir, una colisión ocurre en $t$, y esta colisión se comenzará a resolver en la ranura $t+1$. Hasta que la colisión en $t$ sea resuelta, no se permite la transmisión de otros paquetes generados después de $t_{2}$. El periodo requerido para la resolución de la última colisión ocurrida se llama intervalo de resolución de colisión CRI (del inglés collision resolution interval). Si el intervalo examinado contiene a lo más un paquete, entonces el CRI tiene una duración de una ranura.

Durante un CRI, que comienza con una ranura en colisión, cada estación actúa independientemente de las demás estaciones, ya que utilizan un contador propio con cierto valor en el tiempo $t$, que se denota por $r_{t}$. Cuando una estación transmite por primera vez, debe poner su contador $r_{t}=1$, es decir, debe ubicarse en la celda de transmisión TC (del inglés transmission cell). El valor del 
contador puede variar entre 1 o 2 , en donde $r_{t}=2$ quiere decir que la estación se ubica en la celda de espera WC (del inglés waiting cell). El valor de $r_{t}$ se actualiza de acuerdo a las siguientes reglas:

1. La estación transmite en la ranura $t$ si y sólo si $r_{t}=1$. Un paquete se transmite satisfactoriamente en $t$ si y sólo si $r_{t}=1$ y $x_{t}=N C$.

2. La actualización del contador $r_{t}$ se realiza de la manera siguiente:

a) Si $x_{t-1}=N C$ y $r_{t-1}=2$, entonces $r_{t}=1$

b) Si $x_{t-1}=C$ y $r_{t-1}=2$, entonces $r_{t}=2$

c) Si $x_{t-1}=C$ y $r_{t-1}=1$, entonces:

$r_{t}=1$ con probabilidad de $p=0.5$ o $r_{t}=2$ con probabilidad $q=1-p=0.5$

Como se puede observar, un CRI comienza con una ranura en colisión y termina cuando ocurren dos ranuras consecutivas en NO_COLISIÓN, ya que dos ranuras consecutivas en NO_COLISIÓN no pueden ocurrir en algún otro momento durante el CRI. Entonces, la observación de dos ranuras consecutivas en NO_COLISIÓN indica el final de una CRI para todas las estaciones en la red. El que las estaciones puedan conocer el final de cada CRI, permite que el protocolo 2C trabaje en modo de detección limitada.

Por ejemplo, supóngase una red con siete estaciones. Parte de la evolución de la red, según el protocolo 2C, se observa en la figura 6. En este ejemplo, en la ranura tres, comienza un nuevo CRI con las estaciones que generaron paquetes de datos para transmitir durante el último intervalo examinado antes de $t$ (estaciones $A, B, C$ y $D$ ). El CRI termina en la ranura doce con dos ranuras consecutivas sin colisión. Después de la colisión inicial las estaciones $A$ y $C$ deciden aleatoriamente permanecer en la contienda mientras que las demás deciden esperar. En la siguiente ranura $A$ y $C$ colisionan. La estación $A$ aleatoriamente decide esperar y $C$ decide permanecer por lo que logra una transmisión exitosa. Después de recibir la realimentación NO_COLISIón todas las estaciones en espera regresan a contender, y de esta forma se siguen resolviendo las colisiones hasta el final del CRI con dos ranuras con NO_COLISIÓN consecutivas. El procedimiento anterior vuelve a comenzar en la ranura trece, en donde comienza un nuevo CRI con las estaciones que generaron paquetes de datos para transmitir durante el desarrollo del último CRI (estaciones $E, F$ y $G$ ). 
$\$$

田

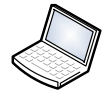

B
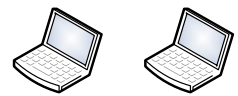

C

D

E

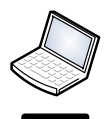

$\$$

E
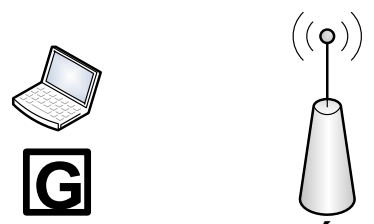

ESTACIÓN BASE

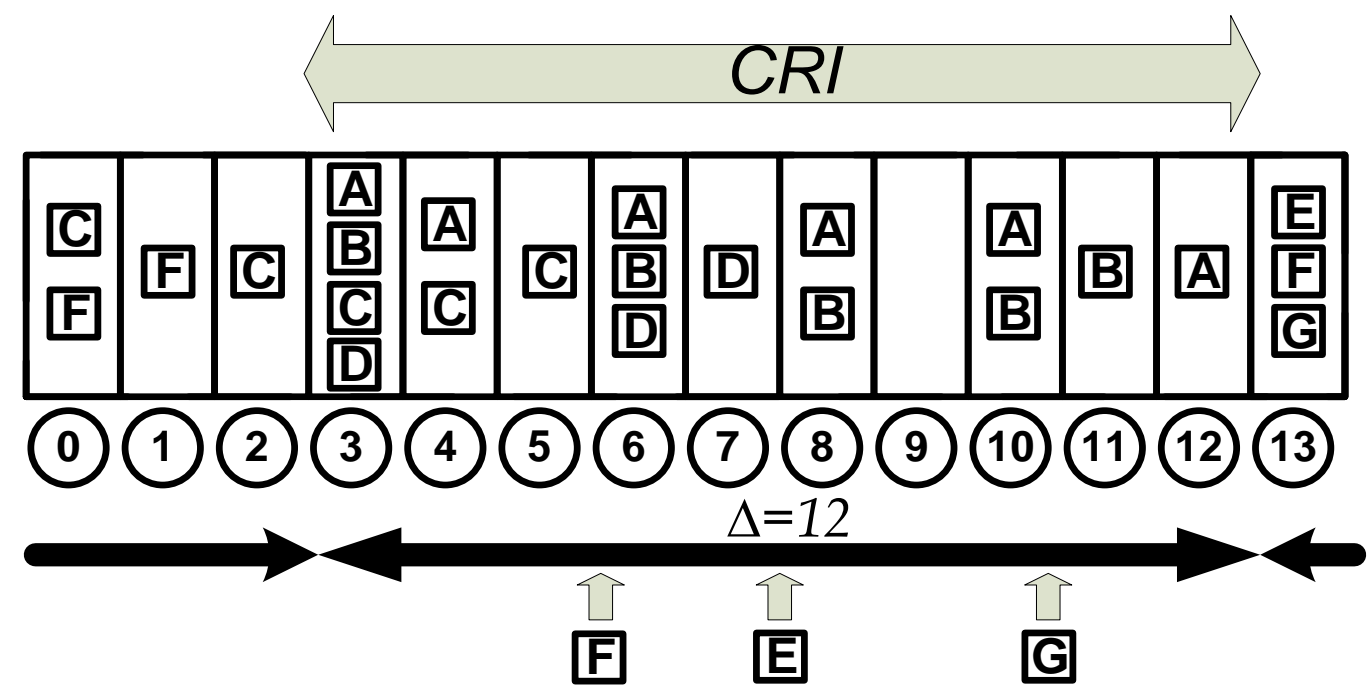

Figura 6. Ejemplo del desarrollo en una red con el protocolo $2 \mathrm{C}$

En el ejemplo de la figura 6, también se puede observar que el tamaño de la ventana es fijo y es de $\Delta=12$, pero como, en este ejemplo, el CRI termina antes de doce ranuras, entonces en la ranura trece ya es posible la transmisión de las estaciones que tuvieron paquetes de datos para transmitir en el intervalo que comprende desde la ranura tres hasta la ranura doce. En la ranura trece comienza también una nueva ventana de examinación con $\Delta=12$, es decir, un intervalo en donde todas las estaciones, que generen nuevos paquetes para su transmisión, podrán intentar transmitirlos al inicio del CRI siguiente a dicha ventana.

Los autores en [7] demuestran que la red opera de forma estable si el tamaño promedio del CRI, dada la ventana de observación $\Delta$, es menor a la propia ventana de observación $\Delta$. La idea anterior es muy deseable en este protocolo, ya que entre menor sea $\Delta$, será menor el número de estaciones que entren en contienda, y como resultado el CRI tendrá menor tamaño. Los autores de este protocolo también presentan un análisis completo del caudal y del retardo, basado en el cómputo de un método teórico recursivo. 
En dicho análisis, asumen un monitoreo continuo de la realimentación y adoptan para cada estación un modelo de Poisson. A partir de estas suposiciones, encuentran que el caudal de datos de este protocolo es de $\lambda=0.4295$ paquetes por ranura para una longitud de la ventana de observación de $\Delta=2.33$ ranuras, es decir, una utilización del $42.95 \%$ con CRIs de duraciones menores a 2.33 ranuras en promedio. En el modo de detección limitada y con tráfico ligero, el retardo de acceso es aproximadamente de 2.5 ranuras de tiempo por paquete.

El protocolo $2 \mathrm{C}$ parte de un protocolo general llamado Z-Cell propuesto en [8], en el cual se tienen características similares con los protocolos de árbol [5] y de pila [6]. Cabe mencionar que se han propuesto varias modificaciones al protocolo $2 \mathrm{C}$ para mejorar su desempeño. Dos modificaciones interesantes se proponen en [9], en donde se sugiere ajustar la probabilidad de transmisión $p$ basándose en la cantidad de estaciones en contienda. En la primera modificación en [9], básicamente los autores proponen que, al final de cada ranura en colisión, la estación base informe la cantidad de transmisiones que colisionaron $(N)$, y entonces, las estaciones que estuvieron involucradas deben modifican su probabilidad de transmisión, para la siguiente ranura, $p=1 / N$; con esta modificación se logra reducir la longitud del CRI en aproximadamente un 50\%. En la segunda modificación en [9], se propone que sólo al inicio del CRI las estaciones involucradas modifiquen su probabilidad de transmisión para la segunda ranura a $p=1 / N$, y para las ranuras posteriores con colisión, dentro del mismo CRI, utilicen $p=0.5$; y con esta modificación se alcanzan resultados similares a los de la primera. Cabe resaltar que con las modificaciones propuestas en [9], al reducir la longitud de cada CRI, se logra reducir el retardo de acceso al medio, además de que se siguen conservando las propiedades atractivas del protocolo $2 \mathrm{C}$ original.

Cabe mencionar que el protocolo $2 \mathrm{C}$ también se ha utilizado para desarrollar protocolos de control de acceso al medio para redes inalámbricas de sensores WSN (del inglés wireless sensor network). Por ejemplo, en [10] se propone hacer uso del protocolo 2C durante la fase de configuración de una WSN en donde se utiliza un protocolo de control de acceso al medio, basado en TDMA, denominado SA-MAC [11], en el cual los nodos toman turnos para transmitir partiendo de una estructura de árbol. 


\subsubsection{Protocolo básico de reservación}

Los protocolos MAC dinámicos de acceso aleatorio son relativamente simples de implementar, y cuando el tráfico sobre la red es ligero, presentan un retardo de acceso bajo. No obstante, estos protocolos pueden limitar el caudal máximo permisible sobre el medio de transmisión y esto puede resultar en una amplia variabilidad en el retardo de acceso. Los protocolos dinámicos de reservación intentan proporcionar un acceso ordenado de las estaciones al medio de transmisión compartido. Sin embargo, tienen la característica de que la cantidad de estaciones, que forman parte de la red, debe ser fija, y entonces no se permite que otras estaciones diferentes puedan utilizar el medio de transmisión, lo cual se puede ver como una desventaja del protocolo.

En una red operando con el protocolo básico de reservación [2], las estaciones toman turnos para transmitir un paquete de datos a toda la capacidad del medio de transmisión compartido. La transmisión de las estaciones se organiza en tramas, y las tramas pueden contener una cantidad variable de ranuras de tiempo. Cada trama es precedida de su correspondiente intervalo de reservación RI (del inglés reservation interval). En su forma más simple, el RI consiste de varias miniranuras de tiempo y cada estación ocupa su miniranura correspondiente para informarles a todas las demás estaciones si tiene o no algún paquete por transmitir. Al finalizar el RI, las estaciones pueden determinar el intervalo de tiempo en el que pueden transmitir sus paquetes (en la correspondiente trama). La cantidad de ranuras de tiempo que tenga cada trama dependerá de la cantidad de estaciones que tengan algún paquete por transmitir. Todas las estaciones conocen la cantidad de ranuras que conforman cada trama y por lo tanto conocen cuándo se presentará otro RI. Cabe mencionar que en esta propuesta no se consideran los retardos de propagación.

La secuencia temporal de un ejemplo de una red operando con el protocolo básico de reservación se puede observar en la figura 7. Supóngase que, en el primer RI sólo la estación número dos y la estación número cuatro tienen paquetes de datos por transmitir. En el siguiente RI, la estación número tres también desea transmitir, y las estaciones dos y cuatro de igual forma desean seguir transmitiendo. 
Por último, en el tercer RI sólo la estación número cuatro desea continuar transmitiendo paquetes de datos. En el ejemplo, se puede apreciar que el tamaño máximo de una trama es igual a la cantidad total de estaciones en la red, que en este ejemplo es de cuatro estaciones.
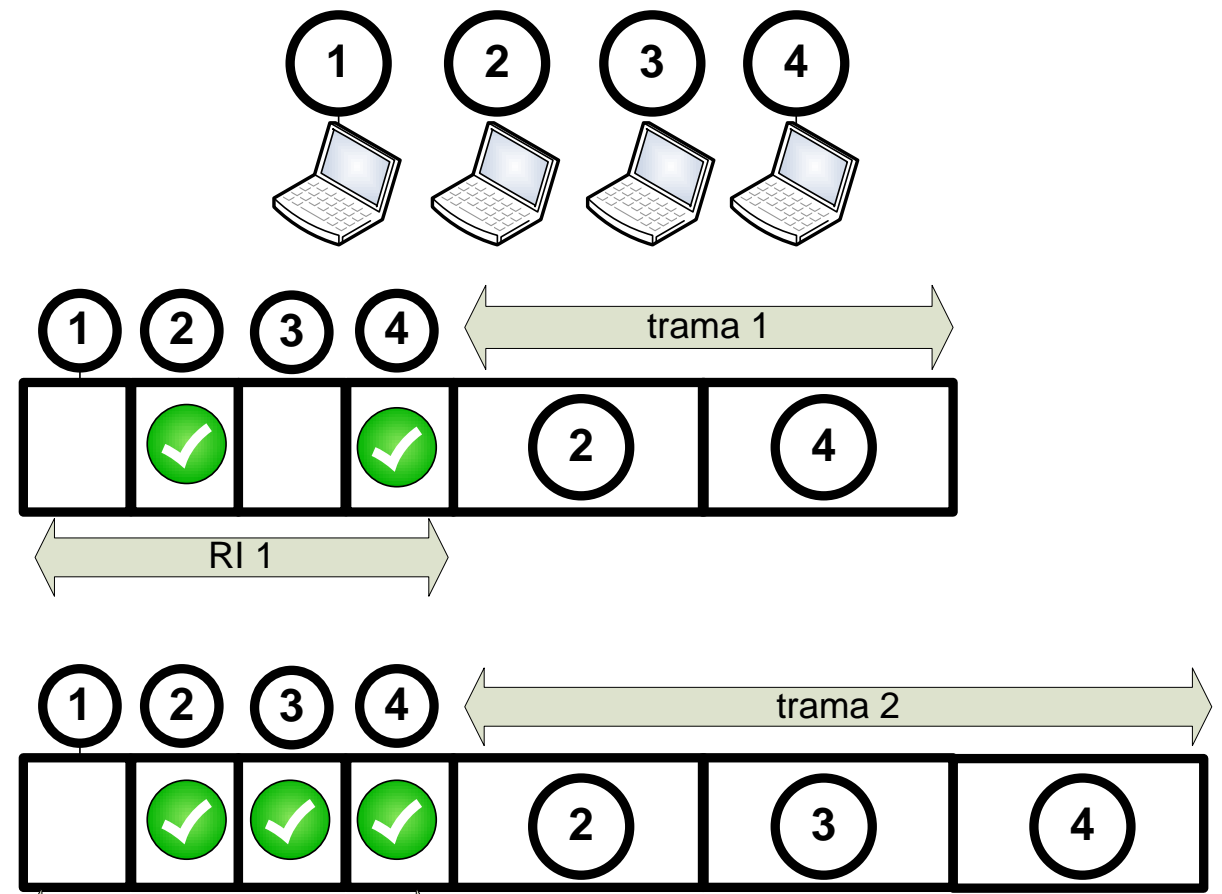

$\mathrm{RI} 2$

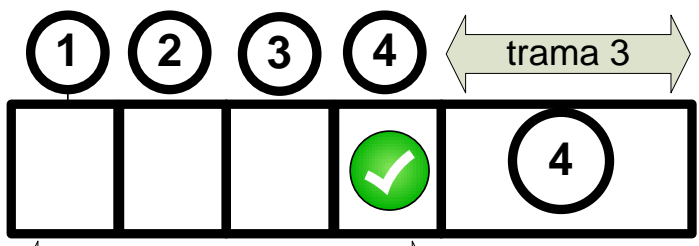

$\mathrm{RI} 3$

Figura 7. Operación de una red con cuatro estaciones operando con el protocolo básico de reservación. 


\section{Capítulo 3}

\section{Protocolo 2C-R ${ }^{2}$}

En este capítulo realizamos la descripción y la evaluación de desempeño de nuestra propuesta, el protocolo $2 \mathrm{C}-\mathrm{R}^{2}$. De igual forma validamos los modelos de simulación para tener la certeza que los resultados encontrados son correctos.

\subsection{Descripción del protocolo}

En nuestra propuesta, la cual denominamos protocolo $2 \mathrm{C}-\mathrm{R}^{2}$, asumimos el tiempo ranurado, consideramos que las estaciones envían un requerimiento de transmisión por cada miniranura de tiempo y un paquete de datos por cada ranura de tiempo. Asumimos una realimentación cuaternaria de COLISIÓN, VACÍO, ÉXITO, o INICIO_DE_RESERVACIÓN, por parte de la estación base al final de cada ranura o miniranura. El retardo de propagación es igual a cero y asumimos un canal libre de errores. Cabe mencionar que, en el particular caso de las redes inalámbricas, al asumir un canal libre de errores podemos decir que en cada estación la relación señal a ruido SNR (del inglés signal to noise ratio) es siempre mayor a la relación señal a ruido mínima necesaria para una correcta recepción $\left(\mathrm{SNR}>\mathrm{SNR}_{\min }\right)$. 
En este trabajo sugerimos que las estaciones compitan por turnos para transmitir paquetes de datos a la capacidad total del medio de transmisión compartido. Cada estación realiza la transmisión de sus paquetes de datos durante la fase de transmisión de datos DTP (del inglés data transmission phase). Cada DTP está compuesta de $M$ tramas y cada trama puede contener una cantidad variable de ranuras de tiempo. Cada DTP está precedida de su correspondiente fase de reservación de recursos RRP (del inglés resource reservation phase). En la RRP, las estaciones que desean transmitir datos podrán reservar una ranura para cada una de las $M$ tramas que componen a la DTP. La RRP consiste de una cantidad variable, pero finita, de miniranuras de tiempo. En la primera miniranura de cada RRP todas las estaciones que tengan paquetes por transmitir (conocidas como estaciones activas) deben solicitar su reservación mediante un paquete de señalización el cual llamamos solicitud de reservación RREQ (del inglés reservation request). Por ejemplo, si sólo una estación solicita una reservación, entonces la duración de la RRP es de una miniranura y dicha estación tendrá reservadas hasta $M$ ranuras consecutivas para transmitir dentro de la correspondiente DTP.

Si existen dos o más estaciones que soliciten reservación, entonces se presenta una colisión en la primera miniranura de la RRP. Esta colisión se resuelve de forma similar a como se resuelven las colisiones de acuerdo al protocolo $2 \mathrm{C}$. El orden en el que se le reservará, a cada estación, una ranura dentro cada una de las $M$ tramas de la siguiente DTP, será el mismo orden en el que cada estación ha logrado solicitar su reservación en la RRP, es decir, el orden en el que lograron enviar satisfactoriamente su RREQ. Con base en la realimentación, las estaciones determinan la ranura de la trama que han reservado y entonces conocerán el momento en el cual pueden transmitir.

Las estaciones deben seguir la realimentación de la estación base desde el momento en que realizan su solicitud de reservación hasta que han transcurrido todas las tramas de la reservación. Si alguna estación deja de transmitir en su respectiva ranura reservada dentro de alguna de las $M$ tramas de la DTP, entonces la estación perderá su ranura reservada. Las demás estaciones pueden determinar cuáles estaciones no transmitieron en su respectiva ranura reservada, y entonces son capaces de calcular el nuevo turno en el que pueden transmitir. 
Como se puede observar, las $M$ tramas que forman cada DTP pudieran no tener la misma longitud, ya que algunas estaciones pueden perder su ranura reservada. Si en algún momento, antes de que transcurran las $M$ tramas, todas las estaciones pierden su reservación, entonces finalizará la DTP y se dará inicio a una nueva RRP. Las demás estaciones activas que generen paquetes por transmitir, cuando está transcurriendo alguna DTP, deben esperar el final de dicha DTP para enviar su RREQ. La estación base informará a todas las estaciones el final de la DTP, y entonces el inicio de una nueva RRP, con una realimentación de INICIO_DE_RESERVACIÓN. De igual forma, las nuevas estaciones que se incorporen a la red cuando esté en curso una DTP saben que deben esperar hasta el inicio de una nueva RRP, es decir, una realimentación de INICIO_DE_RESERVACIÓN, para enviar su RREQ. A continuación se muestra el algoritmo a seguir.

La realimentación proporcionada por la estación base para una miniranura $t$ está dada por $x_{t}$. Cada estación utiliza un contador $r_{t}$ durante la RRP. Cuando una estación genera paquetes de datos para transmitir, entonces necesita una reservación y debe fijar su contador $r_{t}=1$, y en la primera miniranura de la siguiente RRP deberá enviar un RREQ. Como ya se mencionó, si sólo una estación solicita reservación, la RRP tendrá una duración de una miniranura. Si dos o más estaciones solicitan reservación, entonces se producirá una colisión dentro de la RRP, la cual se resolverá de forma similar a como lo hace el protocolo $2 \mathrm{C}$.

Cada estación tiene una variable $n$, en la cual almacena el número de ranura que le corresponde dentro de cada trama de la DTP. Durante la RRP, se le asigna un valor a la variable $n$ de cada estación activa. También, cada estación debe manejar una variable, $l$, en la cual almacena la longitud de la siguiente trama de la DTP en curso. El valor del contador $r_{t}$ puede variar entre uno, dos o ningún valor $(N U L L)$. Dichos valores se actualizan de acuerdo a las siguientes reglas:

1. Si una estación desea transmitir paquetes de datos, dicha estación debe transmitir su RREQ al inicio de la siguiente RRP en la miniranura cero. Debe fijar su contador en $r_{t}=1$ y sus variables $l=0$ y $n=0$ (ya que todavía no tiene una reservación). Un RREQ es transmitido satisfactoriamente en la miniranura $t$ si y sólo si $r_{t}=1$ y $x_{t}=$ Éxito. 
2. La actualización del contador $r_{t}$ y de la variable $n$, dentro de cada RRP, se realiza de la manera siguiente:

a) Si $x_{t-1}=$ VACÍA y $r_{t-1}=2$, entonces $r_{t}=1$

b) Si $x_{t-1}=$ ÉXITO y $r_{t-1}=2$, entonces $n=n+1, l=l+1$ y $r_{t}=1$

c) Si $x_{t-1}=$ ÉXITO y $r_{t-1}=1$, entonces $n=n+1, l=l+1$ y $r_{t}=N U L L$

d) Si $x_{t-l}=$ ÉXITO,$n>0$ y $r_{t-1}=N U L L$, entonces $l=l+1$

e) Si $x_{t-1}=$ COLISIÓN y $r_{t-1}=2$, entonces $r_{t}=2$

f) Si $x_{t-1}=$ COLISIÓN y $r_{t-1}=1$, entonces:

$r_{t}=1$ con probabilidad de 0.5 o $r_{t}=2$ con probabilidad 0.5

Al finalizar la RRP, con un RREQ exitoso en la primera miniranura o con dos RREQ exitosos consecutivos, cada una de las estaciones que solicitaron reservación tendrán asignada la ranura número $n$ en cada una de las $M$ tramas que forman la DTP; es decir, tendrán aseguradas $M$ ranuras, en la siguiente DTP, antes de que se presente una nueva RRP. De igual forma, al final de la RRP, las estaciones conocerán la longitud $l$ (en ranuras de tiempo) de la primera trama de la siguiente DTP. Recordemos que si una estación con reservación deja de transmitir en alguna de sus $M$ ranuras reservadas, entonces perderá la reservación y tendrá que esperar el inicio de una nueva RRP para realizar una nueva solicitud (si es que tiene nuevos paquetes de datos para transmitir). Como se puede observar, el valor de $M$ puede influir en gran medida sobre el desempeño del protocolo.

Una vez que las estaciones activas tengan su reservación, deberán monitorear el medio de transmisión con el fin de conocer si alguna de las estaciones con reservación dejó de transmitir paquetes de datos, esto mediante una realimentación de vacía en alguna ranura de tiempo. Si es el caso, las estaciones que continúen utilizando su reservación deberán calcular su nuevo turno y la longitud para la siguiente trama de la DTP en curso, con la finalidad de reducir el tamaño de las siguientes tramas y así no desperdiciar tiempo ni ancho de banda. Entonces, en cada estación ocurre lo siguiente: si la ranura vacía sucede después del turno de cierta estación (dentro de la actual trama), entonces la estación no modifica su número de ranura reservada $n$ para la siguiente trama y $l=l-1$; en otro caso, modifica su número de ranura reservada a $n=n$-1 para la siguiente trama y de igual forma $l=l$ - 1 . Esta modificación se realiza cada que se presenta una ranura vAcía en cualquiera de las tramas que forman la DTP. 
En resumen, si en alguna trama una o más estaciones dejan de transmitir en su correspondiente ranura reservada, su reservación se cancela; y las demás estaciones se reconfiguran y cada una determina su nuevo turno, es decir, su correspondiente ranura reservada en la siguiente trama, y por lo tanto también conocen cuantas ranuras tendrá la siguiente trama; y como se puede ver, la siguiente trama será de menor tamaño que la anterior. La DTP finaliza cuando transcurren $M$ tramas, o antes, si es que todas las estaciones que realizaron su reservación, en la RRP correspondiente a dicha DTP, dejan de transmitir en algún momento antes de que ocurran las $M$ tramas. La estación base marca el final de la DTP con una realimentación de INICIO_DE_RESERVACIÓN, la cual le indica a todas las estaciones que dará inicio una nueva RRP.

En la figura 8 ilustramos un ejemplo de la operación del protocolo. Supongamos que al inicio de una RRP, envían una RREQ cuatro estaciones (estaciones $A, B, C$ y $D$ ), que generaron paquetes de datos para transmitir durante el tiempo que duró la última DTP, y se tiene que resolver el orden de las ranuras reservadas para la DTP correspondiente de dicha RRP (figura 8a). En el ejemplo, se puede observar que en la primera miniranura de la RRP ocurre una colisión con multiplicidad de cuatro, la cual se debe resolver. Después de la colisión inicial, las estaciones $A$ y $C$ aleatoriamente deciden permanecer en la contienda mientras que $B$ y $D$ deciden esperar. Entonces, en la siguiente miniranura $A$ y $C$ colisionan. La estación $A$ aleatoriamente decide esperar y $C$ decide transmitir su RREQ en la siguiente miniranura, por lo que logra una transmisión exitosa. Después de recibir la realimentación Éxiтo todas las estaciones en espera regresan a contender. Este proceso continúa hasta que todas las estaciones logran exitosamente transmitir su RREQ. También, se puede observar que la RRP tiene una duración variable, que en el ejemplo es de ocho miniranuras de tiempo. En esta primera RRP, se determina el orden en que las estaciones van a poder transmitir en cada una de las $M$ tramas que forman la DTP, como se puede observar en la figura $8 \mathrm{~b}$.

En el ejemplo se muestra que, si alguna de las estaciones con reservación deja de transmitir datos en alguna de sus ranuras reservadas (la estación $B$ en la trama dos), entonces se le cancela su reservación. Cuando la estación base marca el final de dicha DTP, da comienzo una nueva RRP, y las estaciones, que generaron paquetes de datos para transmitir, durante la última DTP y que no tenían reservación, pueden competir por el medio de transmisión, como se muestra en la figura 8b. 

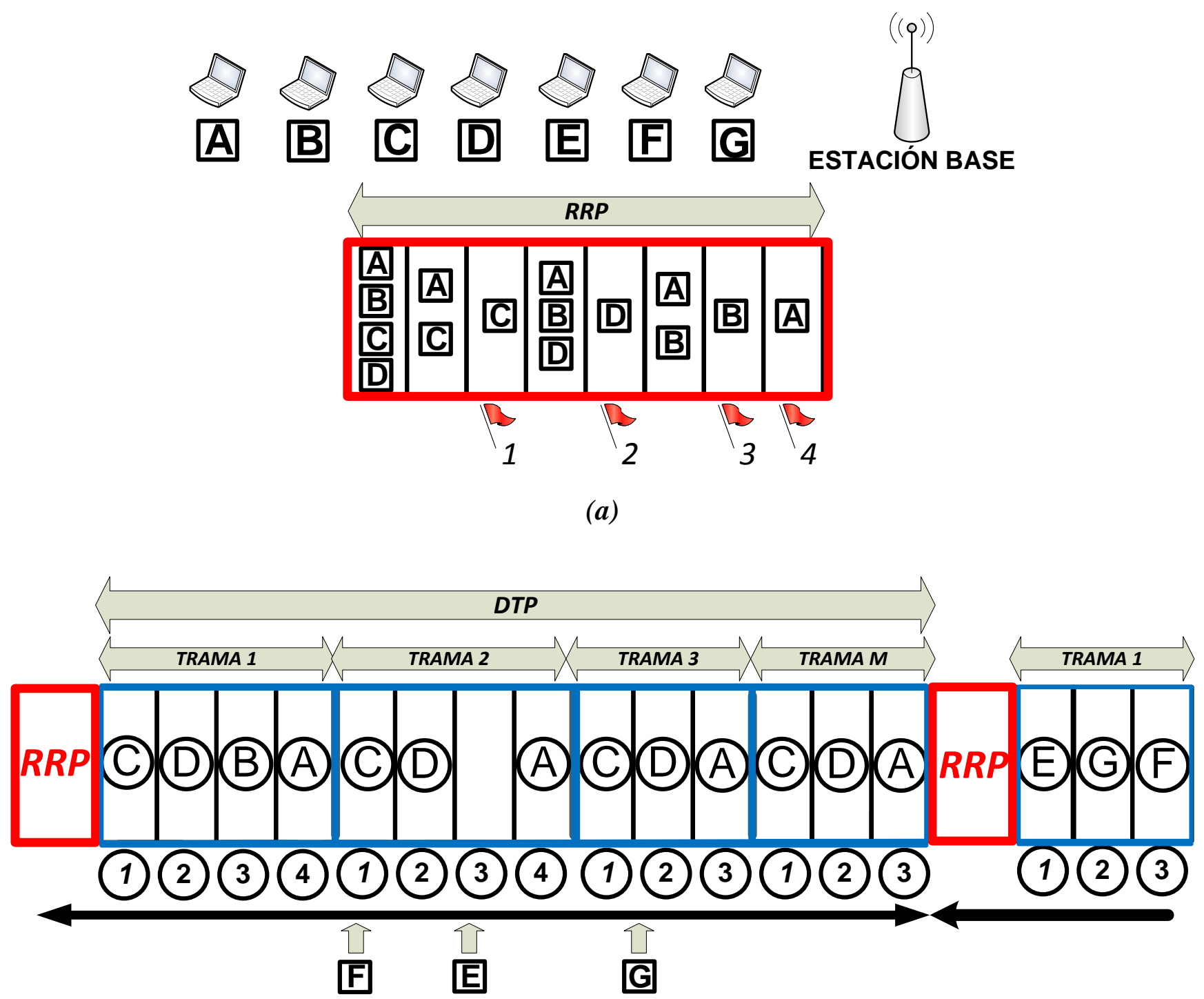

(b)

Figura 8. Ejemplo del desarrollo del protocolo $2 \mathrm{C}-\mathrm{R}^{2}$ en una red con siete estaciones 


\subsection{Evaluación de desempeño}

\subsubsection{Modelos de simulación}

Como ya se mencionó, los modelos de simulación, tanto del protocolo $2 \mathrm{C}$ como del protocolo $2 \mathrm{C}-\mathrm{R}^{2}$, se desarrollaron e implementaron en el simulador de eventos discretos OMNeT++. Es importante resaltar que el propósito principal de nuestras simulaciones es el estudio del rendimiento del protocolo propuesto, por lo cual sólo se implementó la capa MAC sin interacciones con modelos de otras capas (física, red, transporte, etc.), además de que nuestra propuesta no se define para algún modelo de pila de protocolos en particular. En el apéndice A se proporciona una breve descripción de dicho simulador. En primera instancia, validamos la parte de los modelos de simulación correspondiente al protocolo $2 \mathrm{C}$ y al $2 \mathrm{C}-\mathrm{R}^{2}$ en su $\mathrm{RRP}$, basándonos en un método recursivo, presentado en [7], que permite encontrar la duración promedio del CRI (en ranuras de tiempo) cuando éste inicia con $k$ estaciones en contienda. Posteriormente, reforzamos la validación realizando una comparación del comportamiento del CRI, cuando éste comienza con una multiplicidad de $k$ estaciones, basándonos en un análisis de desempeño en donde se modela a una red, que utiliza el protocolo 2C, como una cadena de Markov (este análisis se puede consultar en el apéndice B).

En la figura 9 se muestran los resultados obtenidos usando el método recursivo en [7], en donde también se muestran los resultados obtenidos en el análisis por cadena de Markov, así como los resultados obtenidos mediante los modelos de simulación del protocolo $2 \mathrm{C}$ y del protocolo $2 \mathrm{C}-\mathrm{R}^{2}$ en su RRP. Como se puede observar en la figura 9, la duración del CRI es similar en los cuatro casos antes mencionados, lo cual indica que tanto la implementación del modelo de simulación del protocolo 2C, así como la implementación del modelo de simulación del protocolo $2 \mathrm{C}-\mathrm{R}^{2}$ en su RRP, en el simulador OMNeT++, son correctas en ambos casos.

El análisis por cadena de Markov nos ayuda a analizar más detalladamente el comportamiento del CRI, ya que permite conocer la cantidad de ranuras de tiempo vacías, exitosas y en colisión que se presentan a lo largo del CRI. Las estadísticas del comportamiento del CRI, que se obtienen usando la representación con la cadena de Markov, se muestran en la figura 10. 
En la figura 11, se muestran los resultados que se obtienen en la simulación del protocolo 2C sobre el simulador OMNeT++. Se puede observar la similitud de los resultados mostrados en la figura 11 con respecto los mostrados en la figura 10, lo cual indica que el comportamiento del CRI con el modelo de simulación del protocolo $2 \mathrm{C}$, en cuanto a la cantidad de ranuras de tiempo vacías, exitosas y en colisión, es el esperado de acuerdo a los resultados teóricos obtenidos. De igual forma, se obtienen los valores promedio de miniranuras de tiempo vacías, en colisión y con transmisión exitosa que aparecen en cada uno de los CRI correspondientes a cada RRP del protocolo $2 \mathrm{C}-\mathrm{R}^{2}$ (que es la parte del protocolo $2 \mathrm{C}-\mathrm{R}^{2}$ en donde se utiliza el protocolo $2 \mathrm{C}$ ). Los resultados se muestran en la figura 12. De igual forma, los resultados mostrados en la figura 12 concuerdan con los resultados teóricos de la figura 10. Para finalizar, se valida el modelo de simulación del protocolo $2 \mathrm{C}-\mathrm{R}^{2}$ en su DTP. Para ello, se verifica que, en promedio, la multiplicidad de la colisión al inicio de la RRP fueran igual a la cantidad promedio de ranuras reservadas en la primera trama de cada DTP. Los resultados de la validación del modelo de simulación del protocolo $2 \mathrm{C}-\mathrm{R}^{2}$, en su DTP, se pueden ver en la figura 13 , en donde se puede observar que, en efecto, la DTP presenta el comportamiento esperado.

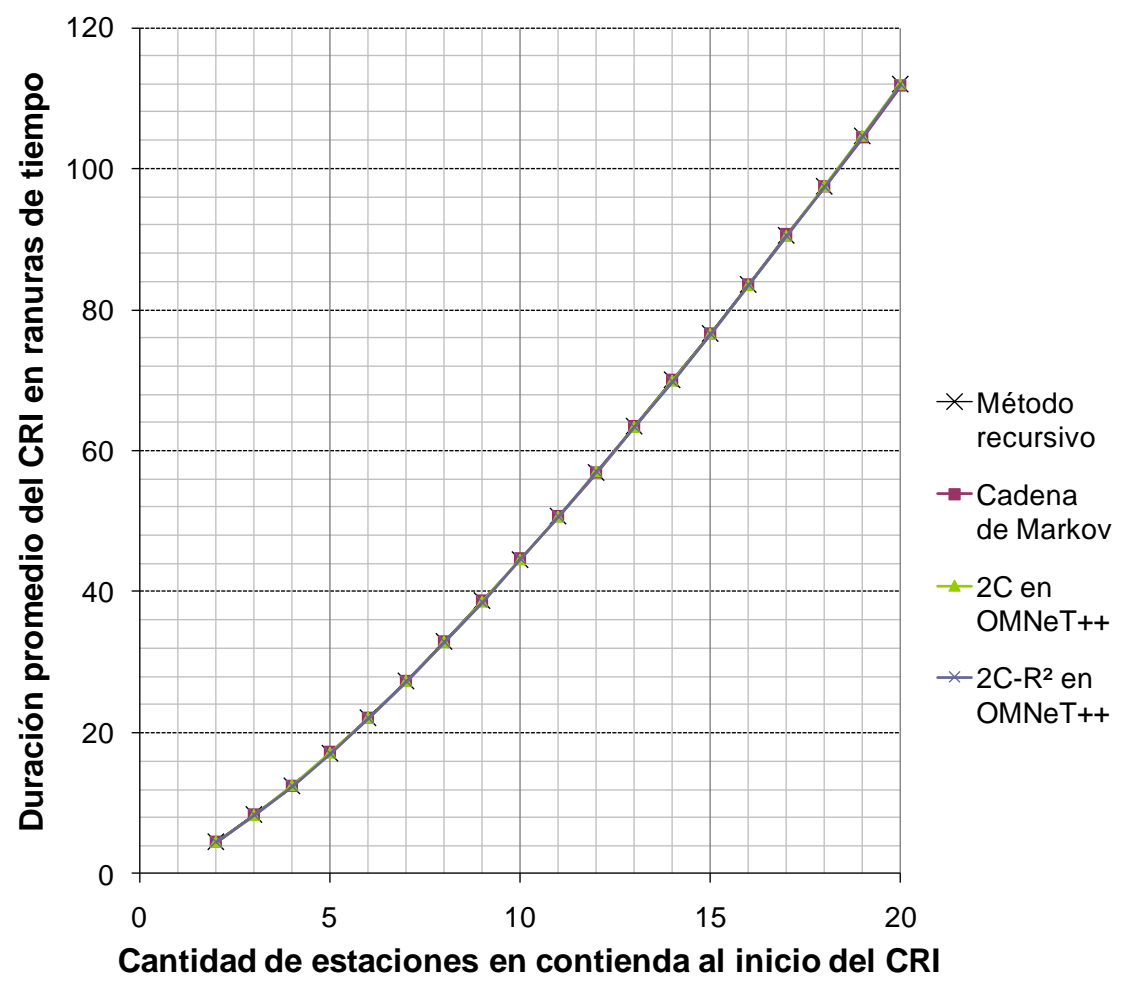

Figura 9. Comparación de la duración promedio del CRI 


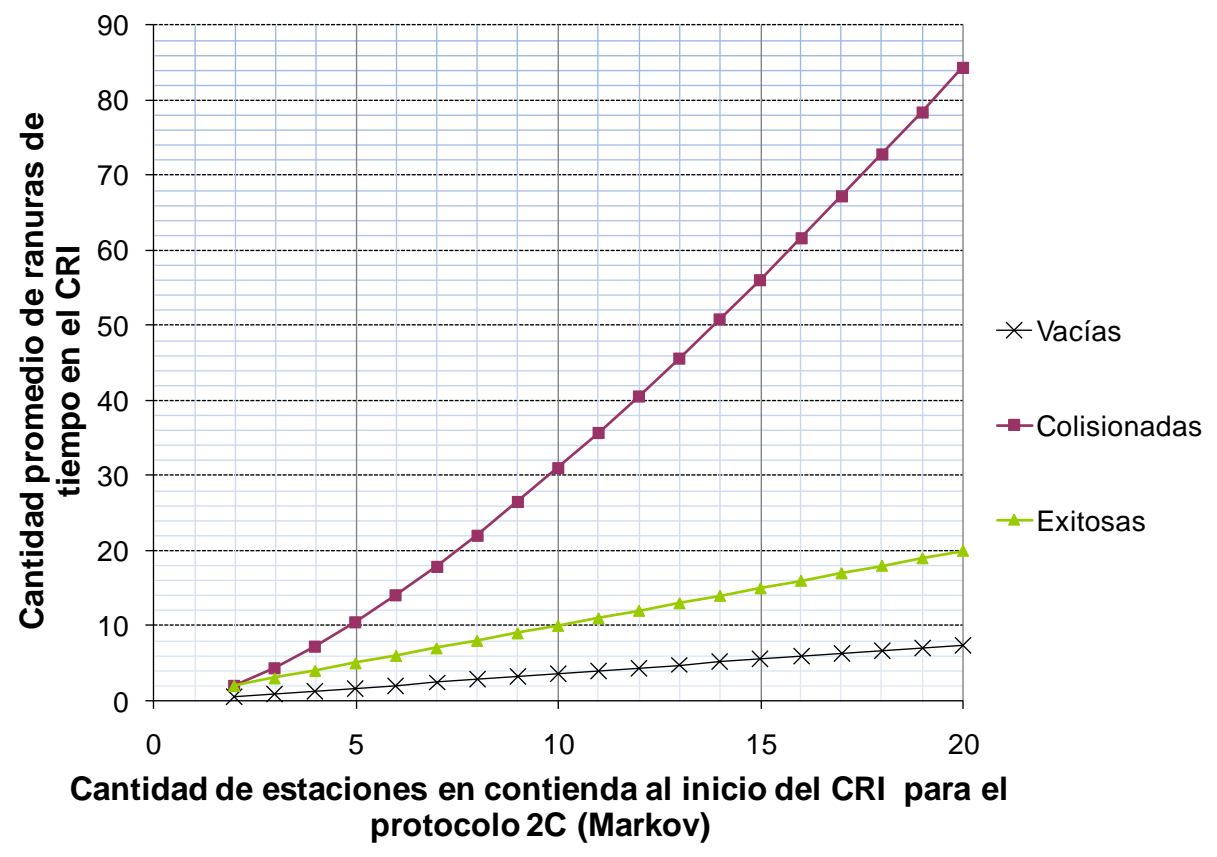

Figura 10. Valores promedio en el protocolo 2C (cadena de Markov)

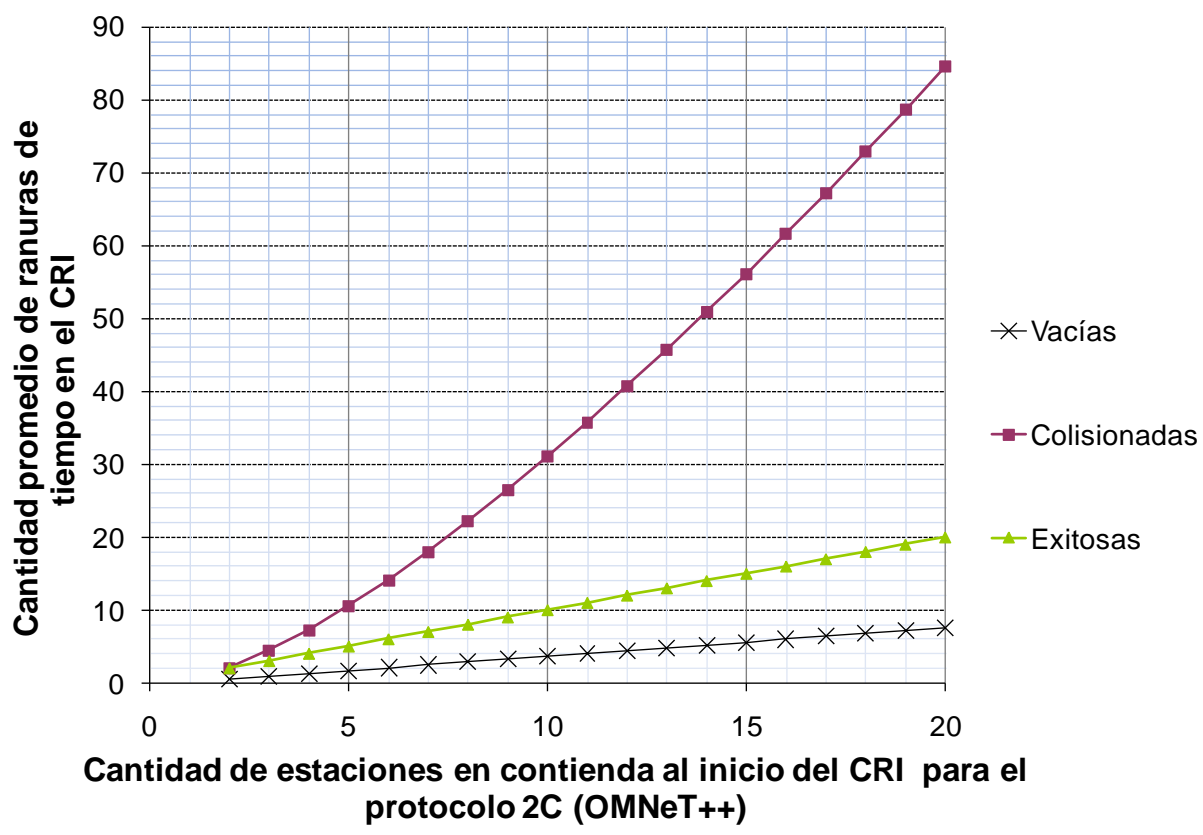

Figura 11. Valores promedio en el protocolo $2 \mathrm{C}(\mathrm{OMNeT}++)$ 


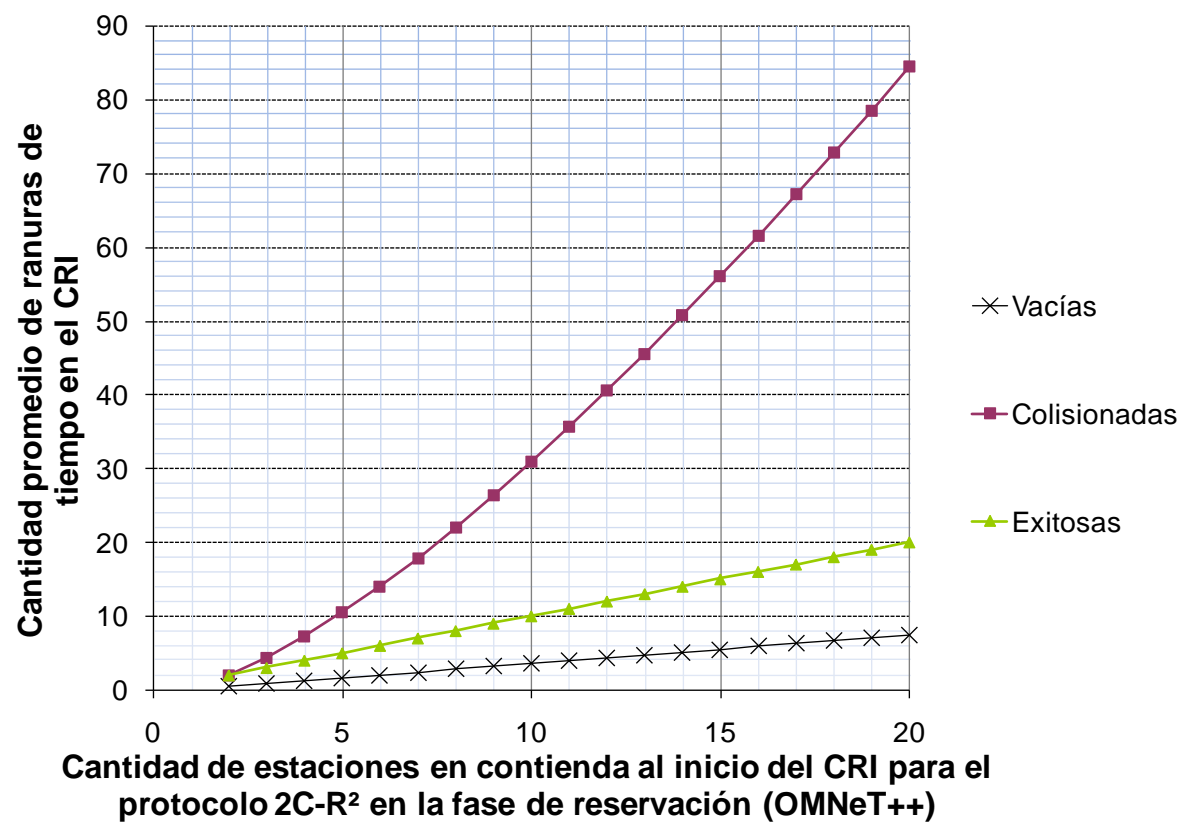

Figura 12. Valores promedio en el protocolo $2 \mathrm{C}-\mathrm{R}^{2}$ en su $\mathrm{RRP}(\mathrm{OMNeT}++)$

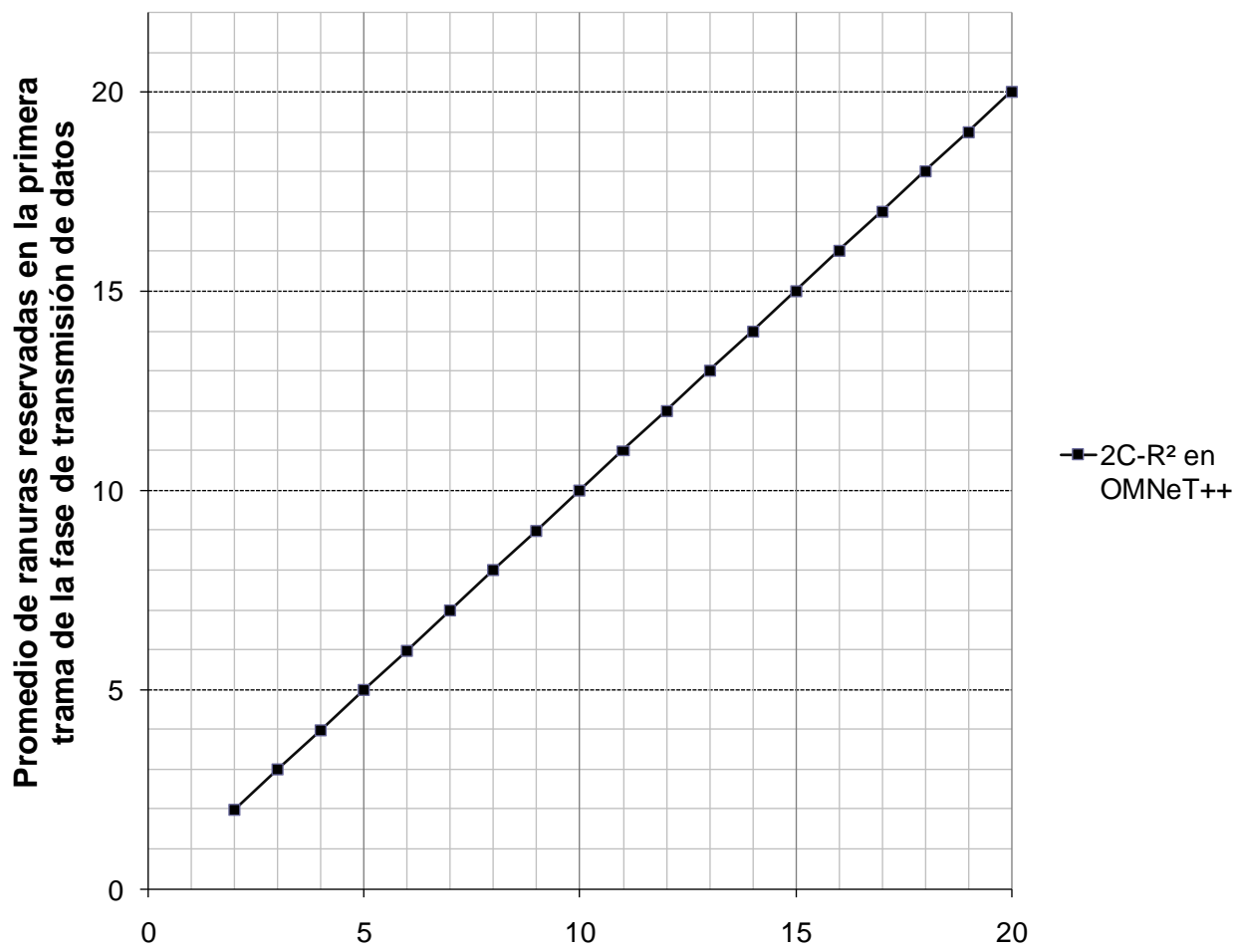

Promedio de estaciones en contienda en la fase de reservación

Figura 13. Validación del protocolo $2 \mathrm{C}-\mathrm{R}^{2}$ en su DTP 


\subsubsection{Medidas de desempeño}

Después de verificar que los modelos de simulación son correctos, realizamos la evaluación de desempeño. Usualmente, se emplean dos medidas para evaluar el desempeño de los protocolos de control de acceso al medio [2]: el retardo de acceso al medio y la utilización efectiva del medio de transmisión. A continuación se describen estas medidas.

El retardo de acceso es el tiempo promedio transcurrido desde que una estación genera un paquete de datos para su transmisión hasta que ese paquete es transmitido satisfactoriamente a través del medio de transmisión. Los protocolos de acceso múltiple buscan minimizar el retardo de acceso, ya que es deseable que las estaciones puedan transmitir sus paquetes de datos, a través del medio de transmisión, lo antes posible. La utilización efectiva del medio de transmisión es el porcentaje del tiempo total en que el medio de transmisión se usa para transmisiones de datos de manera exitosa. Los protocolos de acceso múltiple buscan maximizar la utilización efectiva del medio de transmisión, ya que si la utilización efectiva se acerca al 100\% querrá decir que el medio de transmisión se está aprovechado de una mejor manera.

En este trabajo también se emplea como medida de desempeño el porcentaje efectivo del tiempo total en estado de transmisión, el cual se define, en este trabajo, como porcentaje del tiempo en el que una estación realiza transmisiones exitosas con respecto al tiempo total en el que la misma estación se encuentra en estado de transmisión. Se intuye que lo que se busca es maximizar el porcentaje efectivo del tiempo en estado de transmisión, ya que, por lo general en el particular caso de las redes inalámbricas, los dispositivos inalámbricos gastan más energía cuando se encuentran en estado de transmisión que cuando se encuentran en algún estado de reposo o incluso en un estado de recepción, y por lo tanto es deseable que realicen transmisiones exitosas estando el menor tiempo posible en estado de transmisión, y así aprovechen de mejor manera su energía. Cuando una estación realiza alguna transmisión de cualquier tipo, por ejemplo de paquetes de datos o de señalización, sea exitosa o no, se dice que está en estado de transmisión. 


\subsubsection{Resultados para el protocolo 2C}

Las características del escenario de simulación del protocolo $2 \mathrm{C}$ que implementamos en el simulador OMNeT++ son las siguientes:

- Una estación base que recibe las transmisiones de las demás estaciones de la red.

- Ranuras de tiempo de 223 us (tamaño suficiente para la transmisión de un paquete de datos de un tamaño de 1500 bytes a una velocidad de transmisión de 54 Mbps)

- Realimentación por parte de la estación base, al final de cada ranura, de NO_COLISIÓn y COLISIón.

- Tasa promedio de generación de paquetes de datos para transmitir, de manera independiente e individual por parte de cada estación, de acuerdo a una distribución de Poisson con media $1 / \lambda_{\mathrm{i}}$.

- Retardo de propagación igual a cero

- Canal libre de errores.

\section{Máxima carga admitida}

A partir de los resultados, obtenidos durante la validación del modelo de simulación del protocolo $2 \mathrm{C}$, se puede determinar teóricamente cuál es la tasa promedio total máxima de generación de paquetes de datos para transmitir que puede admitir una red con $N$ estaciones que operan con el protocolo $2 \mathrm{C}$ en condiciones estables, que es la máxima carga que la red puede admitir en condiciones estables (medida en paquetes por ranura de tiempo). A continuación se muestra el razonamiento del predicado anterior.

Denotemos como $T_{N}$ a la duración promedio, en ranuras de tiempo, de un CRI que comienza con una multiplicidad de $N$ estaciones, el cual fue calculado durante la validación del modelo de simulación. Entonces, podemos decir que una red con $N$ estaciones opera en condiciones estables cuando cada una de las $N$ estaciones genera, en promedio a lo más, un paquete de datos para transmitir cada $T_{N}$ ranuras de tiempo; es decir, cuando $\lambda_{\mathrm{i}}=1 / T_{N}$, medida en paquetes por ranura de tiempo). A este resultado lo denotamos como $\lambda_{\mathrm{i}-\mathrm{MAX}}$. 
Como se asume que la generación de paquetes de datos para transmitir se realiza de manera independiente e individual, por parte de las estaciones, de acuerdo a una distribución de Poisson con media $1 / \lambda_{\mathrm{i}}$; entonces se puede deducir que la tasa promedio total máxima de generación de paquetes de datos para transmitir que soporta una red con $N$ estaciones que operan con el protocolo $2 \mathrm{C}$, en

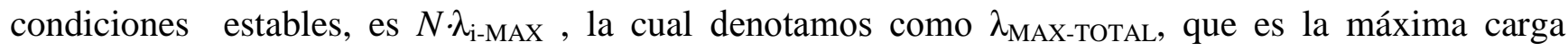
admitida, en promedio, que la red puede soportar, en condiciones estables, medida en paquetes por ranura de tiempo. En la figura 14 se muestran los resultados de este análisis cuando existen desde dos hasta veinte estaciones en la red (los cuales también se pueden observar en la tabla 1 del apéndice C). Por ejemplo, en los resultados que se muestran en la tabla 1 del apéndice $C$, se puede observar que para una red con 10 estaciones, operando con el protocolo 2C en condiciones estables, cada estación puede generar, en promedio a lo mas, 0.0224 paquetes de datos por ranura de tiempo. En otras palabras, la máxima carga admitida promedio que una red con 10 estaciones puede soportar, operando con el protocolo $2 \mathrm{C}$ en condiciones estables, es de $0.0224 \times 10=0.2244$ paquetes de datos por ranura de tiempo, como se observa en la figura 14. Cabe resaltar que todos los resultados numéricos se muestran en las tablas del apéndice $\mathrm{C}$, ya que consideramos importante presentarlos para trabajos futuros.

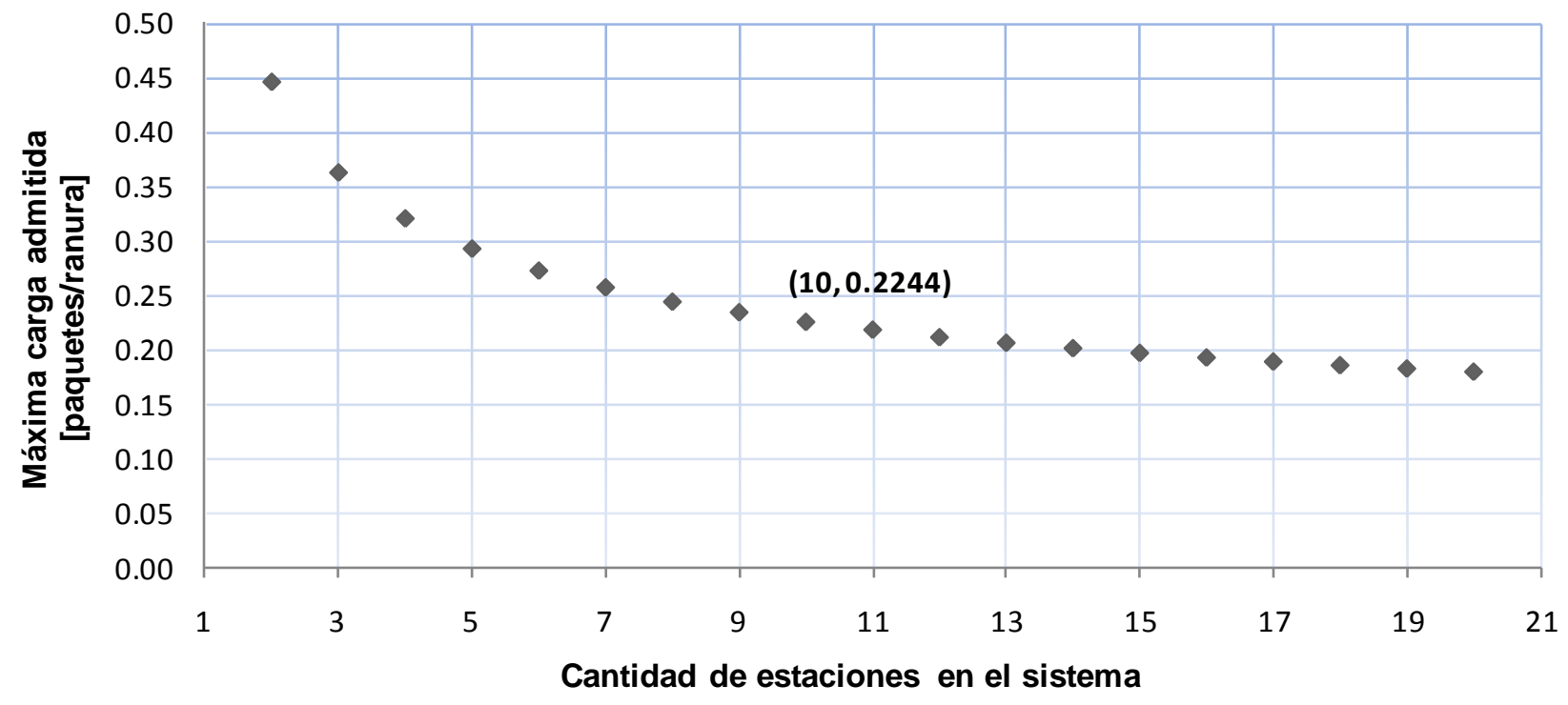

Figura 14. Máxima carga admitida por el protocolo $2 \mathrm{C}$ 


\section{Máxima utilización efectiva}

De la misma manera, con los resultados obtenidos en el proceso de validación del modelo de simulación del protocolo $2 \mathrm{C}$, se puede determinar la máxima utilización efectiva del medio de transmisión que se puede alcanzar, en condiciones estables, en una red con $N$ estaciones que operan con el protocolo 2C. A continuación se muestra el razonamiento del predicado anterior.

Denotemos como $T_{N}$ a la duración promedio, en ranuras de tiempo, de un CRI que comienza con una multiplicidad de $N$ estaciones, el cual fue calculado durante la validación del modelo de simulación, y de esas $T_{N}$ ranuras únicamente $N$ ranuras presentan transmisiones de datos exitosas. Entonces, podemos decir que la máxima utilización esperada en el medio de transmisión, para una red con $N$ estaciones, operando con el protocolo $2 \mathrm{C}$ en condiciones estables, es de $\left[N / T_{N}\right] \cdot 100 \%$, la cual denotamos como $\mathrm{U}_{\mathrm{MAX}}$. Cabe mencionar que la utilización máxima se consigue cuando cada una de las estaciones genera paquetes de datos para transmitir a una razón promedio de $\lambda_{\mathrm{i} \text {-MAX. }}$.

En la figura 15 (ver también la tabla 2 del apéndice C) se muestran los resultados de este análisis cuando existen desde dos hasta veinte estaciones en la red. Por ejemplo, en los resultados que se muestran en la tabla 2 del apéndice $C$ se puede observar que, en una red con 10 estaciones, operando con el protocolo $2 \mathrm{C}$ en condiciones estables, la máxima utilización efectiva que se puede registrar en el medio de transmisión es del $22.44 \%$ del tiempo total con transmisiones de datos exitosas, como se puede observar también en la figura 15.

\section{Simulaciones con el protocolo $2 \mathrm{C}$}

Comenzando las simulaciones del protocolo $2 \mathrm{C}$, en primer lugar se obtiene la utilización efectiva del medio de transmisión en condiciones de saturación. En una red operando en modo saturación todas y cada una de las estaciones que forman parte de la red siempre tienen un paquete para transmitir; en otras palabras, la cola de espera de paquetes por transmitir, en cada estación, nunca está vacía [15]. 


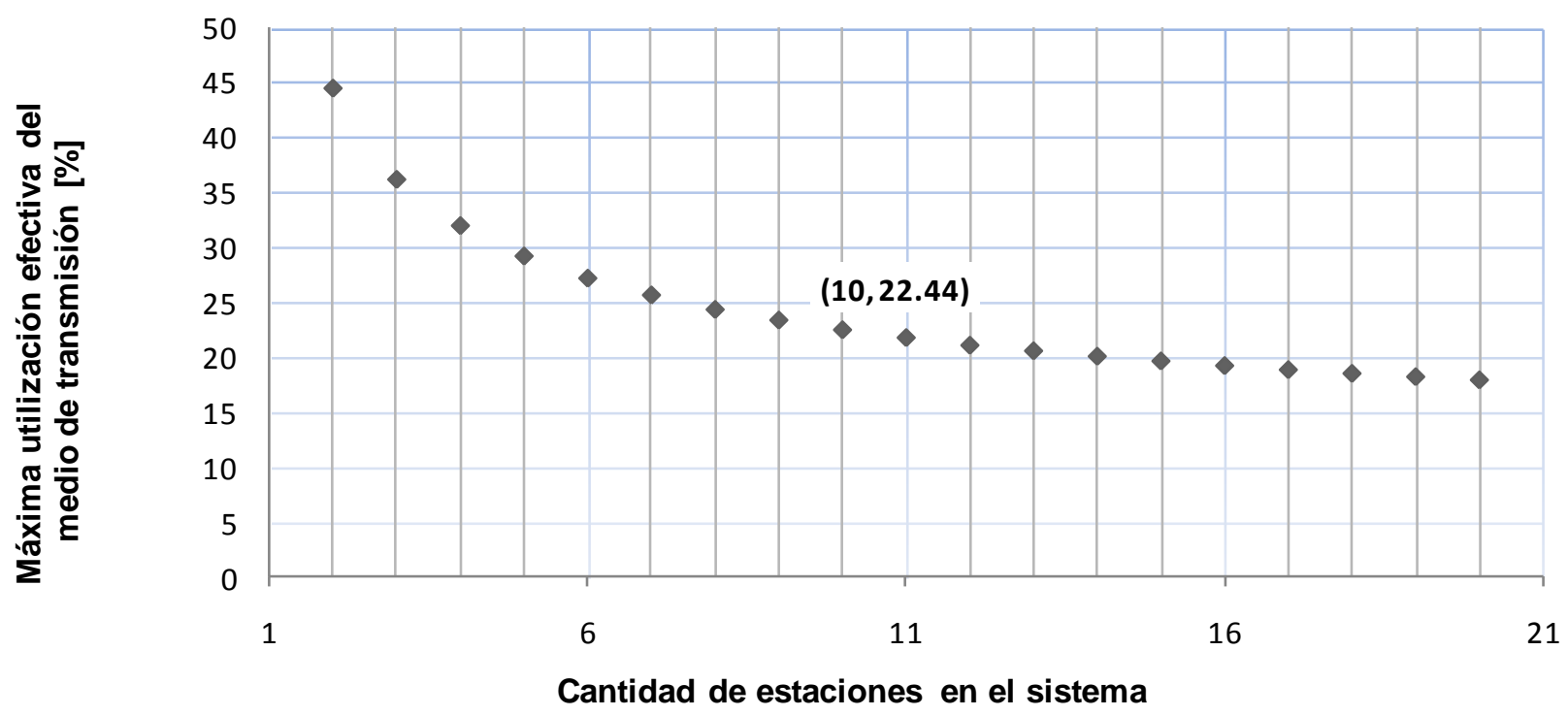

Figura 15. Máxima utilización efectiva del medio de transmisión para una red con el protocolo $2 \mathrm{C}$

La simulación en condiciones de saturación nos permite encontrar la máxima utilización efectiva del medio de transmisión que la red puede presentar en condiciones estables, la cual denotamos como $\mathrm{U}_{\mathrm{SAT}}$. En la figura 16 se muestran los resultados para la utilización efectiva del medio de transmisión, en condiciones de saturación cuando existen desde dos hasta veinte estaciones en la red, para el protocolo 2C (los cuales también se pueden observar en la tabla 10 del apéndice C). Se puede observar que estos resultados concuerdan con los resultados teóricos mostrados en la tabla 2 del apéndice $\mathrm{C}$, lo cual favorece a la validación del modelo de simulación del protocolo 2C.

De igual forma, la simulación en condiciones de saturación nos permite encontrar el mínimo porcentaje efectivo del tiempo total en estado de transmisión que la red puede presentar en condiciones estables, el cual denotamos como $\mathrm{PE}_{\mathrm{SAT}}$, y entonces, se puede encontrar el máximo porcentaje de la energía total utilizada en transmisiones que puede ser desperdiciado, el cual está dado por $100 \%-\mathrm{PE}_{\mathrm{SAT}}$. En la figura 17 (ver también la tabla 11 del apéndice C) se muestran los resultados para el mínimo porcentaje efectivo del tiempo total en estado de transmisión cuando existen desde dos hasta veinte estaciones en la red, para el protocolo $2 \mathrm{C}$. 
Evaluación de desempeño - Resultados para el protocolo 2C

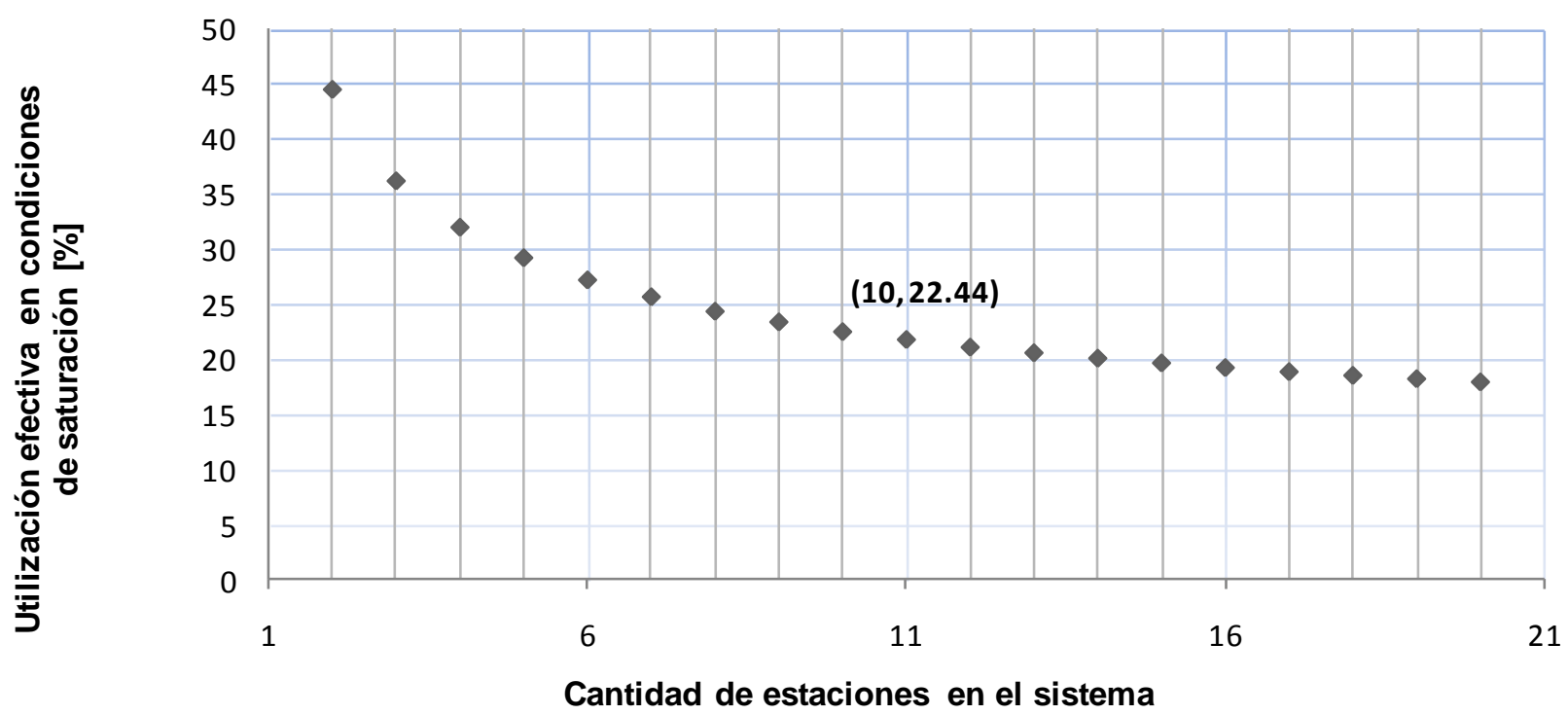

Figura 16. Utilización efectiva del medio de transmisión en condiciones de saturación para el protocolo $2 \mathrm{C}$

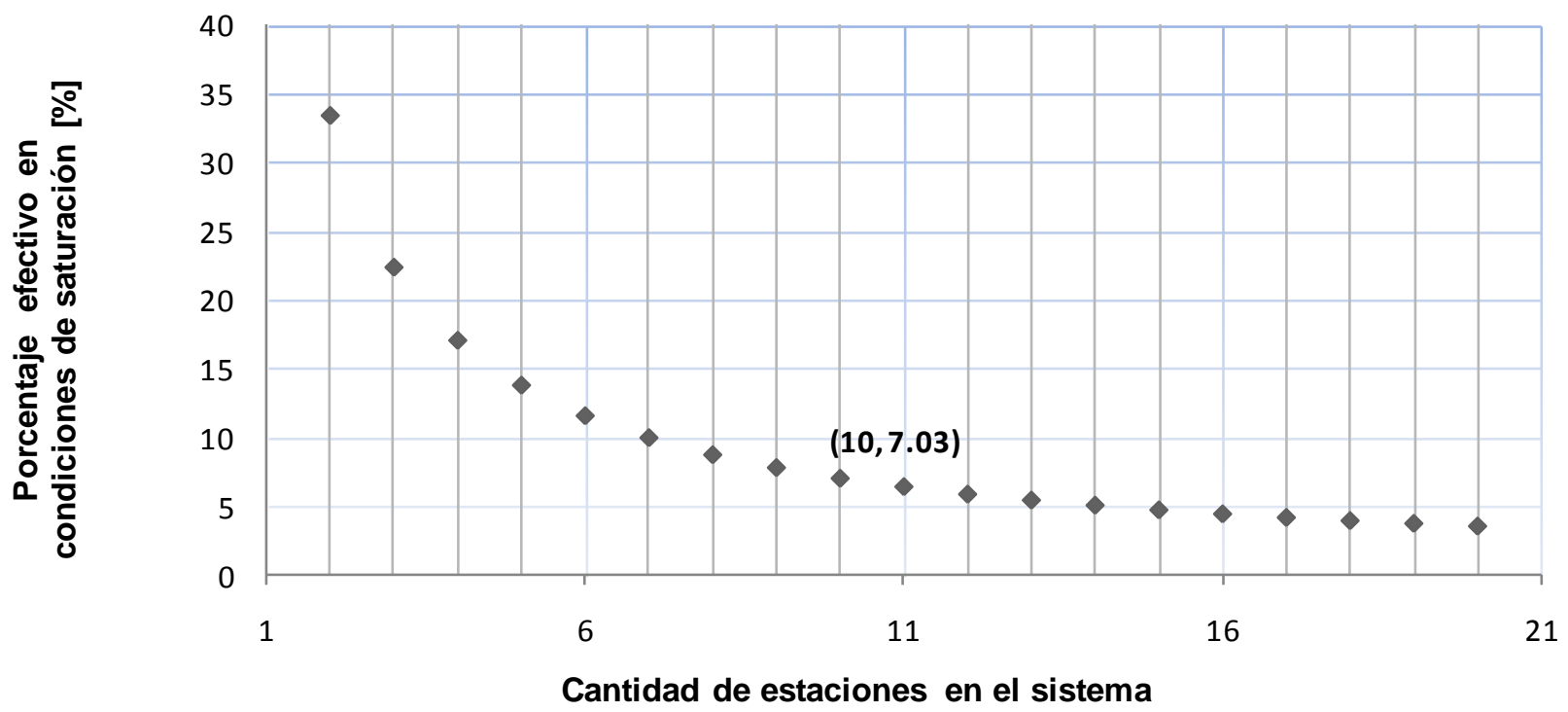

Figura 17. Porcentaje efectivo del tiempo total en estado de transmisión en condiciones de saturación para el protocolo $2 \mathrm{C}$ 
En la figura 18 se muestran los resultados para el comportamiento de la utilización efectiva del medio de transmisión, cuando la red opera con el protocolo $2 \mathrm{C}$ en condiciones estables, para diferentes $\lambda_{\mathrm{i}}$. Se puede observar que entre mayor sea la cantidad de estaciones en la red, menor será la utilización efectiva que el medio de transmisión puede alcanzar, y también menor será la carga admitida con la que la red puede operar en condiciones estables.

En la figura 19 se muestran los resultados para el comportamiento del retardo de acceso al medio de transmisión, cuando la red opera con el protocolo $2 \mathrm{C}$ en condiciones estables, para diferentes $\lambda_{\mathrm{i}}$. Como se puede observar en la figura 19, cuando la carga ofrecida es muy baja el retardo de acceso al medio de transmisión tiende a un valor que está entre la duración de dos ranuras y la duración de tres ranuras lo cual es lógico, ya que cuando una estación desea transmitir cada paquete de datos por primera vez, debe esperar la realimentación, por parte de la estación base, de dos ranuras vacías, el tiempo de espera cuando la carga es muy baja es, en promedio a lo más, el equivalente a dos ranuras, y posteriormente debe transmitir el paquete de datos en la siguiente ranura.

En la figura 20 se muestran los resultados para el comportamiento del porcentaje efectivo del tiempo en estado de transmisión, cuando la red opera con el protocolo $2 \mathrm{C}$ en condiciones estables, para diferentes $\lambda_{\mathrm{i}}$. Como se observa en la figura 20, cuando la carga ofrecida es muy baja, el porcentaje efectivo del tiempo en estado de transmisión tiende al 100\%, lo que quiere decir que toda la energía que ocupa la estación, al permanecer en estado de transmisión, es gastada adecuadamente, ya que ésta es utilizada, en su totalidad, para transmitir paquetes de datos de manera exitosa; y conforme va aumentando la carga ofrecida, aumenta también la cantidad de colisiones y por lo tanto también va en aumento el desperdicio de energía. 


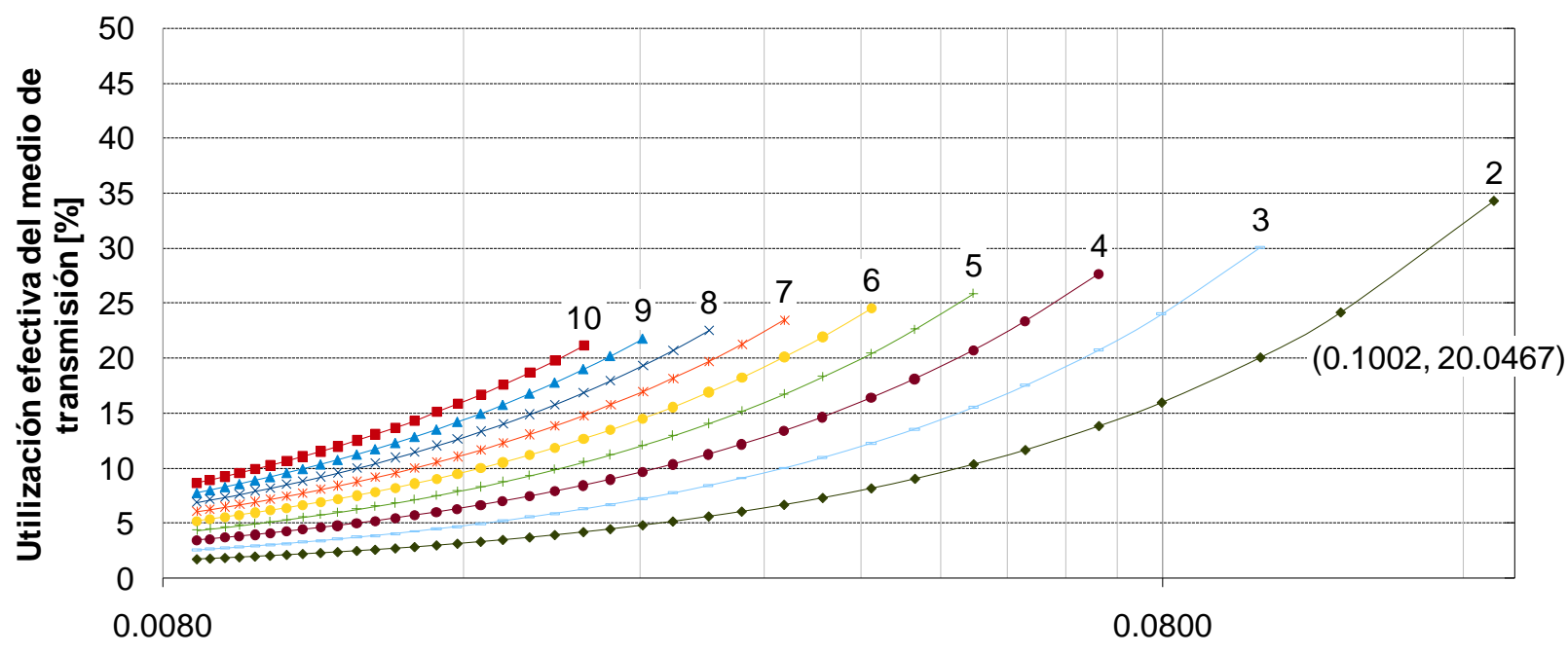

Tasa promedio de generación de paquetes de datos para transmitir por estación [paquetes/ranura]

Figura 18. Utilización efectiva para una red con una cantidad desde dos hasta diez estaciones operando con el protocolo $2 \mathrm{C}$

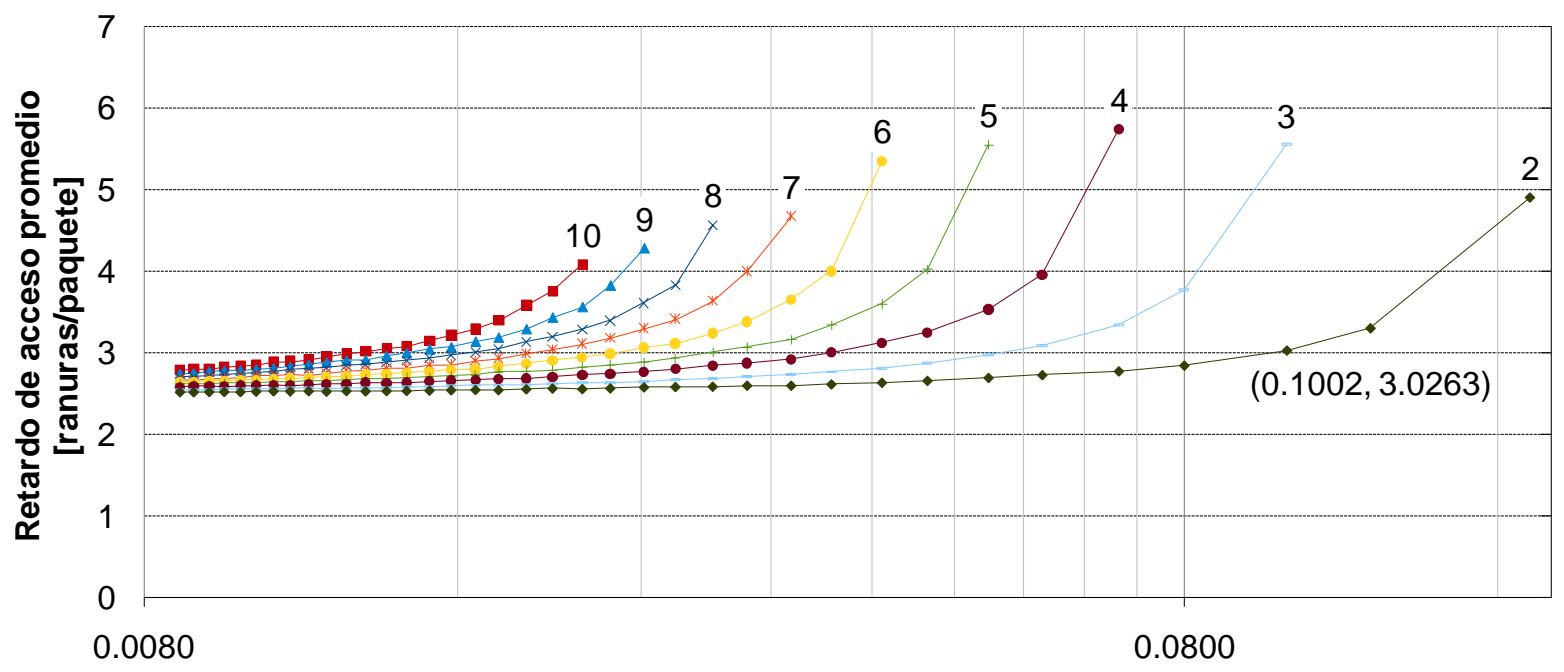

Tasa promedio de generación de paquetes de datos para transmitir por estación [paquetes/ranura]

Figura 19. Retardo de acceso promedio para una red con una cantidad desde dos hasta diez estaciones operando con el protocolo $2 \mathrm{C}$ 
Evaluación de desempeño - Resultados para el protocolo 2C

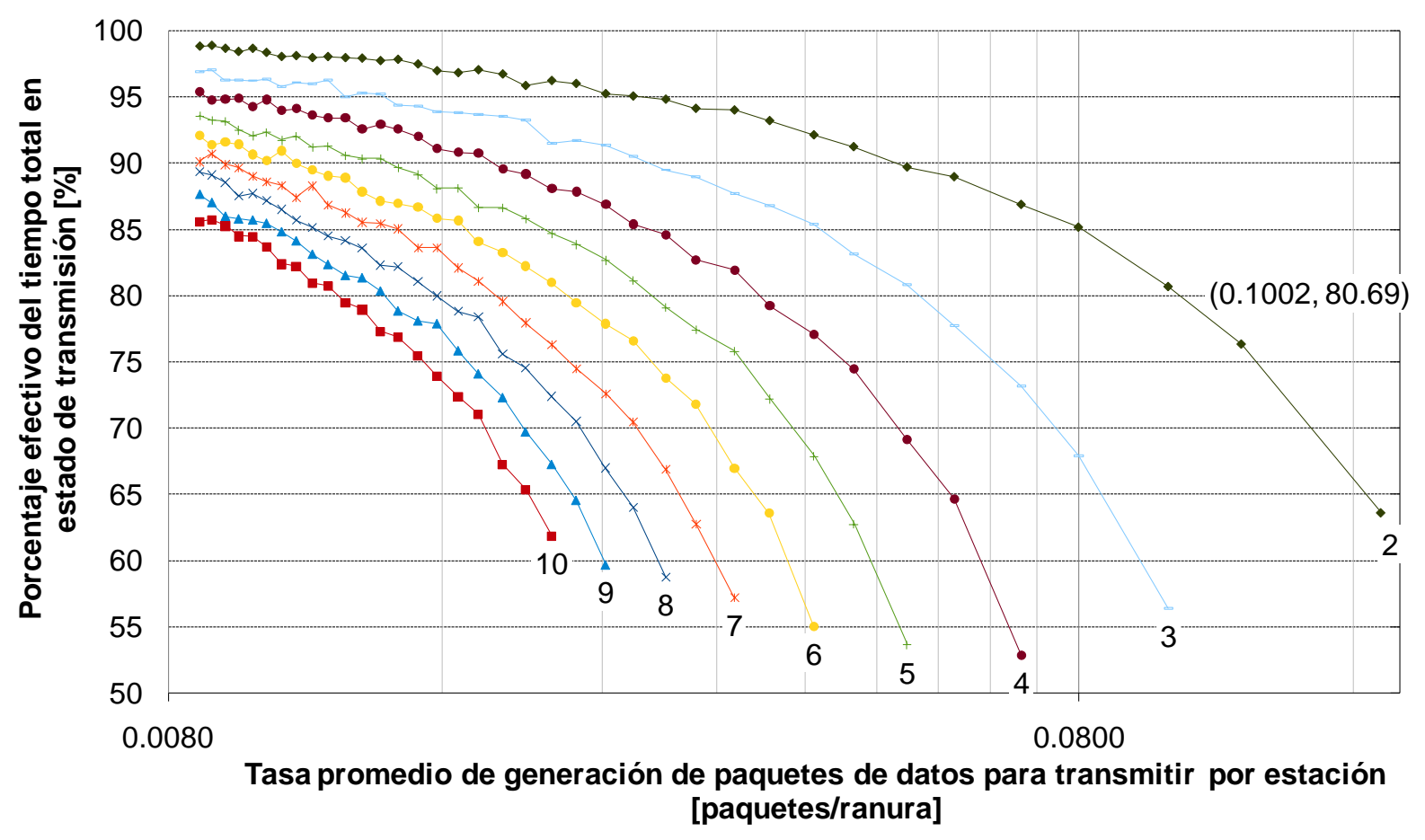

Figura 20. Porcentaje efectivo del tiempo total en estado de transmisión para una red con una cantidad desde dos hasta diez estaciones operando con el protocolo $2 \mathrm{C}$ 


\subsubsection{Resultados para el protocolo $2 \mathrm{C}-\mathrm{R}^{2}$}

Las características del escenario de simulación, del protocolo $2 \mathrm{C}-\mathrm{R}^{2}$, que implementamos en el simulador OMNeT++ son las siguientes:

- Una estación base que recibe las transmisiones de las demás estaciones de la red.

- Ranuras de tiempo de 223 us (tamaño suficiente para la transmisión de un paquete de datos de un tamaño de 1500 bytes a una velocidad de transmisión de 54 Mbps)

- Miniranuras de tiempo de $6 \mu \mathrm{s}$ (tamaño suficiente para la transmisión de un paquete de señalización de un tamaño de 40 bytes a una velocidad de transmisión de 54 Mbps)

- Realimentación por parte de la estación base, al final de cada ranura o miniranura, de vacío, ÉXITO, COLISIÓN e INICIO_DE_RESERVACIÓN.

- Tasa promedio de generación de paquetes de datos para transmitir, de manera independiente e individual por parte de cada estación, de acuerdo a una distribución de Poisson con media $1 / \lambda_{\mathrm{i}}$.

- Retardo de propagación igual a cero

- Canal libre de errores.

\section{Máxima carga admitida}

A partir de los resultados obtenidos durante la validación del modelo de simulación del protocolo $2 \mathrm{C}-\mathrm{R}^{2}$, se puede determinar teóricamente cuál es la tasa total máxima de generación de paquetes de datos para transmitir que soporta una red con $N$ estaciones que operan con el protocolo $2 \mathrm{C}-\mathrm{R}^{2}$ en condiciones estables, que es la máxima carga que la red puede admitir en condiciones estables (medida en paquetes por ranura de tiempo). A continuación se muestra el razonamiento del predicado anterior. 
Denotemos como $\operatorname{Tr}_{N}$ a la duración promedio, en segundos, de un CRI en la RRP que comienza con una multiplicidad de $N$ estaciones, es decir, definamos $\operatorname{Tr}_{N}=n \cdot[6 \mu s /$ miniranura $]$ donde $n$ es la cantidad promedio de miniranuras de tiempo que dura un CRI que comienza con una multiplicidad de $N$ estaciones durante la RRP (el cual fue calculado durante la validación del modelo de simulación). Igualmente denotemos a $T d_{N}$ como la máxima duración, en segundos, de la DTP, que es equivalente al tiempo que duran las $M$ ranuras reservadas por cada una de las $N$ estaciones, es decir, definamos $T d_{N}=N \cdot M \cdot[223 \mu \mathrm{s} /$ ranura $]$.

Entonces, podemos decir que una red con $N$ estaciones con el protocolo $2 \mathrm{C}-\mathrm{R}^{2}$, opera en condiciones estables cuando cada una de esas estaciones genera, en promedio a lo más, $M$ paquetes de datos para transmitir cada $T r_{N}+T d_{N}$ segundos; es decir, cuando $\lambda_{\mathrm{i}}=1 /\left[\operatorname{Tr}_{N}+T d_{N}\right]$ (medida en paquetes por segundo). A este resultado lo denotamos como $\lambda_{\mathrm{i}-\mathrm{MAX}}$. Como se asume que la generación de paquetes de datos para transmitir se realiza de manera independiente e individual, por parte de las estaciones, de acuerdo a una distribución de Poisson con media $1 / \lambda_{\mathrm{i}}$; entonces se puede deducir que la tasa total máxima de generación de paquetes de datos para transmitir que soporta una red con $N$ estaciones que operan con el protocolo $2 \mathrm{C}-\mathrm{R}^{2}$, en condiciones estables, es $N \cdot \lambda_{\text {i-MAX, }}$ la cual denotamos como $\lambda_{\text {MAX-TOTAL }}$ (que es la máxima carga admitida que la red puede soportar, en condiciones estables, medida en paquetes por segundo).

En la figura 21 se muestran los resultados de este análisis cuando existen desde dos hasta veinte estaciones en una red con $M=1$ y hasta $M=6$ ranuras reservadas para la DTP (los resultados numéricos se pueden observar de la tabla 3 hasta la tabla 8 en el apéndice C, para trabajos futuros). Para efectos de comparación, con el protocolo $2 \mathrm{C}$, los resultados de $\lambda_{\mathrm{i} \text {-MAX }}$ y $\lambda_{\mathrm{MAX} \text {-TOTAL }}$ se muestran en unidades de paquetes por ranura de tiempo, en donde una ranura de tiempo equivale a $223 \mu$ s. Por ejemplo, de los resultados que se muestran en la tabla 4 del apéndice $C$, se puede observar que, en una red con 10 estaciones, operando con el protocolo $2 \mathrm{C}-\mathrm{R}^{2}$ en condiciones estables con $M=2$ ranuras de tiempo por reservación, cada estación puede generar, en promedio a lo mas, 0.0943 paquetes de datos por ranura de tiempo. En otras palabras, la máxima carga admitida que una red con 10 estaciones puede soportar, operando con el protocolo $2 \mathrm{C}-\mathrm{R}^{2}$ en condiciones estables con $M=2$ ranuras de tiempo por reservación, es de $0.0943 \times 10=0.9434$ paquetes por ranura de tiempo, como se observa en la figura 21 . 
Máxima utilización efectiva

De la misma manera, con los resultados obtenidos en el proceso de validación del modelo de simulación del protocolo $2 \mathrm{C}-\mathrm{R}^{2}$, se puede determinar la máxima utilización efectiva del medio de transmisión que se puede alcanzar, en condiciones estables, en una red con $N$ estaciones que operan con el protocolo $2 \mathrm{C}-\mathrm{R}^{2}$. A continuación se muestra el razonamiento del predicado anterior.

Denotemos como $\operatorname{Tr}_{N}$ a la duración promedio, en segundos, de un CRI en la RRP que comienza con una multiplicidad de $N$ estaciones (el cual fue calculado durante la validación del modelo de simulación). Igualmente, denotemos a $T d_{N}$ como la duración, en segundos, de la DTP, que es equivalente al tiempo que duran las $M$ ranuras reservadas por cada una de las $N$ estaciones, en donde los $T d_{N}$ segundos presentan transmisiones de datos exitosas (ya que, para la máxima utilización, se ocupan todas las ranuras reservadas).

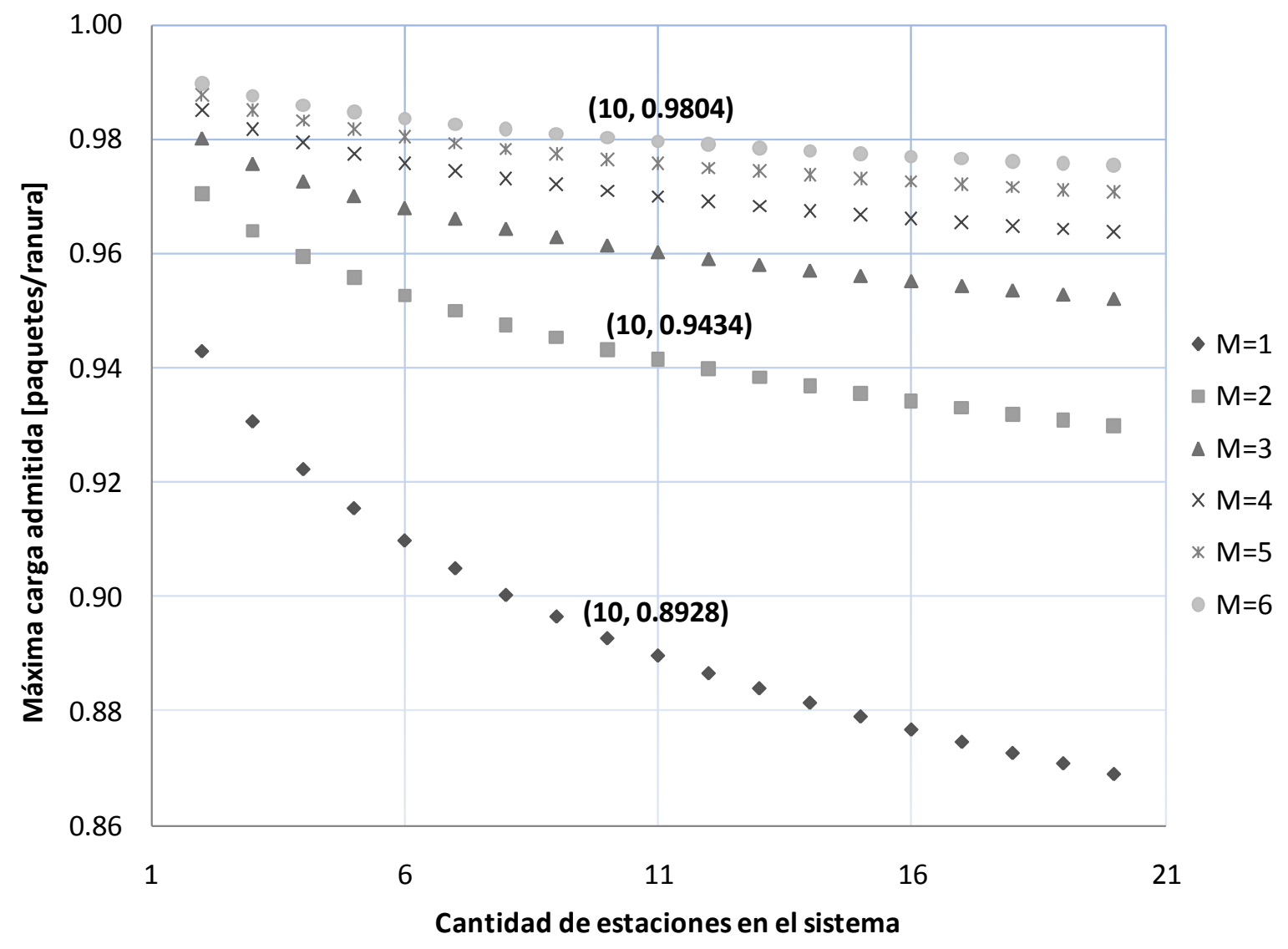

Figura 21. Máxima carga admitida por el protocolo $2 \mathrm{C}-\mathrm{R}^{2}$ 
Entonces podemos decir que, la máxima utilización esperada en el medio de transmisión para una red de $N$ estaciones, operando con el protocolo $2 \mathrm{C}-\mathrm{R}^{2}$ en condiciones estables, es $\left[T d_{N} /\left(\operatorname{Tr}_{N}+T d_{N}\right)\right] \cdot 100 \%$, y la denotamos como U $\mathrm{MAX}$. Cabe mencionar que la utilización máxima se consigue cuando cada una de las estaciones genera paquetes de datos para transmitir a una razón promedio de $\lambda_{\text {i-MAX. }}$

En la figura 22, se muestran los resultados de este análisis cuando existen desde dos hasta veinte estaciones en una red con $M=1$ y hasta $M=6$ ranuras reservadas para la DTP. Por ejemplo, de los resultados que se muestran en la tabla 9 del apéndice $\mathrm{C}$, se puede observar que, en una red con diez estaciones, operando con el protocolo $2 \mathrm{C}-\mathrm{R}^{2}$ en condiciones estables con $M=2$ ranuras de tiempo por reservación, la máxima utilización efectiva que se puede registrar en el medio de transmisión es del 94.34\% del tiempo total con transmisiones de datos exitosas, como también se puede observar en la figura 22.

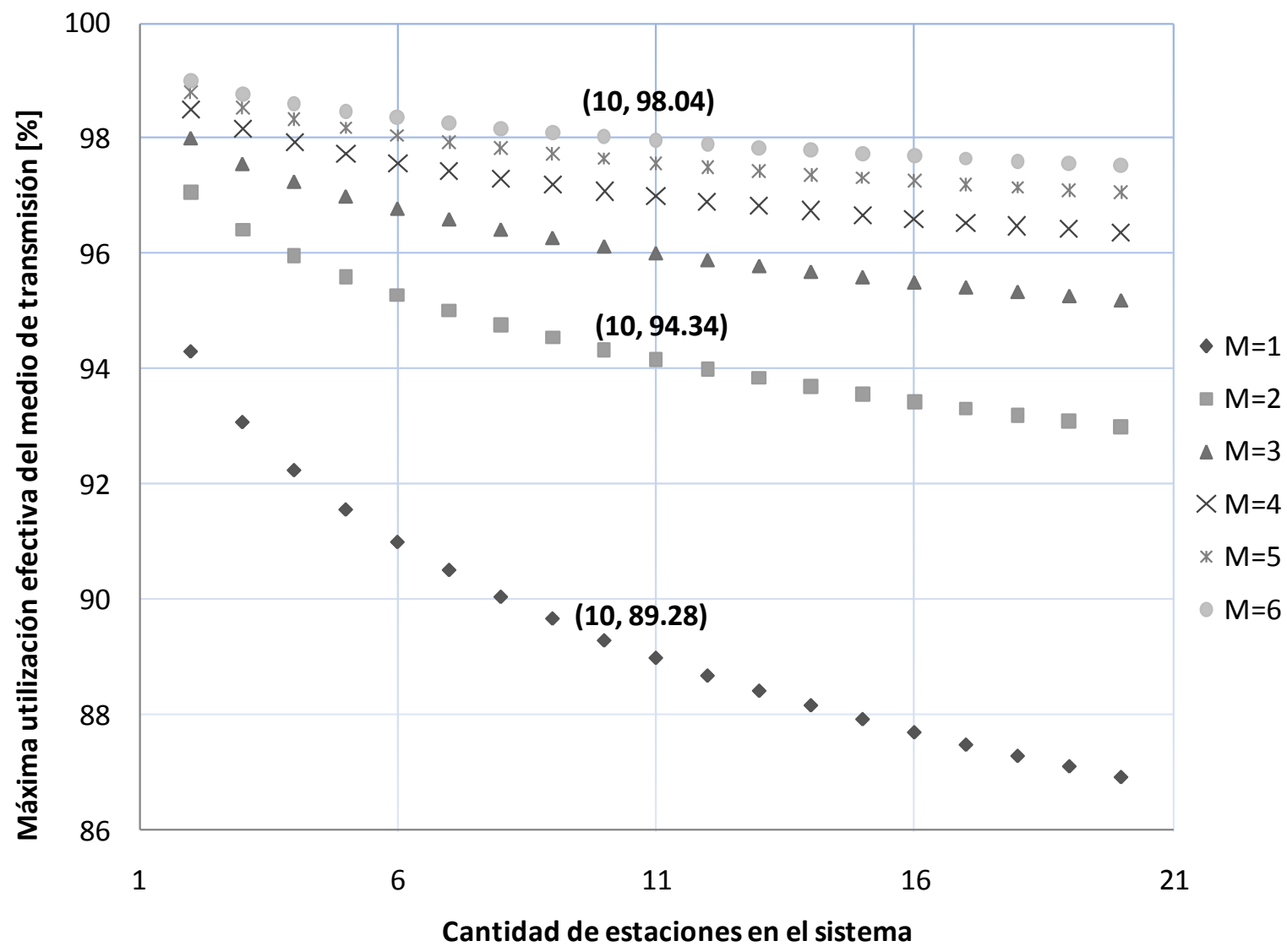

Figura 22. Máxima utilización efectiva del medio de transmisión para una red que opera con el protocolo $2 \mathrm{C}-\mathrm{R}^{2}$ 
Simulaciones con el protocolo $2 C-R^{2}$

Comenzando las simulaciones del protocolo $2 \mathrm{C}-\mathrm{R}^{2}$, en primer lugar se obtiene la utilización efectiva del medio de transmisión en condiciones de saturación. Como ya se mencionó, la simulación en condiciones de saturación nos permite encontrar la máxima utilización efectiva del medio de transmisión que la red puede presentar en condiciones estables, la cual denotamos como $\mathrm{U}_{\mathrm{SAT}}$. En la figura 23 se muestran los resultados obtenidos para la máxima utilización efectiva del medio de transmisión cuando existen desde dos hasta veinte estaciones en la red, para el protocolo $2 \mathrm{C}-\mathrm{R}^{2}$, con $M=1, M=2$ y $M=3$. Como se puede observar en la tabla $12 \mathrm{del}$ apéndice $\mathrm{C}$, estos resultados concuerdan con los resultados teóricos mostrados en la tabla 9 del mismo apéndice, lo cual favorece a la validación del modelo de simulación del protocolo $2 \mathrm{C}-\mathrm{R}^{2}$.

De la misma manera, la simulación en condiciones de saturación nos permite encontrar el mínimo porcentaje efectivo del tiempo total en estado de transmisión que la red puede presentar en condiciones estables, el cual denotamos como $\mathrm{PE}_{\mathrm{SAT}}$, y entonces, se puede encontrar el máximo porcentaje de la energía total utilizada en transmisiones, que es desperdiciado, el cual está dado por 100\%- $\mathrm{PE}_{\mathrm{SAT}}$. En la figura 24 se muestran los resultados obtenidos para el mínimo porcentaje efectivo del tiempo total en estado de transmisión cuando existen desde dos hasta veinte estaciones en la red, para el protocolo $2 \mathrm{C}-\mathrm{R}^{2}$, con $M=1, M=2$ y $M=3$ (los cuales también se muestran en la tabla 13 del apéndice C).

En la figura 25, figura 26 y figura 27 se muestran los resultados para el comportamiento de la utilización efectiva del medio de transmisión, cuando la red opera con el protocolo $2 \mathrm{C}-\mathrm{R}^{2}$ con $M=1$, $M=2$ y $M=3$, en condiciones estables, para diferentes $\lambda_{\mathrm{i}}$. Se puede observar que entre mayor sea la cantidad de estaciones en la red, menor será la utilización efectiva que el medio de transmisión puede alcanzar, y también menor será la carga admitida con la que la red puede operar en condiciones estables. De igual forma se puede apreciar que cuando se asigna una mayor cantidad de ranuras por reservación, es decir, cuando el valor de $M$ es más alto, mayor será la utilización efectiva que la red puede lograr. 
Evaluación de desempeño - Resultados para el protocolo 2C-R²

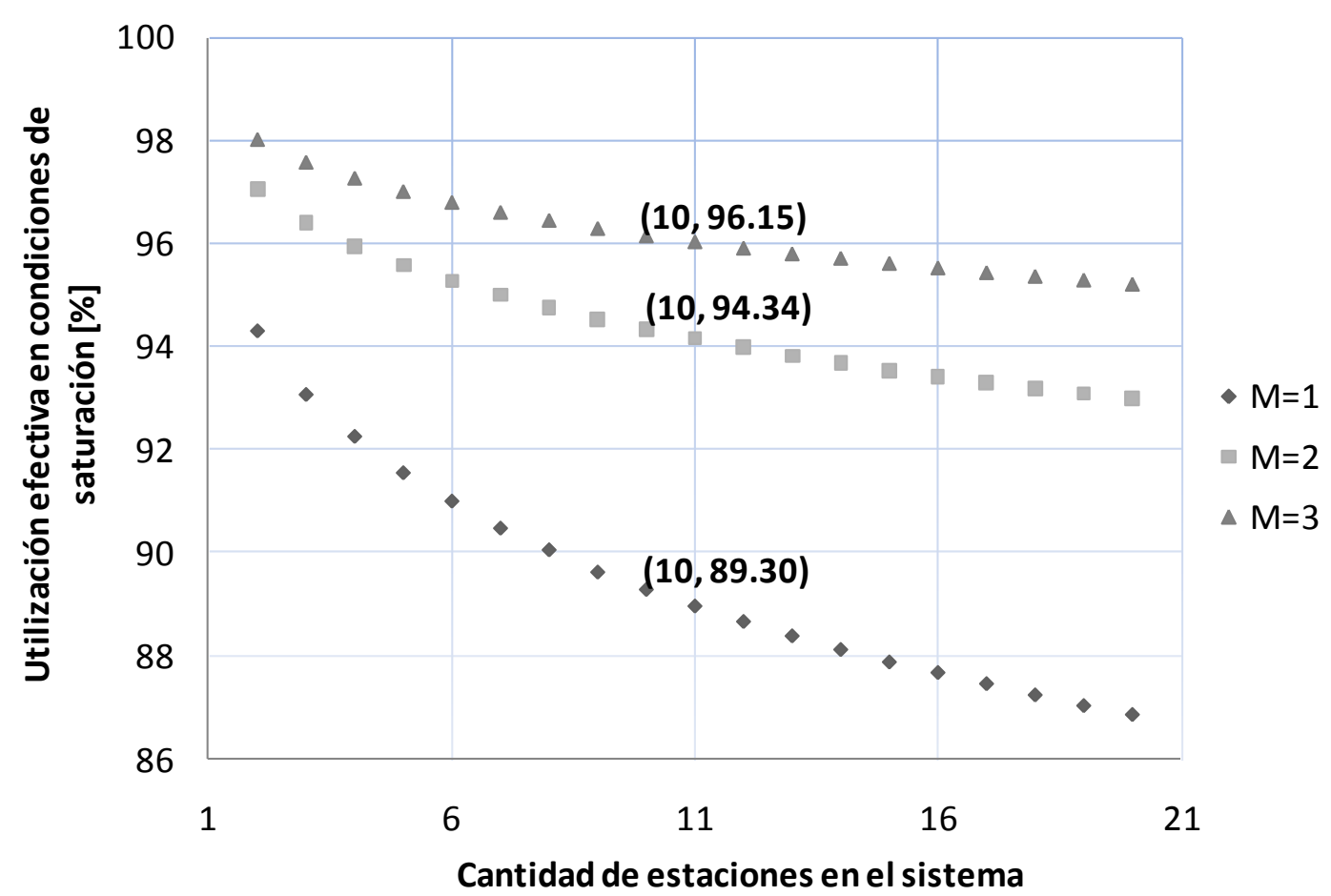

Figura 23. Utilización efectiva del medio de transmisión en condiciones de saturación para el protocolo $2 \mathrm{C}-\mathrm{R}^{2}$

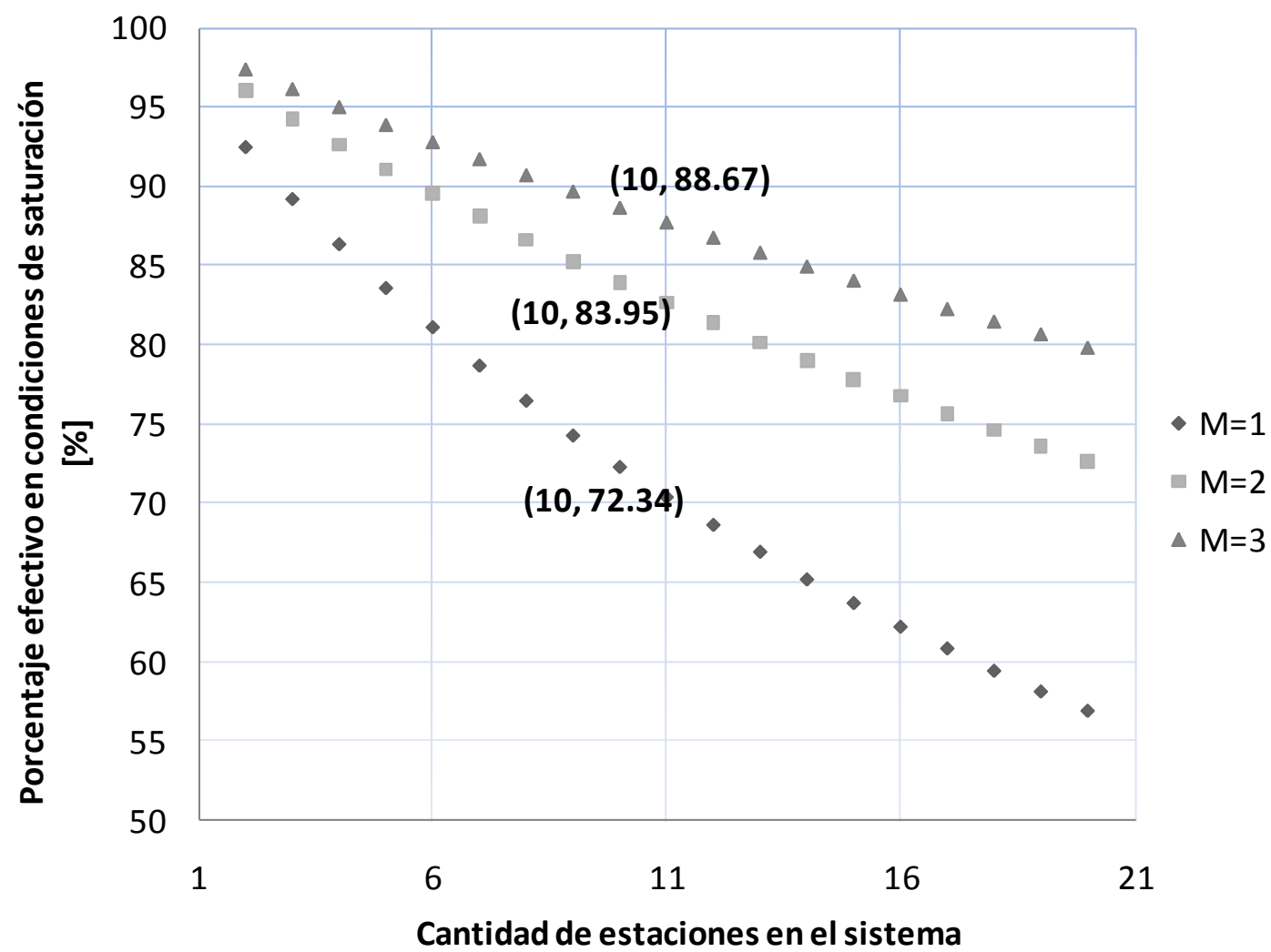

Figura 24. Porcentaje efectivo del tiempo total en estado de transmisión en condiciones de saturación para el protocolo $2 \mathrm{C}-\mathrm{R}^{2}$ 
En la figura 28, figura 29 y figura 30 se muestran los resultados para el comportamiento del retardo de acceso al medio de transmisión, cuando la red opera con el protocolo $2 \mathrm{C}-\mathrm{R}^{2}$ con $M=1, M=2$ y $M=3$, en condiciones estables, para diferentes $\lambda_{\mathrm{i}}$. Como se puede observar en la figura 28 , cuando la carga ofrecida es muy baja el retardo de acceso tiende a un valor que está entre el tiempo que dura una ranura más una miniranura y el tiempo que dura una ranura más dos miniranuras, lo cual es lógico, ya que cuando una estación desea transmitir cada paquete de datos, por primera vez, debe esperar el inicio de la siguiente RRP (que es un tiempo de espera muy pequeño, cuando la carga ofrecida es muy baja, y es de, en promedio a lo más, el tiempo que dura una miniranura), después debe transmitir su solicitud de reservación (que por lo menos ocupa una miniranura) y posteriormente debe transmitir el paquete de datos en su ranura reservada. También se puede ver que entre mayor sea la cantidad de ranuras por reservación, el retardo de acceso también será mayor, ya que cada DTP tendrá una mayor duración y por consecuencia las fases de reservación tardarán más en presentarse.

En la figura 31, figura 32 y figura 33 se muestran los resultados para el comportamiento del porcentaje efectivo del tiempo total en estado de transmisión, cuando la red opera con el protocolo $2 \mathrm{C}-\mathrm{R}^{2}$, con $M=1, M=2$ y $M=3$, en condiciones estables, para diferentes $\lambda_{\mathrm{i}}$. Como se observa, en la figura 31 y en la figura 32, cuando la carga es muy baja el porcentaje efectivo del tiempo en estado de transmisión tiende más al 100\% conforme la cantidad de ranuras por reservación aumenta, es decir, conforme el valor de $M$ es más alto. Esto significa que, con el protocolo $2 \mathrm{C}-\mathrm{R}^{2}$, casi toda la energía que ocupa la estación, al permanecer en estado de transmisión, es gastada adecuadamente, ya que es utilizada para transmitir paquetes de datos de manera exitosa. Nótese que, con el protocolo $2 \mathrm{C}-\mathrm{R}^{2}$, el porcentaje efectivo del tiempo en estado de transmisión nunca va a llegar al $100 \%$, ya que si una estación desea transmitir paquetes de datos, de manera exitosa, primero debe enviar una solicitud de reservación, y para ello debe situarse en estado de transmisión y gastar energía para transmitir su solicitud de reservación, y este tiempo no es utilizado para la transmisión de paquetes de datos. 


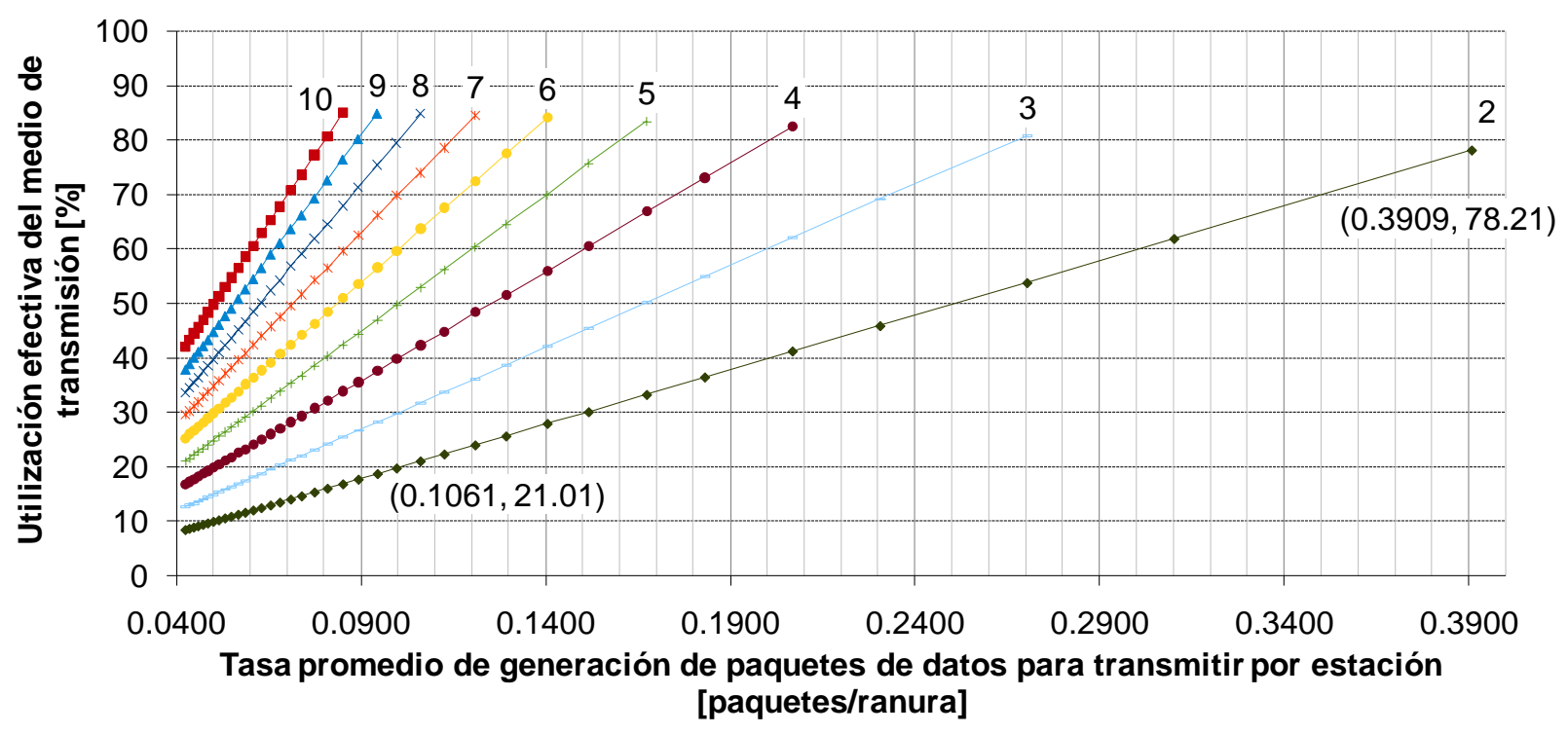

Figura 25. Utilización efectiva para una red con una cantidad desde dos hasta diez estaciones operando con el protocolo $2 \mathrm{C}-\mathrm{R}^{2}$ con $M=1$

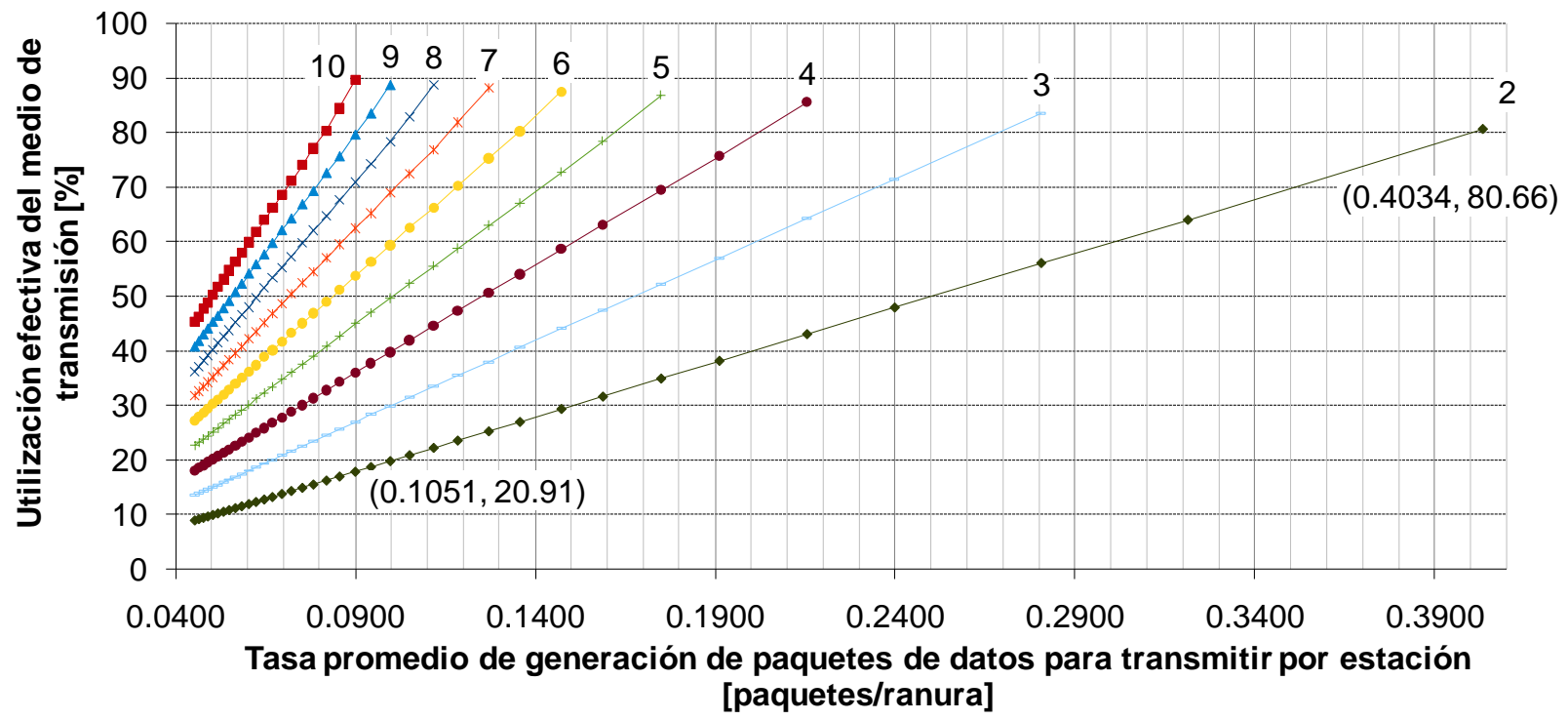

Figura 26. Utilización efectiva para una red con una cantidad desde dos hasta diez estaciones operando con el protocolo $2 \mathrm{C}-\mathrm{R}^{2}$ con $M=2$ 


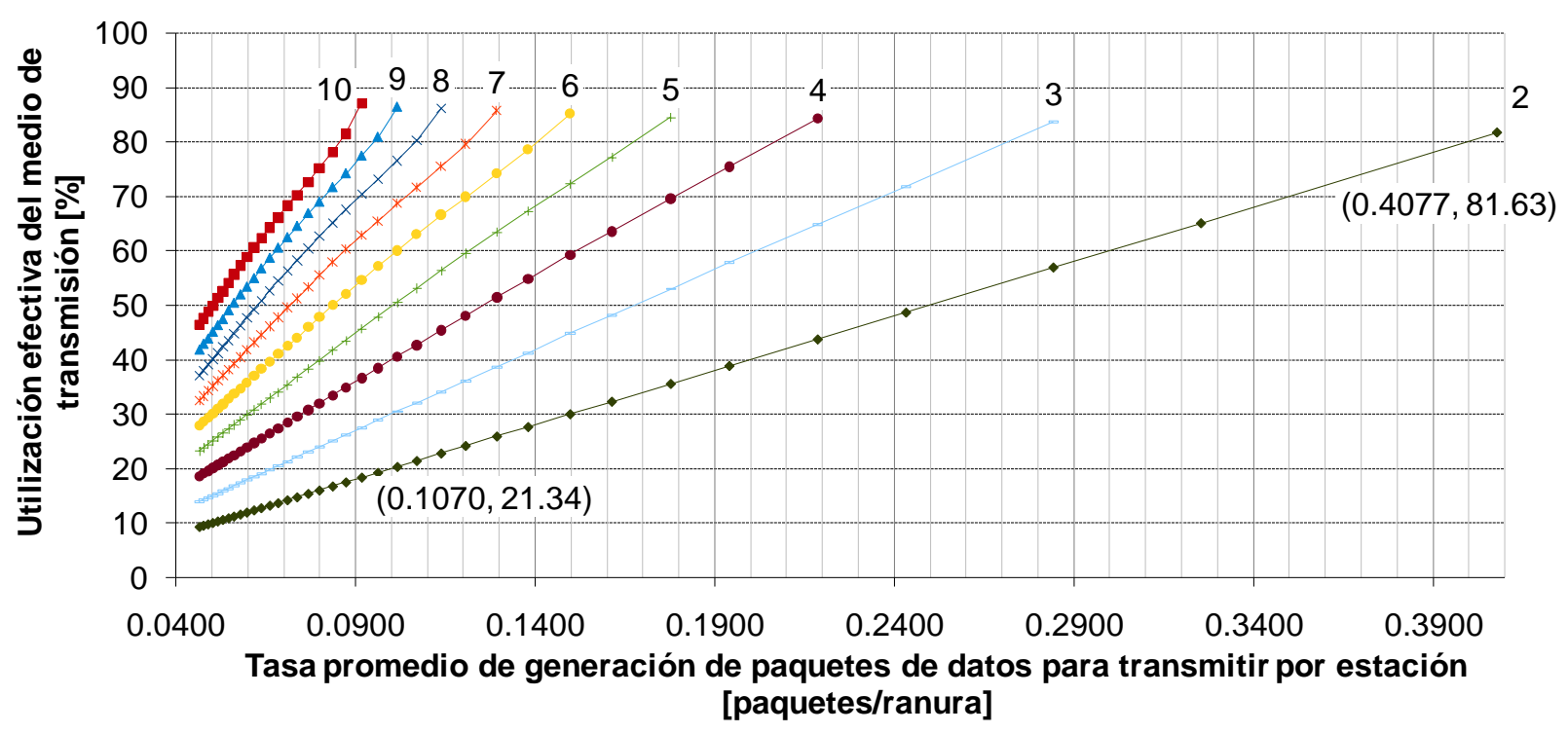

Figura 27. Utilización efectiva para una red con una cantidad desde dos hasta diez estaciones operando con el protocolo $2 \mathrm{C}-\mathrm{R}^{2}$ con $M=3$

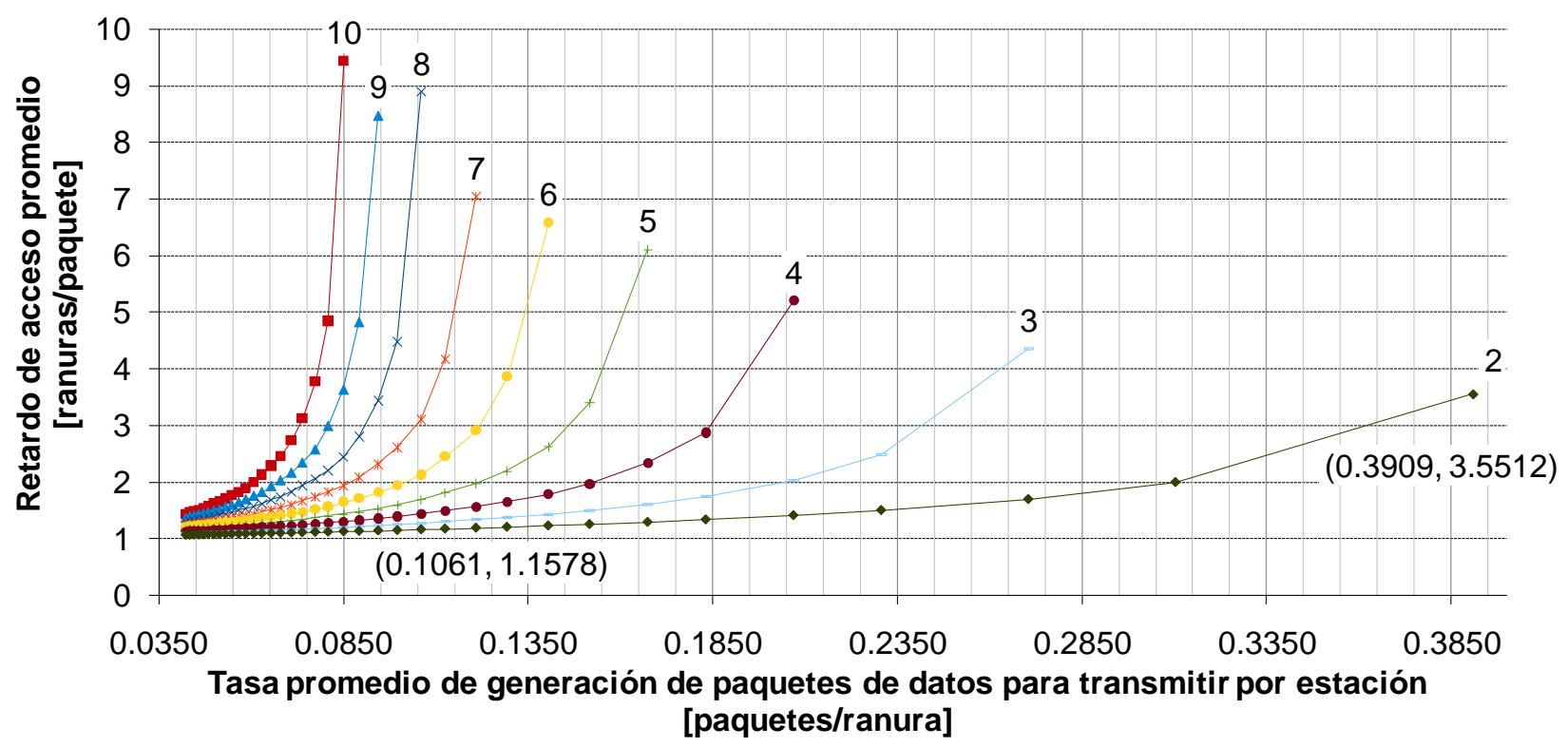

Figura 28. Retardo de acceso promedio para una red con una cantidad desde dos hasta diez estaciones operando con el protocolo $2 \mathrm{C}-\mathrm{R}^{2} \operatorname{con} M=1$ 


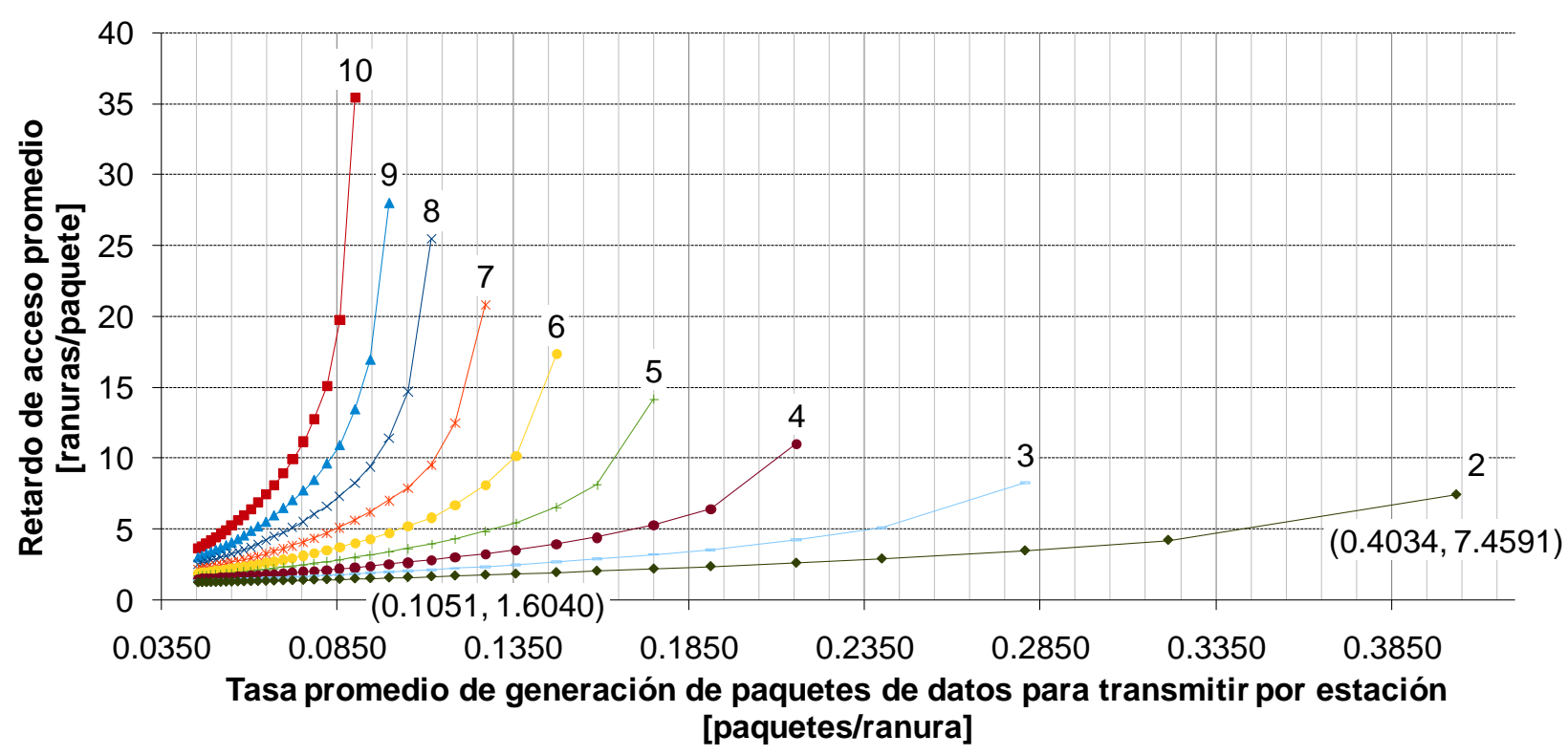

Figura 29. Retardo de acceso promedio para una red con una cantidad desde dos hasta diez estaciones operando con el protocolo $2 \mathrm{C}-\mathrm{R}^{2}$ con $M=2$

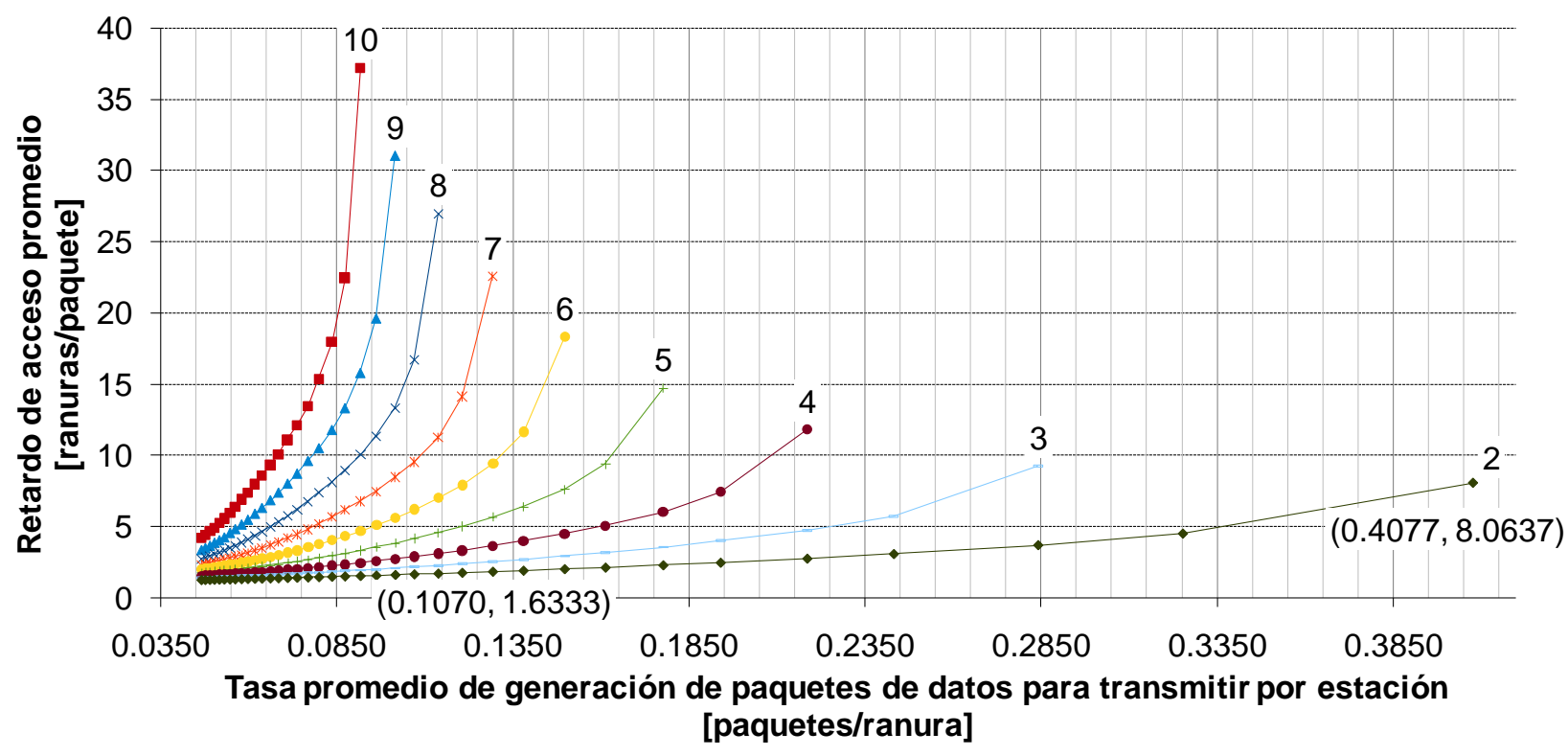

Figura 30. Retardo de acceso promedio para una red con una cantidad desde dos hasta diez estaciones operando con el protocolo $2 \mathrm{C}-\mathrm{R}^{2}$ con $M=3$ 
Evaluación de desempeño - Resultados para el protocolo 2C-R²

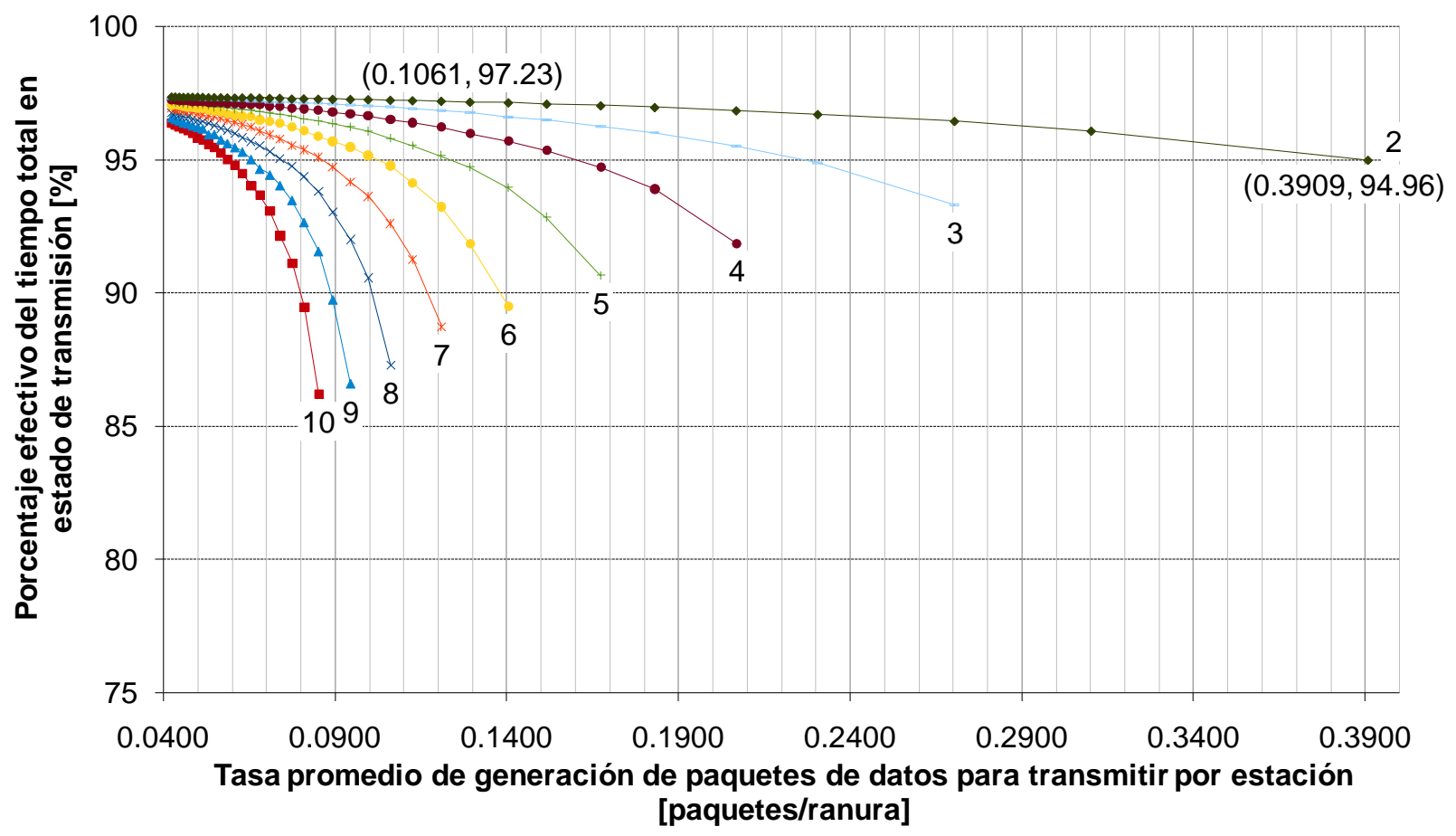

Figura 31. Porcentaje efectivo del tiempo total en estado de transmisión para una red con una cantidad desde dos hasta diez estaciones operando con el protocolo $2 \mathrm{C}-\mathrm{R}^{2}$ con $M=1$

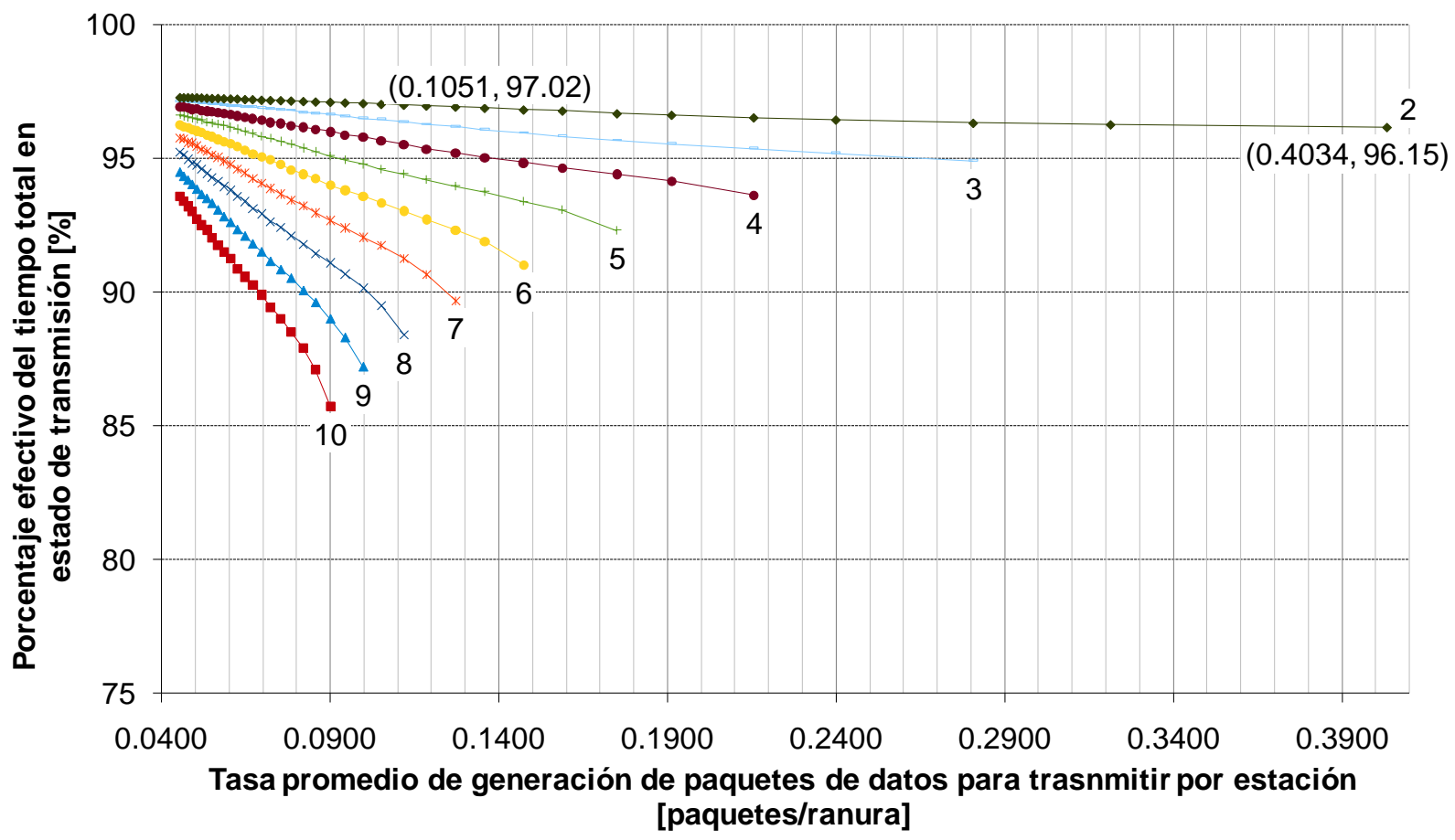

Figura 32. Porcentaje efectivo del tiempo total en estado de transmisión para una red con una cantidad desde dos hasta diez estaciones operando con el protocolo $2 \mathrm{C}-\mathrm{R}^{2}$ con $M=2$ 


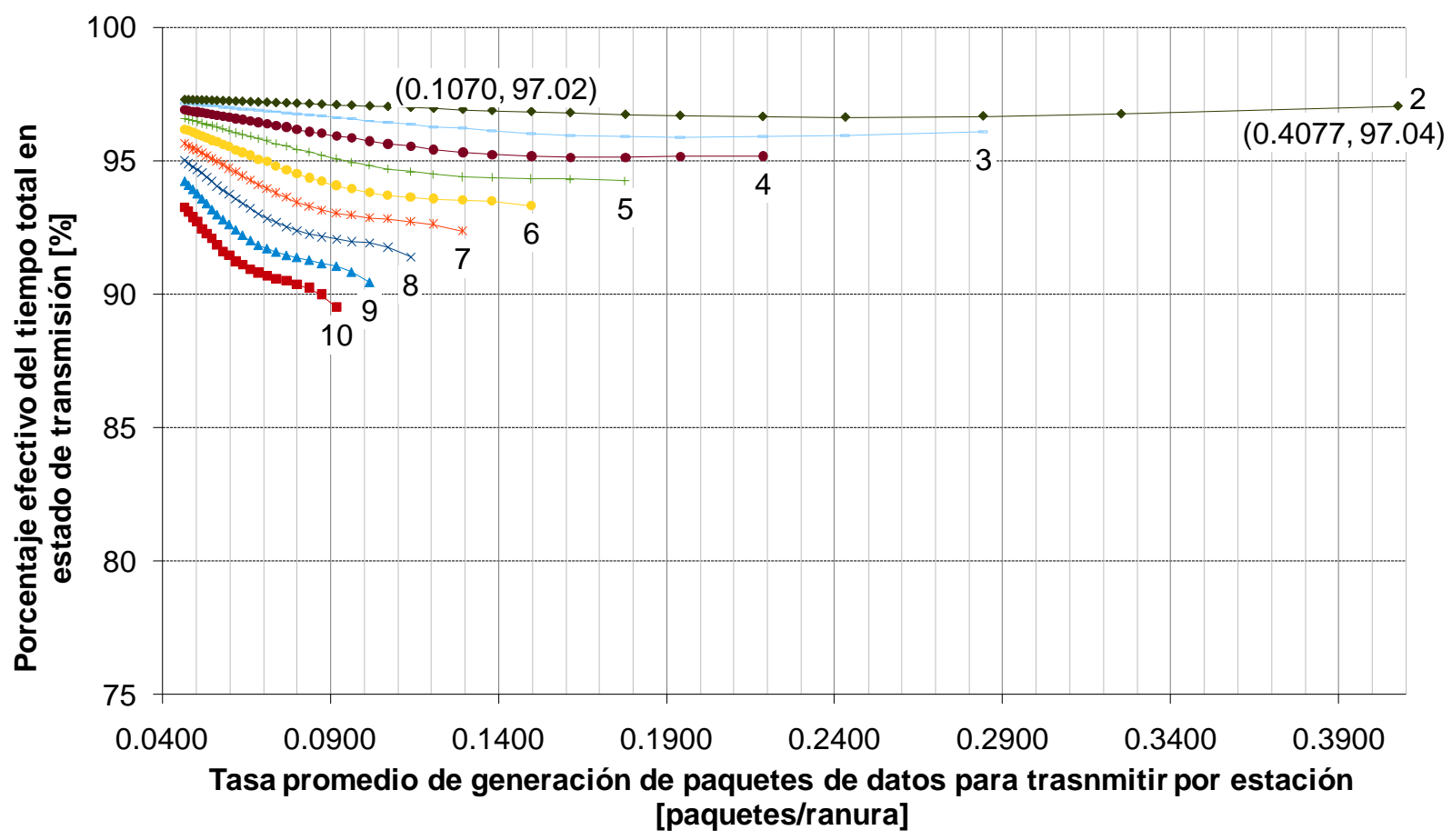

Figura 33. Porcentaje efectivo del tiempo total en estado de transmisión para una red con una cantidad desde dos hasta diez estaciones operando con el protocolo $2 \mathrm{C}-\mathrm{R}^{2}$ con $M=3$

\subsubsection{Comparación del $2 \mathrm{C}-\mathrm{R}^{2}$ con respecto al $2 \mathrm{C}$}

Con base en los resultados para la utilización efectiva del medio de transmisión (tiempo efectivamente utilizado para transmisión de datos), se puede observar que el protocolo $2 \mathrm{C}-\mathrm{R}^{2}$ puede alcanzar una utilización efectiva máxima de casi el 100\% (ver figura 23), mayor al $80 \%$ con $M=1$, y va aumentando conforme aumenta el valor de $M$, como se observa en la figura 25, figura 26 y figura 27. El protocolo 2C apenas alcanza valores entre $20 \%$ y $35 \%$, como se ve en la figura 18, y sólo puede llegar alcanzar una utilización máxima del $45 \%$ (figura 16). De igual forma, el protocolo $2 \mathrm{C}-\mathrm{R}^{2}$ permite una mayor carga, por parte de las estaciones que forman parte de la red, con respecto al protocolo $2 \mathrm{C}$, como se observa en la figura 14 y figura 21. 
En cuanto al tiempo que tarda un paquete de datos en ser transmitido, se puede apreciar que, en las mismas condiciones de carga ofrecida, el protocolo $2 \mathrm{C}$ presenta un mayor retardo de acceso promedio que el protocolo $2 \mathrm{C}-\mathrm{R}^{2}$, como se muestra en la figura 19 , sin embargo, entre mayor sea la cantidad de estaciones en la red mayor será el retardo de acceso para el protocolo $2 \mathrm{C}-\mathrm{R}^{2}$, como se puede ver en la figura 28 , figura 29 y figura 30 , llegando a alcanzar retardos de hasta cien ranuras por paquete de datos, en condiciones estables. Cabe mencionar que si se aumenta la cantidad de ranuras otorgadas por reservación, para el protocolo $2 \mathrm{C}-\mathrm{R}^{2}$ (valores mayores para $M$ ), entonces el retardo de acceso también aumenta, lo cual se puede ver como una desventaja. Cuando la carga ofrecida a la red es muy baja, el protocolo $2 \mathrm{C}-\mathrm{R}^{2}$ presenta un menor retardo de acceso promedio que el protocolo $2 \mathrm{C}$, ya que, en su modalidad de detección limitada, el protocolo $2 \mathrm{C}$ indica que deben presentarse dos ranuras vacías consecutivas para que una estación intente transmitir un paquete de datos; por el contrario, con el protocolo $2 \mathrm{C}-\mathrm{R}^{2}$, sólo debe transcurrir una miniranura, en la $\mathrm{RRP}$, para que la estación realice su reservación y pueda transmitir, en la ranura siguiente, su paquete de datos. Como ya se mencionó, protocolo $2 \mathrm{C}-\mathrm{R}^{2}$ admite una mayor carga que el protocolo $2 \mathrm{C}$, pero entre mayor sea ésta, también será mayor el retardo de acceso.

Analizando los resultados para el porcentaje efectivo del tiempo total en estado de transmisión, se puede decir que el protocolo propuesto tiene un porcentaje substancialmente mayor de trasmisiones exitosas, respecto al protocolo $2 \mathrm{C}$, cuando la carga que las estaciones ofrecen a la red es media o alta. Cuando la carga ofrecida por las estaciones es muy baja, el protocolo $2 \mathrm{C}$ aprovecha de una mejor forma la energía que gasta en modo de transmisión y el porcentaje efectivo del tiempo total en estado de transmisión se puede acercar mucho al 100\%, como se ve en la figura 17 y figura 20. Por lo anterior, se puede decir que el protocolo $2 \mathrm{C}-\mathrm{R}^{2}$ permite un mejor aprovechamiento de la energía que consume cuando la carga ofrecida es media o alta (ver figura 24), y va aumentando conforme la cantidad de ranuras por reservación es mayor, lo cual es un punto importante en dispositivos con limitaciones en consumo energético, como se observa en la figura 31 , figura 32 y figura 33. 


\section{Conclusiones}

En este trabajo se propone y se evalúa el desempeño, principalmente por medio de simulación, de un protocolo híbrido de control de acceso al medio con reservación de recursos síncrono de detección limitada, denominado protocolo $2 \mathrm{C}-\mathrm{R}^{2}$. También, en este trabajo se evalúa el desempeño de un protocolo de acceso aleatorio sin reservación, principalmente por medio de simulación, el protocolo 2C.

De los resultados que se obtienen en la evaluación de desempeño, se puede concluir que nuestra propuesta presenta un mejor desempeño comparado con el protocolo $2 \mathrm{C}$, en cuanto a la utilización efectiva del medio de transmisión, cuando la carga ofrecida a la red es alta. Cuando la carga ofrecida a la red es muy baja, ambos protocolos presentan el mismo desempeño en ese aspecto.

En lo que se refiere al retardo de acceso al medio de transmisión, el protocolo $2 \mathrm{C}-\mathrm{R}^{2}$ presenta menores retardos, con respecto al protocolo $2 \mathrm{C}$, en las mismas condiciones de carga ofrecida a la red. Cabe mencionar que con el protocolo $2 \mathrm{C}-\mathrm{R}^{2}$ se pueden presentar retardos de acceso muy altos, por ejemplo, de casi cien ranuras de tiempo con veinte estaciones en la red cuando $M=2$, pero éstos se presentan en condiciones de estabilidad y cuando la carga ofrecida por las estaciones es alta.

En cuanto al porcentaje efectivo del tiempo total en estado de transmisión, cuando la carga ofrecida es muy baja, es mejor utilizar el protocolo $2 \mathrm{C}$ en lugar del protocolo $2 \mathrm{C}-\mathrm{R}^{2}$, ya que, como no existe un alto riesgo de colisión, con una alta probabilidad el paquete de datos se transmitirá con éxito al primer intento, y entonces no será necesario realizar algún tipo de reservación. Por el contrario, cuando la carga ofrecida es media o alta, lo mejor es realizar primero una reservación con paquetes pequeños de señalización y luego realizar la transmisión de los paquetes de datos, y entonces desperdiciar poca energía a causa de las colisiones que se presentan en la RRP. 
En resumen, cuando la carga ofrecida a la red es baja, el acceso aleatorio logra un buen desempeño y probablemente no se justifique el utilizar otros métodos para compartir el medio de transmisión. Sin embargo, los resultados obtenidos muestran que, con medias o altas cargas de tráfico, como se presentan en distintos escenarios en la actualidad, un protocolo que combine acceso aleatorio y reservación puede mejorar significativamente el desempeño. El protocolo propuesto, $2 \mathrm{C}-\mathrm{R}^{2}$, es un ejemplo de este enfoque híbrido y puede ser una buena opción para controlar el acceso a un medio de transmisión cuando la carga ofrecida a la red es media o alta y cuando se requiere un bajo consumo energético, como por ejemplo en redes inalámbricas de sensores.

Cabe mencionar que, con los resultados obtenidos durante la realización de este proyecto se presentó un poster en la 11 a Feria de Posgrados de Calidad 2010 del CONACYT, en representación de la Maestría en Ciencias y Tecnologías de la Información de la Universidad Autónoma Metropolitana. 


\section{Referencias}

[1] Tanenbaum Andrew, "Redes de Computadoras", Cuarta Edición, Prentice Hall 2003.

[2] Leon-Garcia Alberto y Widjaja, Indra, "Communication Newtworks", McGraw Hill 2001.

[3] Wireless LAN Medium Access Control (MAC) and Physical Layer (PHY) Specification, IEEE Std. 802.11-1999 edition, 1999.

[4] Le H.-C., Guyennet H.y Zerhouni N., "A New Contention Access Method for Collision Avoidance in Wireless Sensor Networks", Proc. of the 6th International Conference on Networking (ICN'07), pp.27-34, 2007.

[5] Capetanakis J. I., "Tree algorithms for packet broadcast channel”, IEEE Transactions on Information Theory, vol. IT-25, pp. 505-515, septiembre 1979.

[6] Tsybakov B. S. y Vvedenskaya N. D., "Random Multiple-Access Stack Algorithm", Probl. Peredachi Inf., vol. 16, no. 3, pp. 80-94, 1980.

[7] Paterakis M. y Papantoni-Kazakos P., "A Simple Window Random Access Algorithm with Advantageous Properties", IEEE Transactions on Information Theory, vol. IT-35, no. 5, pp. 1124 - 1130, septiembre 1989.

[8] Paterakis M. y Papanti-Kazakos P., "A Limited Sensing Random-Access Algorithm with Binary Success-Failure Feedback”, IEEE Transactions on Communications, vol. COM-37, no. 5, pp. 526-530, mayo 1989.

[9] Alarcon-Ramos L., Lopez-Guerrero M. y Makrakis, D., "Adaptive 2C: A Novel Access Control for Fair and Efficient Channel Sharing” Canadian Conference on Electrical and Computer Engineering (CCECE), pp. 643-646, 2007.

[10] Royo F., Lopez-Guerreo M., Orozco-Barbosa L. y Olivares T., " $2 C$-WSN: $a$ configuration protocol based on TDMA communications over WSN", Proc. of the 28th IEEE Global Communications Conference, pp. 4057-4062, 2009. 
[11] Royo F., Olivares T. y Orizco-Barbosa L., “A synchronous engine for wireless sensor networks", Telecommunications Systems, vol. 40, no. 3-4, pp. 151-159, abril 2009.

[12] Fayolle G., Flajolet P., Hofri M. y Jacquet P., "Analysis of a stack algorithm for random multiple-access communication", IEEE Transactions on Information Theory, vol. IT-31, no. 2, pp. $244-254$, marzo 1985.

[13] Manual de usuario del Sistema de Simulación por Eventos Discretos OMNeT++ Versión 4.0, 2008.

[14] Rom Raphael y Sidi Moshe, "Multiple Access Protocols", Springer-Verlag 1989.

[15] Bianchi Giuseppe, "Performance Analysis of the IEEE 802.11 Distributed Coordination Function", IEEE Journal on Selected Areas in Communications, vol. 18, no. 3, pp. 535-547, marzo 2000.

[16] Isaacson D. L. y Madsen R. W., "Markov Chains Theory and Applications", U.S.A., John Wiley and Sons, 1976. 


\section{Lista de figuras}

Figura 1. Sólo una estación transmite sobre el medio compartido

Figura 2. Dos o más estaciones transmiten simultáneamente

Figura 3. Ejemplos de la clasificación de los protocolos MAC con base en la clasificación proporcionada en [2].

Figura 4. Ejemplo del protocolo de árbol binario para cinco estaciones activas 17

Figura 5. Ejemplo del protocolo de pila para una red con tres estaciones para la $(a)$ primera ranura tiempo, $(b)$ segunda, $(c)$ tercera, $(d)$ cuarta, $(e)$ quinta y $(f)$ sexta 20

Figura 6. Ejemplo del desarrollo en una red con el protocolo $2 \mathrm{C}$ 23

Figura 7. Operación de una red con cuatro estaciones operando con el protocolo básico de reservación... 26

Figura 8. Ejemplo del desarrollo del protocolo $2 \mathrm{C}-\mathrm{R}^{2}$ en una red con siete estaciones. 32

Figura 9. Comparación de la duración promedio del CRI 34

Figura 10. Valores promedio en el protocolo 2C (cadena de Markov)..... 35

Figura 11. Valores promedio en el protocolo $2 \mathrm{C}(\mathrm{OMNeT}++)$ 35

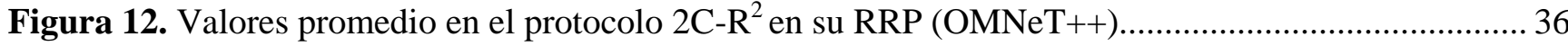

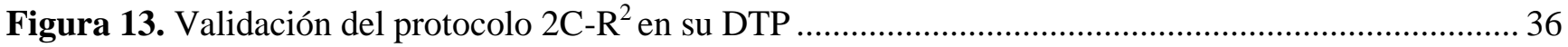

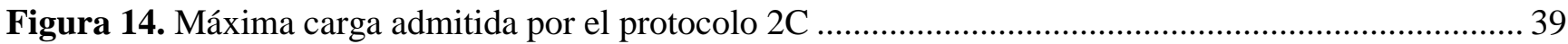

Figura 15. Máxima utilización efectiva del medio de transmisión para una red con el protocolo 2C ......... 41

Figura 16. Utilización efectiva del medio de transmisión en condiciones de saturación para el protocolo $2 \mathrm{C}$ 42

Figura 17. Porcentaje efectivo del tiempo total en estado de transmisión en condiciones de saturación para el protocolo $2 \mathrm{C}$

Figura 18. Utilización efectiva para una red con una cantidad desde dos hasta diez estaciones operando con el protocolo $2 \mathrm{C}$

Figura 19. Retardo de acceso promedio para una red con una cantidad desde dos hasta diez estaciones operando con el protocolo $2 \mathrm{C}$ 
Figura 20. Porcentaje efectivo del tiempo total en estado de transmisión para una red con una cantidad desde dos hasta diez estaciones operando con el protocolo $2 \mathrm{C}$ 45

Figura 21. Máxima carga admitida por el protocolo $2 \mathrm{C}-\mathrm{R}^{2}$ 48

Figura 22. Máxima utilización efectiva del medio de transmisión para una red que opera con el protocolo $2 \mathrm{C}-\mathrm{R}^{2}$

Figura 23. Utilización efectiva del medio de transmisión en condiciones de saturación para el protocolo $2 \mathrm{C}-\mathrm{R}^{2}$ 51

Figura 24. Porcentaje efectivo del tiempo total en estado de transmisión en condiciones de saturación para el protocolo $2 \mathrm{C}-\mathrm{R}^{2}$

Figura 25. Utilización efectiva para una red con una cantidad desde dos hasta diez estaciones operando con el protocolo $2 \mathrm{C}-\mathrm{R}^{2}$ con $M=1$

Figura 26. Utilización efectiva para una red con una cantidad desde dos hasta diez estaciones operando con el protocolo $2 \mathrm{C}-\mathrm{R}^{2}$ con $M=2$

Figura 27. Utilización efectiva para una red con una cantidad desde dos hasta diez estaciones operando con el protocolo $2 \mathrm{C}-\mathrm{R}^{2}$ con $M=3$

Figura 28. Retardo de acceso promedio para una red con una cantidad desde dos hasta diez estaciones operando con el protocolo $2 \mathrm{C}-\mathrm{R}^{2}$ con $M=1$

Figura 29. Retardo de acceso promedio para una red con una cantidad desde dos hasta diez estaciones operando con el protocolo $2 \mathrm{C}-\mathrm{R}^{2}$ con $M=2$.

Figura 30. Retardo de acceso promedio para una red con una cantidad desde dos hasta diez estaciones operando con el protocolo $2 \mathrm{C}-\mathrm{R}^{2} \operatorname{con} M=3$

Figura 31. Porcentaje efectivo del tiempo total en estado de transmisión para una red con una cantidad desde dos hasta diez estaciones operando con el protocolo $2 \mathrm{C}-\mathrm{R}^{2}$ con $M=1$

Figura 32. Porcentaje efectivo del tiempo total en estado de transmisión para una red con una cantidad desde dos hasta diez estaciones operando con el protocolo $2 \mathrm{C}-\mathrm{R}^{2}$ con $M=2$

Figura 33. Porcentaje efectivo del tiempo total en estado de transmisión para una red con una cantidad desde dos hasta diez estaciones operando con el protocolo $2 \mathrm{C}-\mathrm{R}^{2}$ con $M=3$.

Figura 34. Modelo de Markov para una red de computadoras utilizando el protocolo $2 \mathrm{C}$ 70

Figura 35. (a) Fases de la cadena de Markov y (b) su modelo genérico para $n \geq 2$. 


\section{Lista de tablas}

Tabla 1. Tasa máxima de generación de paquetes de datos para el protocolo $2 \mathrm{C}$............................75

Tabla 2. Máxima utilización efectiva del medio de transmisión para una red con el protocolo 2C .......76

Tabla 3. Tasa máxima de generación de paquetes de datos para el protocolo $2 \mathrm{C}-\mathrm{R}^{2}$ con $M=1$...........76

Tabla 4. Tasa máxima de generación de paquetes de datos para el protocolo $2 \mathrm{C}-\mathrm{R}^{2}$ con $M=2 \ldots \ldots \ldots \ldots . . .77$

Tabla 5. Tasa máxima de generación de paquetes de datos para el protocolo $2 \mathrm{C}-\mathrm{R}^{2}$ con $M=3 \ldots \ldots \ldots \ldots .77$

Tabla 6. Tasa máxima de generación de paquetes de datos para el protocolo $2 \mathrm{C}-\mathrm{R}^{2}$ con $M=4 \ldots \ldots \ldots \ldots . .78$

Tabla 7. Tasa máxima de generación de paquetes de datos para el protocolo $2 \mathrm{C}-\mathrm{R}^{2}$ con $M=5 \ldots \ldots \ldots \ldots .78$

Tabla 8. Tasa máxima de generación de paquetes de datos para el protocolo $2 \mathrm{C}-\mathrm{R}^{2}$ con $M=6 \ldots \ldots \ldots \ldots . . .79$

Tabla 9. Máxima utilización efectiva del medio de transmisión para una red que opera con el protocolo $2 \mathrm{C}-\mathrm{R}^{2}$

Tabla 10. Utilización efectiva del medio de transmisión en condiciones de saturación para el protocolo $2 \mathrm{C}$

Tabla 11. Porcentaje efectivo del tiempo total en estado de transmisión en condiciones de saturación para el protocolo $2 \mathrm{C}$

Tabla 12. Utilización efectiva en condiciones de saturación para el protocolo $2 \mathrm{C}-\mathrm{R}^{2}$

Tabla 13. Porcentaje efectivo del tiempo total en estado de transmisión en condiciones de saturación para el protocolo $2 \mathrm{C}-\mathrm{R}^{2}$ 


\section{Apéndice A: Simulador de eventos discretos OMNeT++}

OMNeT++ es un simulador de eventos discretos, modular, orientado a objetos, encauzado a la simulación de redes de computadoras. Este simulador tiene una arquitectura genérica y puede ser utilizado para analizar problemas de diferentes dominios en [13]:

- Modelado de redes de comunicaciones alambradas e inalámbricas

- Modelado de protocolos

- Modelado de redes de encolamiento

- Modelado de multiprocesadores y otros sistemas de hardware distribuidos

- Validación de arquitecturas de hardware

- Evaluación de desempeño de sistemas de software complejos

En general, OMNeT++ puede ser usado para modelar y simular algunos sistemas en donde es apropiado un enfoque por eventos discretos, y el cual pueda ser mapeado, de forma conveniente, en entidades que se comunican mediante el paso de mensajes. Uno de los ingredientes fundamentales de esta infraestructura es su arquitectura por componentes para los modelos de simulación. Los modelos son ensamblados con componentes reusables denominados módulos. Un módulo puede ser conectado con otro módulo vía sus compuertas, y combinados forman módulos compuestos. Los módulos se comunican mediante paso de mensajes, y los mensajes pueden contener estructuras de datos arbitrarias. Los módulos pueden pasar mensajes a través de rutas predefinidas vía las compuertas, o directamente a su destino (usado para simulaciones inalámbricas, por ejemplo). 
Los módulos en el más bajo nivel de jerarquía son llamados módulos simples, son programados en $\mathrm{C}++$, y hacen uso de la librería de simulación. Las simulaciones en OMNeT++ pueden ser corridas sobre varias interfaces de usuario. En el modo gráfico, interfaces animadas son altamente utilizadas para demostraciones y depuración; la interface por línea de comandos es la mejor opción cuando se realizan grupos de ejecución. OMNeT++ también soporta simulaciones distribuidas en forma paralela. OMNeT++ puede usar varios mecanismos para la comunicación entre las particiones de la simulación distribuida paralelamente, por ejemplo MPI o los denominados pipes.

OMNeT++ puede ser utilizado en sistemas operativos como Linux, MAC OS-X, Windows entre otros. OMNeT++ ha sido desarrollado por András Varga en colaboración con el Departamento de Telecomunicaciones de la Universidad Técnica de Budapest, en Hungría. Actualmente OMNeT++ es un software de libre distribución para fines académicos. 


\section{Apéndice B: Modelado del 2C como una cadena de Markov}

El análisis presentado en este apéndice fue desarrollado por el Dr. Miguel López Guerrero y aparecerá incluido en una publicación próximamente. En este análisis se representa una red de computadoras, que utiliza el protocolo 2C, como una cadena de Markov cuyos estados pueden ser identificados por el par (TC, WC), es decir, por el numero de paquetes en la celda de transmisión TC y por el numero de paquetes en la celda de espera WC. Este modelo se muestra en la figura 34. Las marcas "Start" indican aquellos estados en los que puede comenzar una CRI, dependiendo de la cantidad de transmisiones simultaneas que se presenten en la primera ranura de cada CRI. En este análisis se considera que en la fase $n$ puede haber $i$ estaciones en la celda de transmisión (donde $i$ esta en el intervalo $0 \leq i \leq n)$, y $n$ - $i$ estaciones en la celda de espera. Entonces, un estado de la fase $n$ únicamente puede ser distinguido por el índice $i$. En este análisis se utiliza esta notación para los subíndices de las probabilidades de transición de la cadena de Markov, las cuales se muestran en la figura 34.

La cadena consiste de diferentes fases, como se puede observar en la figura 35, y cada una de esas fases comienza con una colisión $(C)$ de multiplicidad $n$ en el estado $(n, 0)$ y termina con una transmisión exitosa $(S)$ en el estado $(1, n-1)$. Como se puede apreciar, una vez que el sistema transita a un estado con una transmisión exitosa, es decir, al estado $(1, n-1)$, los demás estados dentro de la misma fase no serán visitados de nuevo dentro del mismo CRI. En la figura 35, se utiliza notación de lenguaje $\mathrm{C}$ para mostrar cómo se incrementan los contadores de ranuras en colisión, éxito y vacío $(E)$. Entonces, el estado $(1, n-1)$ se puede considerar como un estado absorbente para determinada fase, lo cual permite que se pueda realizar un análisis independiente para cada una de las fases de la cadena. En este análisis se representa a cada una de las fases, para $n \geq 2$, como se muestra en la figura 35 b. Tomando como referencia la figura $35 \mathrm{~b}$, se calculan las probabilidades de transición, para la fase $n$ con $n \geq 2$, como se muestra a continuación. 


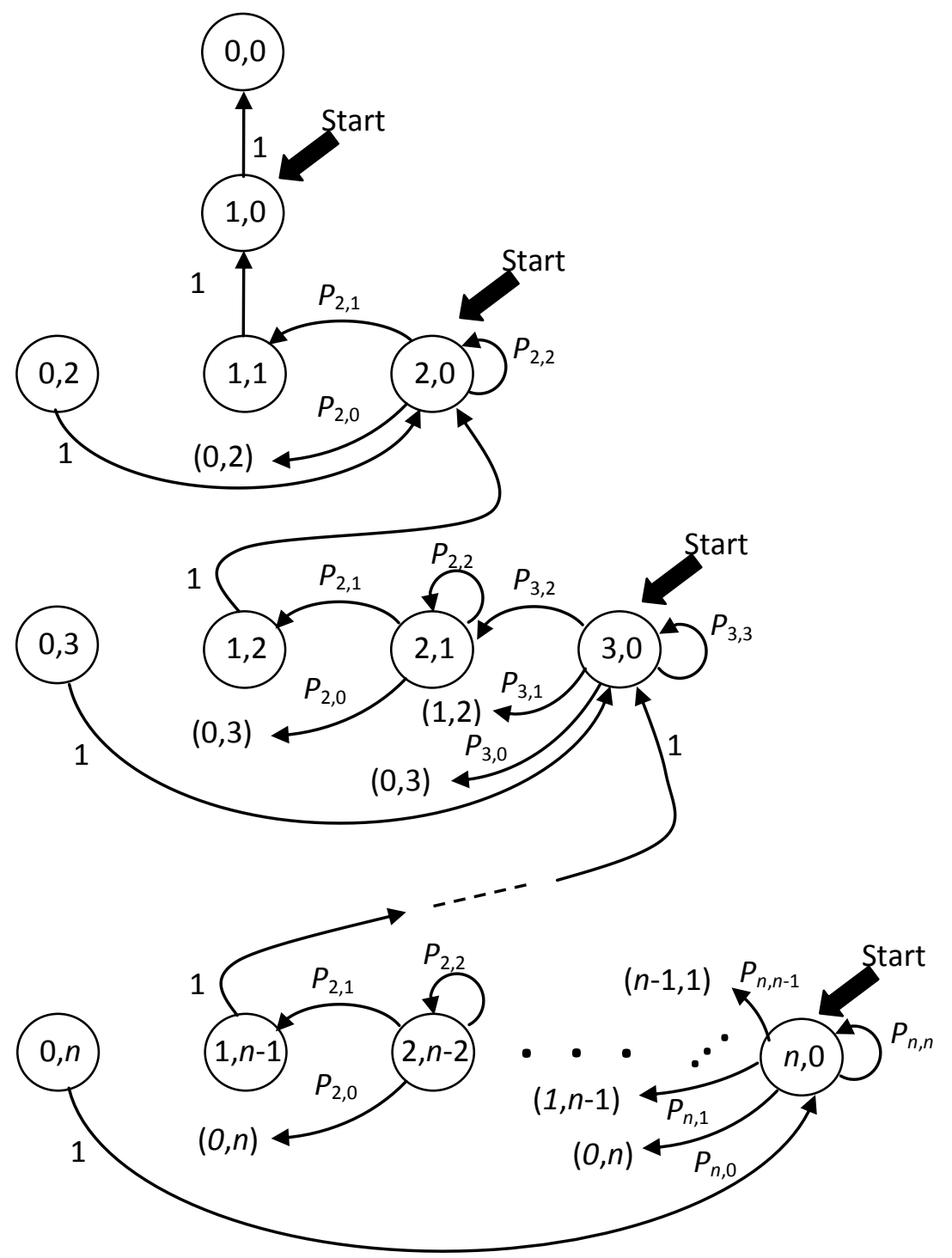

Figura 34. Modelo de Markov para una red de computadoras utilizando el protocolo $2 \mathrm{C}$

Transición del estado $(1, n-1)$ al mismo estado $(1, n-1)$

$P_{1,1}=1$

a) Transición del estado $(0, n)$ al estado $(n, 0)$

$P_{0, n}=1$

b) Transiciones desde el estado $(i, n-i)$ al estado $(j, n-j)$

$P_{i, j}=\left(\begin{array}{c}i \\ j\end{array}\right) p^{j}(1-p)^{i-j} \quad 2 \leq i \leq n \quad j=0, \ldots, i$ 

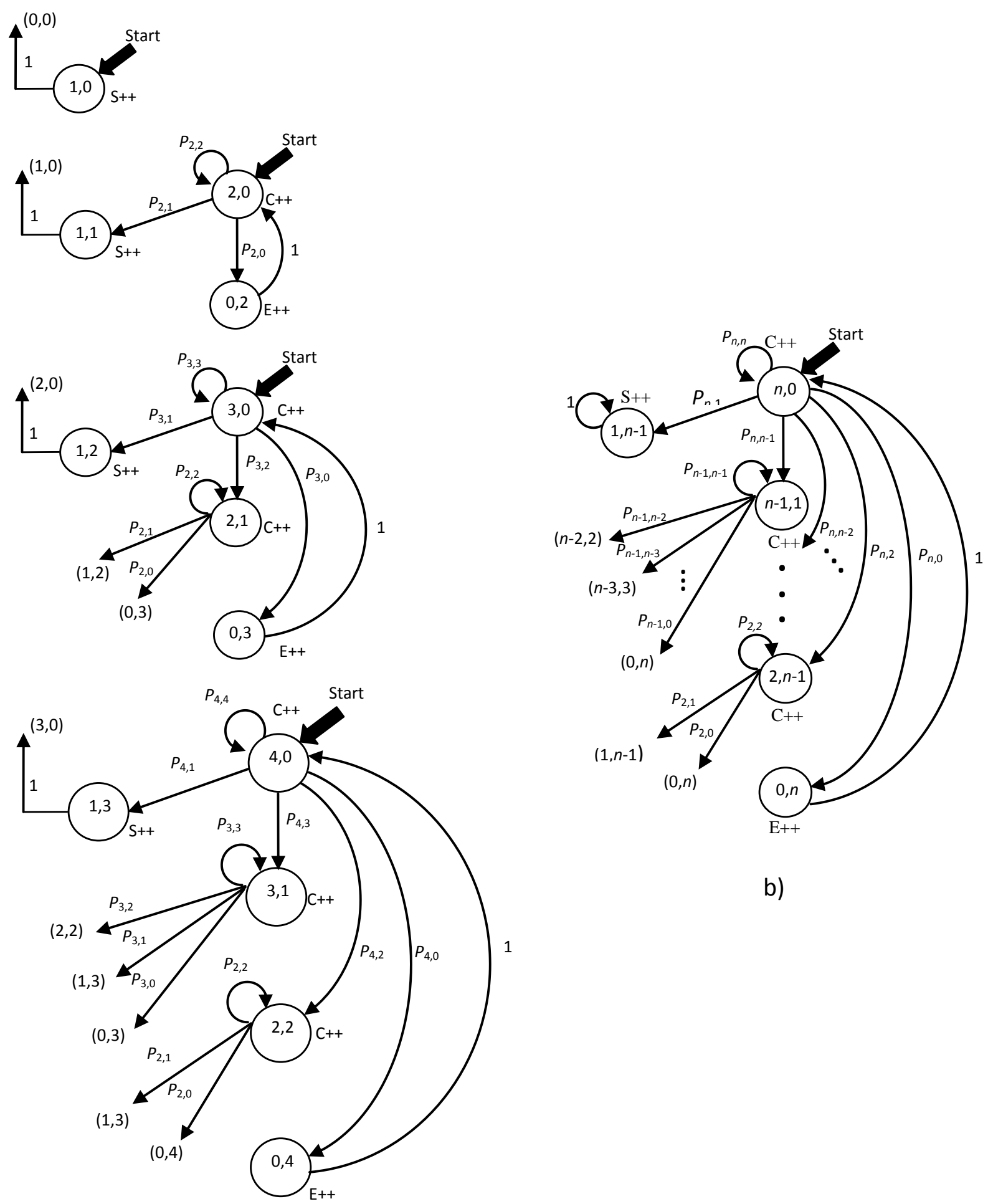

a)

Figura 35. (a) Fases de la cadena de Markov y (b) su modelo genérico para $n \geq 2$ 
Se utiliza esa información para crear la matriz de probabilidades de transición $P$, que representan a la fase $n$, como se muestra a continuación:

$$
P=\left[\begin{array}{cccccccccc}
0 & 0 & 0 & 0 & \cdots & 0 & 0 & \cdots & 0 & 1 \\
0 & 1 & 0 & 0 & \cdots & 0 & 0 & \cdots & 0 & 0 \\
P_{2,0} & P_{2,1} & P_{2,2} & 0 & \cdots & 0 & 0 & \cdots & 0 & 0 \\
\vdots & \vdots & \vdots & \vdots & \ddots & \vdots & \vdots & \vdots & \vdots & \vdots \\
P_{i, 0} & P_{i, 1} & P_{i, 2} & P_{i, 3} & \cdots & P_{i, i} & 0 & \vdots & 0 & 0 \\
\vdots & \vdots & \vdots & \vdots & \ddots & \vdots & \vdots & \vdots & \vdots & \vdots \\
P_{n, 0} & P_{n, 1} & P_{n, 2} & P_{n, 3} & \cdots & P_{n, i} & P_{n+1, i} & \cdots & P_{n, n-1} & P_{n, n}
\end{array}\right]
$$

A partir de la matriz de probabilidades de transición, se determina la cantidad de visitas esperadas a cada uno de los estados transitorios antes de la absorción, y con esto pueden determinar la cantidad de ranuras tipo $C$ y $E$ en la fase $n$. Para esto, primero obtienen la matriz de probabilidades de transición entre los estados no absorbentes $(R)$. La matriz $R$ se obtiene cancelando el renglón y la columna correspondientes a las transiciones a y desde los estados absorbentes. La matriz $R$ tiene la siguiente forma general:

$$
R=\left[\begin{array}{ccccccccc}
0 & 0 & 0 & \cdots & 0 & 0 & \cdots & 0 & 1 \\
P_{2,0} & P_{2,2} & 0 & \cdots & 0 & 0 & \cdots & 0 & 0 \\
\vdots & \vdots & \vdots & \ddots & 0 & 0 & \cdots & 0 & 0 \\
P_{i, 0} & P_{i, 2} & P_{i, 3} & \cdots & P_{i, i} & 0 & \cdots & 0 & 0 \\
\vdots & \vdots & \vdots & \ddots & \vdots & \vdots & \ddots & \vdots & \vdots \\
P_{n, 0} & P_{n, 2} & P_{n, 3} & \cdots & P_{n, i} & P_{n+1, i} & \cdots & P_{n, n-1} & P_{n, n}
\end{array}\right]
$$

A partir de $R$, se obtiene la matriz fundamental $Q$ basándose en [16]:

$$
Q=(I-R)^{-1}
$$


En este análisis se denota a cada elemento de $Q$ como $q_{i, j}$, en donde $i, j=0,2,3, \ldots, n$. Cada elemento de $Q$ representa el cantidad esperada de visitas al estado $j$ iniciando desde el estado $i$ antes de la absorción ( si $i=j$, entonces el estado inicial es incluido en el contador). Ya que cada fase de un CRI comienza en el estado $(n, 0)$, la última fila de la matriz $Q$ es la que proporciona la información que se busca con este análisis. De esta manera, se puede encontrar la cantidad esperada de ranuras vacías que suceden en la fase $n\left(E^{(n)}\right)$ como se muestra a continuación:

$$
E^{(n)}=q_{n, 0}
$$

Y la cantidad esperada de ranuras con colisión $C^{(n)}$ en la fase $n$ es:

$$
C^{(n)}=\sum_{j=2}^{n} q_{n, j}
$$

Se sabe que la cantidad esperada de ranuras con transmisiones exitosas en la fase $n\left(S^{(n)}\right)$ es 1. Entonces, dado que en el inicio de un CRI se presenta una colisión de multiplicidad $k \geq 2$, la cantidad total esperada de ranuras vacias en el CRI es:

$$
E_{k}=\sum_{m=2}^{k} E^{(m)}
$$

Y la cantidad total esperada, en el CRI, de ranuras con colisión es:

$$
C_{k}=\sum_{m=2}^{n} C^{(m)}
$$

De la misma manera, la cantidad total esperada de ranuras con transmisiones exitosas es:

$$
S_{k}=1+\sum_{m=2}^{k} S^{(m)}=k
$$

Se utiliza este método para investigar la cantidad resultante de ranuras $E, C$ y $S$ que se producen cuando un CRI comienza con multiplicidades de diferentes magnitudes. Utilizando las ecuaciones $(f)$, $(g)$ y $(h)$, nosotros generamos la figura 10, la cual mostramos en la parte de validación de los modelos de simulación dentro de este trabajo. 


\section{Apéndice C: Tablas de resultados}

Tabla 1. Tasa máxima de generación de paquetes de datos para el protocolo $2 \mathrm{C}$

\begin{tabular}{cccc}
\hline $\begin{array}{c}\boldsymbol{N} \\
\text { [estaciones] }\end{array}$ & $\begin{array}{c}\boldsymbol{T}_{\boldsymbol{N}} \\
\text { [ranuras] }\end{array}$ & $\begin{array}{c}\boldsymbol{\lambda}_{\text {i-MAX }} \\
\text { [paquetes/ranura] }\end{array}$ & $\begin{array}{c}\boldsymbol{\lambda}_{\text {MAX-TOTAL }} \\
\text { [paquetes/ranura] }\end{array}$ \\
\hline 2 & 4.49 & 0.2226 & 0.4452 \\
3 & 8.29 & 0.1206 & 0.3618 \\
4 & 12.52 & 0.0799 & 0.3195 \\
5 & 17.14 & 0.0583 & 0.2917 \\
6 & 22.10 & 0.0453 & 0.2715 \\
7 & 27.33 & 0.0366 & 0.2561 \\
8 & 32.93 & 0.0304 & 0.2429 \\
9 & 38.59 & 0.0259 & 0.2332 \\
10 & 44.57 & 0.0224 & 0.2244 \\
11 & 50.65 & 0.0197 & 0.2172 \\
12 & 57.08 & 0.0175 & 0.2102 \\
13 & 63.38 & 0.0158 & 0.2051 \\
14 & 69.95 & 0.0143 & 0.2002 \\
15 & 76.59 & 0.0131 & 0.1958 \\
16 & 83.51 & 0.0120 & 0.1916 \\
17 & 90.49 & 0.0111 & 0.1879 \\
18 & 97.57 & 0.0102 & 0.1845 \\
19 & 104.71 & 0.0096 & 0.1815 \\
20 & 112.02 & 0.0089 & 0.1785 \\
\hline
\end{tabular}


Tabla 2. Máxima utilización efectiva del medio de transmisión para una red con el protocolo 2C

\begin{tabular}{cc}
\hline $\begin{array}{c}\boldsymbol{N} \\
\text { [estaciones] }\end{array}$ & $\begin{array}{c}\mathbf{U}_{\mathbf{M A X}} \\
{[\%]}\end{array}$ \\
\hline 2 & 44.52 \\
3 & 36.18 \\
4 & 31.95 \\
5 & 29.17 \\
6 & 27.15 \\
7 & 25.61 \\
8 & 24.29 \\
9 & 23.32 \\
10 & 22.44 \\
11 & 21.72 \\
12 & 21.02 \\
13 & 20.51 \\
14 & 20.02 \\
15 & 19.58 \\
16 & 19.16 \\
17 & 18.79 \\
18 & 18.45 \\
19 & 18.15 \\
20 & 17.85 \\
\hline
\end{tabular}

Tabla 3. Tasa máxima de generación de paquetes de datos para el protocolo $2 \mathrm{C}-\mathrm{R}^{2} \operatorname{con} M=1$

\begin{tabular}{cccc}
\hline $\begin{array}{c}\boldsymbol{N} \\
\text { [estaciones] }\end{array}$ & $\begin{array}{c}\boldsymbol{T r}_{\boldsymbol{N}} \boldsymbol{+} \boldsymbol{T d}_{\boldsymbol{N}} \\
\text { [segundos] }\end{array}$ & $\begin{array}{c}\boldsymbol{\lambda}_{\text {i-MAX }} \\
\text { [paquetes/ranura] }\end{array}$ & $\begin{array}{c}\boldsymbol{\lambda}_{\text {MAX-TOTAL }} \\
\text { [paquetes/ranura] }\end{array}$ \\
\hline 2 & 0.00047296 & 0.4715 & 0.9430 \\
3 & 0.00071879 & 0.3102 & 0.9307 \\
4 & 0.00096706 & 0.2306 & 0.9224 \\
5 & 0.00121785 & 0.1831 & 0.9155 \\
6 & 0.00147048 & 0.1517 & 0.9099 \\
7 & 0.00172478 & 0.1293 & 0.9050 \\
8 & 0.00198139 & 0.1125 & 0.9004 \\
9 & 0.00223843 & 0.0996 & 0.8966 \\
10 & 0.00249773 & 0.0893 & 0.8928 \\
11 & 0.00275686 & 0.0809 & 0.8898 \\
12 & 0.00301796 & 0.0739 & 0.8867 \\
13 & 0.00327919 & 0.0680 & 0.8841 \\
14 & 0.00354155 & 0.0630 & 0.8815 \\
15 & 0.00380490 & 0.0586 & 0.8791 \\
16 & 0.00406912 & 0.0548 & 0.8768 \\
17 & 0.00433409 & 0.0515 & 0.8747 \\
18 & 0.00459927 & 0.0485 & 0.8727 \\
19 & 0.00486487 & 0.0458 & 0.8709 \\
20 & 0.00513193 & 0.0435 & 0.8691 \\
\hline
\end{tabular}


Tabla 4. Tasa máxima de generación de paquetes de datos para el protocolo $2 \mathrm{C}-\mathrm{R}^{2}$ con $M=2$

\begin{tabular}{cccc}
\hline $\begin{array}{c}\boldsymbol{N} \\
\text { [estaciones] }\end{array}$ & $\begin{array}{c}\boldsymbol{T r}_{\boldsymbol{N}} \boldsymbol{+} \boldsymbol{T d}_{\boldsymbol{N}} \\
\text { [segundos] }\end{array}$ & $\begin{array}{c}\boldsymbol{\lambda}_{\text {i-MAX }} \\
\text { [paquetes/ranura] }\end{array}$ & $\begin{array}{c}\boldsymbol{\lambda}_{\text {MAX-TOTAL }} \\
\text { [paquetes/ranura] }\end{array}$ \\
\hline 2 & 0.00091896 & 0.4853 & 0.9707 \\
3 & 0.00138779 & 0.3214 & 0.9641 \\
4 & 0.00185906 & 0.2399 & 0.9596 \\
5 & 0.00233285 & 0.1912 & 0.9559 \\
6 & 0.00280848 & 0.1588 & 0.9528 \\
7 & 0.00328578 & 0.1357 & 0.9502 \\
8 & 0.00376539 & 0.1184 & 0.9476 \\
9 & 0.00424543 & 0.1051 & 0.9455 \\
10 & 0.00472773 & 0.0943 & 0.9434 \\
11 & 0.00520986 & 0.0856 & 0.9417 \\
12 & 0.00569396 & 0.0783 & 0.9399 \\
13 & 0.00617819 & 0.0722 & 0.9385 \\
14 & 0.00666355 & 0.0669 & 0.9370 \\
15 & 0.00714990 & 0.0624 & 0.9357 \\
16 & 0.00763712 & 0.0584 & 0.9344 \\
17 & 0.00812509 & 0.0549 & 0.9332 \\
18 & 0.00861327 & 0.0518 & 0.9320 \\
19 & 0.00910187 & 0.0490 & 0.9310 \\
20 & 0.00959193 & 0.0465 & 0.9299 \\
\hline
\end{tabular}

Tabla 5. Tasa máxima de generación de paquetes de datos para el protocolo $2 \mathrm{C}-\mathrm{R}^{2}$ con $M=3$

\begin{tabular}{cccc}
\hline $\begin{array}{c}\boldsymbol{N} \\
\text { [estaciones] }\end{array}$ & $\begin{array}{c}\boldsymbol{T r}_{\boldsymbol{N}} \boldsymbol{+} \boldsymbol{T d}_{\boldsymbol{N}} \\
\text { [segundos] }\end{array}$ & $\begin{array}{c}\boldsymbol{\lambda}_{\text {i-MAX }} \\
\text { [paquetes/ranura] }\end{array}$ & $\begin{array}{c}\boldsymbol{\lambda}_{\text {MAX-TOTAL }} \\
\text { [paquetes/ranura] }\end{array}$ \\
\hline 2 & 0.00136496 & 0.4901 & 0.9803 \\
3 & 0.00205679 & 0.3253 & 0.9758 \\
4 & 0.00275106 & 0.2432 & 0.9727 \\
5 & 0.00344785 & 0.1940 & 0.9702 \\
6 & 0.00414648 & 0.1613 & 0.9680 \\
7 & 0.00484678 & 0.1380 & 0.9662 \\
8 & 0.00554939 & 0.1206 & 0.9644 \\
9 & 0.00625243 & 0.1070 & 0.9630 \\
10 & 0.00695773 & 0.0962 & 0.9615 \\
11 & 0.00766286 & 0.0873 & 0.9603 \\
12 & 0.00836996 & 0.0799 & 0.9591 \\
13 & 0.00907719 & 0.0737 & 0.9581 \\
14 & 0.00978555 & 0.0684 & 0.9571 \\
15 & 0.01049490 & 0.0637 & 0.9562 \\
16 & 0.01120512 & 0.0597 & 0.9553 \\
17 & 0.01191609 & 0.0561 & 0.9544 \\
18 & 0.01262727 & 0.0530 & 0.9536 \\
19 & 0.01333887 & 0.0502 & 0.9529 \\
20 & 0.01405193 & 0.0476 & 0.9522 \\
\hline
\end{tabular}


Tabla 6. Tasa máxima de generación de paquetes de datos para el protocolo $2 \mathrm{C}-\mathrm{R}^{2}$ con $M=4$

\begin{tabular}{cccc}
\hline $\begin{array}{c}\boldsymbol{N} \\
\text { [estaciones] }\end{array}$ & $\begin{array}{c}\boldsymbol{T r}_{\boldsymbol{N}} \boldsymbol{+} \boldsymbol{T d}_{\boldsymbol{N}} \\
\text { [segundos] }\end{array}$ & $\begin{array}{c}\boldsymbol{\lambda}_{\text {i-MAX }} \\
\text { [paquetes/ranura] }\end{array}$ & $\begin{array}{c}\boldsymbol{\lambda}_{\text {MAX-TOTAL }} \\
\text { [paquetes/ranura] }\end{array}$ \\
\hline 2 & 0.00181096 & 0.4926 & 0.9851 \\
3 & 0.00272579 & 0.3272 & 0.9817 \\
4 & 0.00364306 & 0.2448 & 0.9794 \\
5 & 0.00456285 & 0.1955 & 0.9775 \\
6 & 0.00548448 & 0.1626 & 0.9758 \\
7 & 0.00640778 & 0.1392 & 0.9744 \\
8 & 0.00733339 & 0.1216 & 0.9731 \\
9 & 0.00825943 & 0.1080 & 0.9720 \\
10 & 0.00918773 & 0.0971 & 0.9709 \\
11 & 0.01011586 & 0.0882 & 0.9700 \\
12 & 0.01104596 & 0.0808 & 0.9690 \\
13 & 0.01197619 & 0.0745 & 0.9683 \\
14 & 0.01290755 & 0.0691 & 0.9675 \\
15 & 0.01383990 & 0.0645 & 0.9668 \\
16 & 0.01477312 & 0.0604 & 0.9661 \\
17 & 0.01570709 & 0.0568 & 0.9654 \\
18 & 0.01664127 & 0.0536 & 0.9648 \\
19 & 0.01757587 & 0.0508 & 0.9643 \\
20 & 0.01851193 & 0.0482 & 0.9637 \\
\hline
\end{tabular}

Tabla 7. Tasa máxima de generación de paquetes de datos para el protocolo $2 \mathrm{C}-\mathrm{R}^{2} \operatorname{con} M=5$

\begin{tabular}{cccc}
\hline $\begin{array}{c}\boldsymbol{N} \\
\text { [estaciones] }\end{array}$ & $\begin{array}{c}\boldsymbol{T r}_{\boldsymbol{N}}+\boldsymbol{T} \boldsymbol{d}_{\boldsymbol{N}} \\
\text { [segundos] }\end{array}$ & $\begin{array}{c}\boldsymbol{\lambda}_{\text {i-MAX }} \\
\text { [paquetes/ranura] }\end{array}$ & $\begin{array}{c}\boldsymbol{\lambda}_{\text {MAX-TOTAL }} \\
\text { [paquetes/ranura] }\end{array}$ \\
\hline 2 & 0.00225696 & 0.4940 & 0.9881 \\
3 & 0.00339479 & 0.3284 & 0.9853 \\
4 & 0.00453506 & 0.2459 & 0.9834 \\
5 & 0.00567785 & 0.1964 & 0.9819 \\
6 & 0.00682248 & 0.1634 & 0.9806 \\
7 & 0.00796878 & 0.1399 & 0.9794 \\
8 & 0.00911739 & 0.1223 & 0.9783 \\
9 & 0.01026643 & 0.1086 & 0.9775 \\
10 & 0.01141773 & 0.0977 & 0.9766 \\
11 & 0.01256886 & 0.0887 & 0.9758 \\
12 & 0.01372196 & 0.0813 & 0.9751 \\
13 & 0.01487519 & 0.0750 & 0.9744 \\
14 & 0.01602955 & 0.0696 & 0.9738 \\
15 & 0.01718490 & 0.0649 & 0.9732 \\
16 & 0.01834112 & 0.0608 & 0.9727 \\
17 & 0.01949809 & 0.0572 & 0.9721 \\
18 & 0.02065527 & 0.0540 & 0.9717 \\
19 & 0.02181287 & 0.0511 & 0.9712 \\
20 & 0.02297193 & 0.0485 & 0.9707 \\
\hline
\end{tabular}


Tabla 8. Tasa máxima de generación de paquetes de datos para el protocolo $2 \mathrm{C}-\mathrm{R}^{2}$ con $M=6$

\begin{tabular}{cccc}
\hline $\begin{array}{c}\boldsymbol{N} \\
\text { [estaciones] }\end{array}$ & $\begin{array}{c}\boldsymbol{T r}_{\boldsymbol{N}}+\boldsymbol{T d}_{\boldsymbol{N}} \\
\text { [segundos] }\end{array}$ & $\begin{array}{c}\boldsymbol{\lambda}_{\text {i-MAX }} \\
\text { [paquetes/ranura] }\end{array}$ & $\begin{array}{c}\boldsymbol{\lambda}_{\text {MAX-TOTAL }} \\
\text { [paquetes/ranura] }\end{array}$ \\
\hline 2 & 0.00270296 & 0.4950 & 0.9900 \\
3 & 0.00406379 & 0.3292 & 0.9877 \\
4 & 0.00542706 & 0.2465 & 0.9862 \\
5 & 0.00679285 & 0.1970 & 0.9849 \\
6 & 0.00816048 & 0.1640 & 0.9838 \\
7 & 0.00952978 & 0.1404 & 0.9828 \\
8 & 0.01090139 & 0.1227 & 0.9819 \\
9 & 0.01227343 & 0.1090 & 0.9811 \\
10 & 0.01364773 & 0.0980 & 0.9804 \\
11 & 0.01502186 & 0.0891 & 0.9798 \\
12 & 0.01639796 & 0.0816 & 0.9791 \\
13 & 0.01777419 & 0.0753 & 0.9786 \\
14 & 0.01915155 & 0.0699 & 0.9781 \\
15 & 0.02052990 & 0.0652 & 0.9776 \\
16 & 0.02190912 & 0.0611 & 0.9771 \\
17 & 0.02328909 & 0.0575 & 0.9767 \\
18 & 0.02466927 & 0.0542 & 0.9763 \\
19 & 0.02604987 & 0.0514 & 0.9759 \\
20 & 0.02743193 & 0.0488 & 0.9755 \\
\hline
\end{tabular}

Tabla 9. Máxima utilización efectiva del medio de transmisión para una red que opera con el protocolo $2 \mathrm{C}-\mathrm{R}^{2}$

\begin{tabular}{|c|c|c|c|c|c|c|}
\hline \multirow{2}{*}{$\begin{array}{c}\mathrm{N} \\
\text { [estaciones] }\end{array}$} & \multicolumn{6}{|c|}{$\mathbf{U}_{\mathbf{M A X}} \quad[\%]$} \\
\hline & $M=1$ & $M=2$ & $M=3$ & $M=4$ & $M=5$ & $M=6$ \\
\hline 2 & 94.30 & 97.07 & 98.03 & 98.51 & 98.81 & 99.00 \\
\hline 3 & 93.07 & 96.41 & 97.58 & 98.17 & 98.53 & 98.77 \\
\hline 4 & 92.24 & 95.96 & 97.27 & 97.94 & 98.34 & 98.62 \\
\hline 5 & 91.55 & 95.59 & 97.02 & 97.75 & 98.19 & 98.49 \\
\hline 6 & 90.99 & 95.28 & 96.80 & 97.58 & 98.06 & 98.38 \\
\hline 7 & 90.50 & 95.02 & 96.62 & 97.44 & 97.94 & 98.28 \\
\hline 8 & 90.04 & 94.76 & 96.44 & 97.31 & 97.83 & 98.19 \\
\hline 9 & 89.66 & 94.55 & 96.30 & 97.20 & 97.75 & 98.11 \\
\hline 10 & 89.28 & 94.34 & 96.15 & 97.09 & 97.66 & 98.04 \\
\hline 11 & 88.98 & 94.17 & 96.03 & 97.00 & 97.58 & 97.98 \\
\hline 12 & 88.67 & 93.99 & 95.91 & 96.90 & 97.51 & 97.91 \\
\hline 13 & 88.41 & 93.85 & 95.81 & 96.83 & 97.44 & 97.86 \\
\hline 14 & 88.15 & 93.70 & 95.71 & 96.75 & 97.38 & 97.81 \\
\hline 15 & 87.91 & 93.57 & 95.62 & 96.68 & 97.32 & 97.76 \\
\hline 16 & 87.68 & 93.44 & 95.53 & 96.61 & 97.27 & 97.71 \\
\hline 17 & 87.47 & 93.32 & 95.44 & 96.54 & 97.21 & 97.67 \\
\hline 18 & 87.27 & 93.20 & 95.36 & 96.48 & 97.17 & 97.63 \\
\hline 19 & 87.09 & 93.10 & 95.29 & 96.43 & 97.12 & 97.59 \\
\hline 20 & 86.91 & 92.99 & 95.22 & 96.37 & 97.07 & 97.55 \\
\hline
\end{tabular}


Tabla 10. Utilización efectiva del medio de transmisión en condiciones de saturación para el protocolo $2 \mathrm{C}$

\begin{tabular}{cc}
\hline $\begin{array}{c}\boldsymbol{N} \\
\text { [estaciones] }\end{array}$ & $\begin{array}{c}\mathbf{U}_{\text {SAT }} \\
{[\%]}\end{array}$ \\
\hline 2 & 44.52 \\
3 & 36.18 \\
4 & 31.95 \\
5 & 29.17 \\
6 & 27.15 \\
7 & 25.61 \\
8 & 24.29 \\
9 & 23.32 \\
10 & 22.44 \\
11 & 21.72 \\
12 & 21.02 \\
13 & 20.51 \\
14 & 20.02 \\
15 & 19.58 \\
16 & 19.16 \\
17 & 18.79 \\
18 & 18.45 \\
19 & 18.15 \\
20 & 17.85 \\
\hline
\end{tabular}

Tabla 11. Porcentaje efectivo del tiempo total en estado de transmisión en condiciones de saturación para el protocolo $2 \mathrm{C}$

\begin{tabular}{cc}
\hline $\begin{array}{c}\boldsymbol{N} \\
\text { [estaciones] }\end{array}$ & $\begin{array}{c}\mathbf{P E}_{\mathbf{S A T}} \\
{[\%]}\end{array}$ \\
\hline 2 & 33.43 \\
3 & 22.39 \\
4 & 17.07 \\
5 & 13.81 \\
6 & 11.58 \\
7 & 9.99 \\
8 & 8.75 \\
9 & 7.81 \\
10 & 7.03 \\
11 & 6.42 \\
12 & 5.88 \\
13 & 5.44 \\
14 & 5.07 \\
15 & 4.73 \\
16 & 4.44 \\
17 & 4.18 \\
18 & 3.95 \\
19 & 3.75 \\
20 & 3.55 \\
\hline
\end{tabular}


Tabla 12. Utilización efectiva en condiciones de saturación para el protocolo $2 \mathrm{C}-\mathrm{R}^{2}$

\begin{tabular}{|c|c|c|c|}
\hline \multirow{2}{*}{$\begin{array}{c}\mathrm{N} \\
\text { [estaciones] }\end{array}$} & \multicolumn{3}{|c|}{$\mathbf{U}_{\text {SAT }} \quad[\%]$} \\
\hline & $M=1$ & $M=2$ & $M=3$ \\
\hline 2 & 94.29 & 97.07 & 98.02 \\
\hline 3 & 93.06 & 96.41 & 97.58 \\
\hline 4 & 92.25 & 95.95 & 97.27 \\
\hline 5 & 91.55 & 95.59 & 97.01 \\
\hline 6 & 91.00 & 95.28 & 96.80 \\
\hline 7 & 90.48 & 95.01 & 96.61 \\
\hline 8 & 90.06 & 94.76 & 96.45 \\
\hline 9 & 89.63 & 94.54 & 96.29 \\
\hline 10 & 89.30 & 94.34 & 96.15 \\
\hline 11 & 88.98 & 94.17 & 96.03 \\
\hline 12 & 88.68 & 94.00 & 95.91 \\
\hline 13 & 88.40 & 93.83 & 95.80 \\
\hline 14 & 88.14 & 93.70 & 95.71 \\
\hline 15 & 87.90 & 93.55 & 95.61 \\
\hline 16 & 87.69 & 93.44 & 95.53 \\
\hline 17 & 87.48 & 93.31 & 95.44 \\
\hline 18 & 87.26 & 93.20 & 95.36 \\
\hline 19 & 87.05 & 93.10 & 95.29 \\
\hline 20 & 86.88 & 93.00 & 95.21 \\
\hline
\end{tabular}

Tabla 13. Porcentaje efectivo del tiempo total en estado de transmisión en condiciones de saturación para el protocolo $2 \mathrm{C}-\mathrm{R}^{2}$

\begin{tabular}{|c|c|c|c|}
\hline \multirow{2}{*}{$\begin{array}{c}\mathrm{N} \\
\text { [estaciones] }\end{array}$} & \multicolumn{3}{|c|}{$\mathbf{P E}_{\mathrm{SAT}}$} \\
\hline & $\mathrm{M}=1$ & $M=2$ & $M=3$ \\
\hline 2 & 92.54 & 96.13 & 97.38 \\
\hline 3 & 89.26 & 94.32 & 96.14 \\
\hline 4 & 86.41 & 92.67 & 95.01 \\
\hline 5 & 83.64 & 91.13 & 93.89 \\
\hline 6 & 81.16 & 89.59 & 92.80 \\
\hline 7 & 78.74 & 88.13 & 91.73 \\
\hline 8 & 76.52 & 86.65 & 90.72 \\
\hline 9 & 74.32 & 85.30 & 89.69 \\
\hline 10 & 72.34 & 83.95 & 88.67 \\
\hline 11 & 70.44 & 82.67 & 87.74 \\
\hline 12 & 68.68 & 81.40 & 86.79 \\
\hline 13 & 66.98 & 80.17 & 85.84 \\
\hline 14 & 65.24 & 78.99 & 84.97 \\
\hline 15 & 63.74 & 77.81 & 84.08 \\
\hline 16 & 62.25 & 76.77 & 83.20 \\
\hline 17 & 60.88 & 75.62 & 82.29 \\
\hline 18 & 59.47 & 74.61 & 81.50 \\
\hline 19 & 58.16 & 73.63 & 80.70 \\
\hline 20 & 56.94 & 72.61 & 79.85 \\
\hline
\end{tabular}




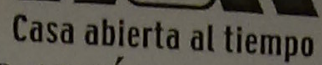 \\ INIVERSIDAD AUTÓNOMIA METROPOLITANA}

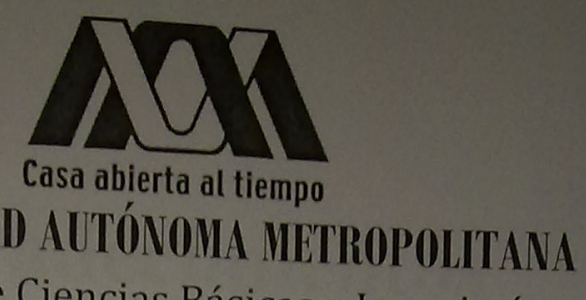

División de Ciencias Básicas e Ingeniería

\section{Propuesta y evaluación de un protocolo híbrido de control de acceso al medio (MAC) \\ con reservación de recursos}

Idónea comunicación de resultados presentada por

Pablo Damián Hernández Durán

Para obtener el grado de

Maestro en Ciencias y Tecnologías de la

Información

Asesor: Dr. Miguel López Guerrero

Defendida públicamente en la UAM-Iztapalapa el 31 de Agosto del 2010 a las 10:00 hrs.

Jurado Calificador:

Presidente: Dr. Javier Gómez Castellanos

Secretario: Dr. Víctor Manuel Ramos Ramos

Vocal: $\quad$ Dr. Miguel López Guerrero

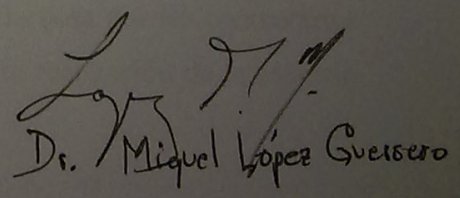

Derechos reservados (C) Pablo Damián Hernández Durán 2010. 